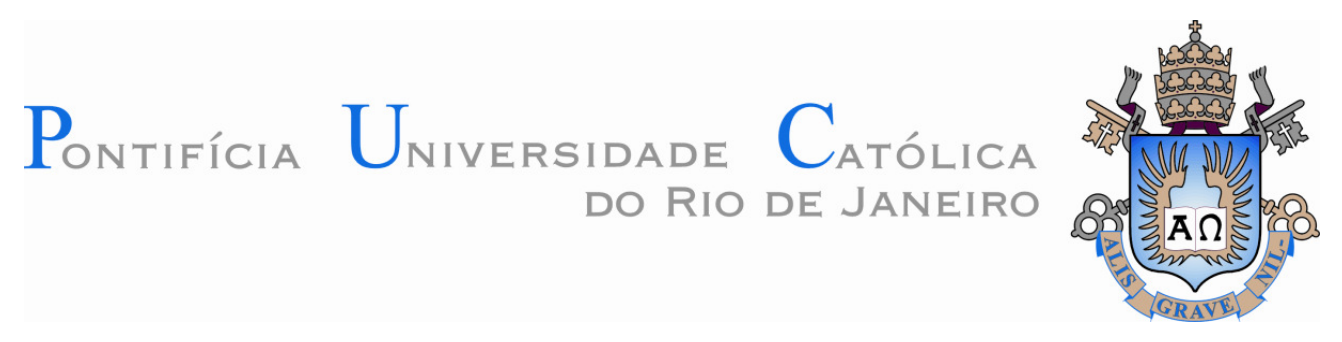

Carlos Augusto Gomes Loiola

Um Taxi para Euclides: Uma Geometria Não Euclidiana na Educação Básica

Dissertação de Mestrado

Dissertação apresentada ao Programa de PósGraduação em Matemática da PUC-Rio como requisito parcial para obtenção do grau de Mestre em Matemática.

Orientadora: Profa ${ }^{\text {. }}$ Christine Sertã Costa

Rio de Janeiro Abril de 2014 


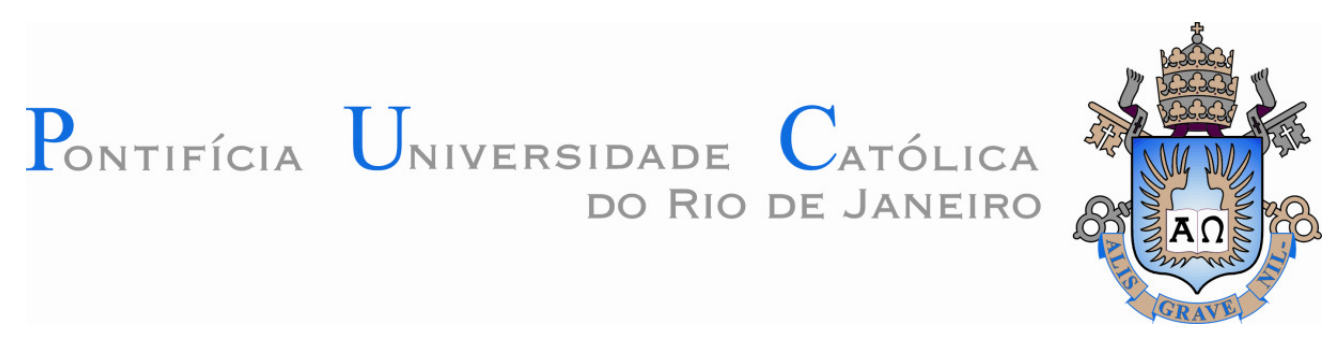

Carlos Augusto Gomes Loiola

\title{
Um Taxi para Euclides: \\ Uma Geometria Não Euclidiana na Educação Básica
}

Dissertação apresentada ao Programa de Pós-Graduação em Matemática da PUC-Rio como requisito parcial para obtenção do grau de Mestre em Matemática. Aprovada pela Comissão Examinadora abaixo assinada.

\author{
Profa. Christine Sertã Costa \\ Orientadora \\ Departamento de Matemática PUC-Rio \\ Prof. Sinésio Pesco \\ Departamento de Matemática PUC-Rio
}

Prof. Francisco Roberto Pinto Mattos Universidade do Estado do Rio de Janeiro

Prof. Marcos Craizer

Departamento de Matemática PUC-Rio

Prof. José Eugênio Leal Coordenador Setorial do Centro Técnico Científico PUC-Rio 
Todos os direitos reservados. É proibida a reprodução total ou parcial do trabalho sem autorização da universidade, do autor e do orientador.

\section{Carlos Augusto Gomes Loiola}

Graduou-se em Engenharia Civil pela Universidade Federal de Juiz de Fora em 1982. Licenciado em Matemática pela Universidade Federal Rural do Rio de Janeiro em 2001, onde escreveu a monografia Método Simplex Via Estrutura Dicionário. Pós graduado em Novas Tecnologias no Ensino da Matemática Lante - UFF ( Laboratório de Novas Tecnologias de Ensino Universidade Federal Fluminense) em 2011, onde escreveu a monografia Explorando a Equação da Reta com o Software Geogebra. É Professor efetivo da Secretaria de Educação do Estado do Rio de Janeiro.

Ficha Catalográfica

Loiola, Carlos A. G.
Um taxi para Euclides: uma geometria não euclidiana na educação
básica / Carlos Augusto Gomes Loiola ; orientadora: Christine Sertã Costa. -
2014.
\[ 96 \text { f. : il. (color.) ; } 30 \mathrm{~cm} \]
Dissertação (mestrado)-Pontifícia Universidade Católica do Rio de
Janeiro, Departamento de Matemática, 2014.
Inclui referências bibliográficas.
1. Matemática - Teses. 2. Euclides. 3. Quinto postulado. 4. Geometria
do taxi. 5. Lugar geométrico. 6. Ensino. I. Costa, Christine Sertã. II. Pontifícia
Universidade Católica do Rio de Janeiro. Departamento de Matemática. III.
Título.

CDD: 510 
Às três pessoas mais importantes com as quais posso compartilhar o meu tempo de vida: Lúcia Helena, Renata e Mayra. 


\section{Agradecimentos}

À minha orientadora Professora Christine Sertã Costa pelo aprendizado que pude adquirir em nosso convívio.

Aos professores que ao longo do curso nos dedicaram seu tempo e conhecimento.

Aos colegas que com amizade, descontração e colaboração possibilitaram tornar mais amena a nossa caminhada.

À Pontifícia Universidade Católica do Rio de Janeiro por acreditar e contribuir com o desenvolvimento do Mestrado Profissional em Rede Nacional (Profmat) e a CAPES pelo apoio financeiro. 


\section{Resumo}

Loiola, Carlos A. Gomes; Costa, Christine Sertã (Orientadora). Um Taxi para Euclides: Uma Geometria Não Euclidiana na Educação Básica. Rio de Janeiro, 2014. 96p. Dissertação de Mestrado - Departamento de Matemática, Pontifícia Universidade Católica do Rio de Janeiro.

A dissertação em tela foi desenvolvida com o intuito de proporcionar ao professor de matemática uma introdução ao estudo das Geometrias Não Euclidianas, um assunto carente em nossas salas de aulas tanto do Ensino Básico como das Licenciaturas em Matemática. Em consonância com os Parâmetros Curriculares Nacionais, são historicamente construídos os conhecimentos matemáticos apresentados para discutir o Quinto Postulado dos Elementos de Euclides e para apresentar a descoberta de novas geometrias. Para ser apresentada de forma mais detalhada, foi escolhida uma Geometria Não Euclidiana que pode ser facilmente entendida e contextualizada por alunos do Ensino Médio: a Geometria do Táxi. Tal geometria, além de possibilitar ligações com outros conteúdos do Ensino Básico também é um modelo para a geografia urbana, oferecendo ao alunado a possibilidade de interação com questões motivadoras, interdisciplinares e próximas do seu cotidiano. É apresentada uma sugestão de dinâmica que compara os conceitos das distâncias euclidiana e do táxi além de discutir a definição de circunferência e sua representação tanto na Geometria Euclidiana como na Geometria do Táxi. Além disso, alguns resultados da aplicação da referida dinâmica em turmas do 3o. ano do Ensino Médio do C.E. Professor Ney Cidade Palmeiro, localizado na cidade de Itaguaí no Rio de Janeiro, também são relatados. Pretende-se que este trabalho seja mais uma contribuição para o aprimoramento da formação continuada dos professores das escolas de ensino básico no país.

\section{Palavras-chave}

Euclides; Quinto Postulado; Geometria do Taxi; Lugar Geométrico; Ensino. 


\section{Abstract}

Loiola, Carlos A. Gomes; Costa, Christine Sertã (Advisor). A Taxicab for Euclid: A Non Euclidean Geometry in Basic Education. Rio de Janeiro, 2014. 96p. MSc. Dissertation - Departamento de Matemática, Pontifícia Universidade Católica do Rio de Janeiro.

The present dissertation was developed with the intention of providing the mathematics teacher an introduction to the study of Non Euclidean Geometry, one lacking subject in our classrooms as much as the basic education and undergraduate mathematics. In line with the National Curriculum Parameters, mathematical knowledge presented to discuss the Fifth Postulate of Euclid's Elements, and to present the discovery of new geometries are historically constructed. To be presented in more details, we choose a non Euclidean Geometry that can be easily understood and contextualized by high school students: the Taxicab Geometry. This geometry, in addition to allowing connections with other content of basic education, such geometry is a model for urban geography, offering the pupils the opportunity to their everyday issues. A suggested activity to be developed in the classroom by students who compares the concepts of taxi distance and euclidean distance and besides discussing the definition of a circle and its representation in both Euclidean Geometry as in the Taxi appears. Futhermore, some results of implementing this activity in class 3rd. year of high school the Colégio Estadual Professor Ney Cidade Palmeiro, located in Itaguaí in Rio de Janeiro, are also reported. It is intended that this work is a futher contribuition to the improvement of continuing education of teachers of primary schools in the country.

\section{Keywords}

Euclid; Fifth Postulate; Non-Euclidean Geometry; Taxicab Geometry; Locus; Education. 


\section{Sumário}

$\begin{array}{ll}\text { Introdução } & 13\end{array}$

$\begin{array}{ll}\text { 1. Euclides } & 17\end{array}$

2. Os Elementos 22

3. O Quinto Postulado 30

4. Uma Primeira Geometria Não Euclidiana 38

5. A Geometria do Taxi 42

5.1 Métrica 42

5.2 Comparações da Geometria do Taxi com a Euclidiana no $R^{2} \quad 45$

5.2.1 Distância 46

5.2.2 Menores Caminhos entre Dois Pontos 46

5.2.3 Circunferência 48

5.2.4 Elipse $\quad 50$

5.2.5 Parábola $\quad 53$

5.2.6 Hipérbole $\quad 55$

6. Dinâmica: Caminhando Pelas Ruas da Minha Cidade 58

7. Conclusão 65

8. Referências Bibliográficas 66

9. Anexo 68

9.1 Espaço Euclidiano $\quad 68$

$9.1 .1\left(R^{N}, D_{E}\right) \quad 68$

$9.1 .2\left(R^{N}, D_{T}\right) \quad 70$

9.2 Distância de Ponto a Reta 71 


\section{Lista de figuras}

Figura 1 Mapa de Alexandria $\quad 17$

Figura 2 Capa da primeira edição inglesa de Os Elementos (1570) 22

Figura 3 Fragmento de papiro de Os Elementos 23

Figura 4 Página da primeira edição impressa em latim (1482) 30

Figura 5 Quadrilátero usado por Ibn-al-Haytham na tentativa de demonstração do Quinto Postulado 35

Figura 6 Quadrilátero usado por Omar Khayyam na tentativa de demonstração do Quinto Postulado 35

Figura 7 Argumento usado por Nasir Eddin al-Tusi na tentativa de demonstração do Quinto Postulado 36

Figura 8 Circle Limited III (1959) - M.C.Escher 38

Figura 9 Carta de Janos Bolyai a seu pai 39

Figura 10 Métrica Euclidiana 43

Figura 11 Métrica do Taxi 44

Figura 12 Negação da congruência LAL 45

Figura 13 Trajetória do taxi entre os pontos A e B 47

Figura 14 Circunferência Euclidiana 48

Figura 15 Circunferência do Taxi 49

Figura 16 Cálculo da área do Círculo do Taxi 50

Figura 17 Elipse Euclidiana $\quad 51$

Figura 18 Elipse do Taxi 52

Figura 19 Parábola Euclidiana 54

Figura 20 Parábola do Taxi 55

Figura 21 Hipérbole Euclidiana $\quad 56$

Figura 22 Hipérbole do Taxi 57

Figura 23 Resposta dos alunos a atividade proposta 59

Figura 24 Resposta dos alunos a atividade proposta 59

Figura 25 Folha distribuída aos alunos 60

Figura 26 Resposta dos alunos a atividade proposta 61

Figura 27 Resposta dos alunos a atividade proposta 61

Figura 28 Resposta dos alunos a atividade proposta 62 
Figura 29 Resposta dos alunos a atividade proposta 62

Figura 30 Sofware Geometria do Taxi - Distância 63

Figura 31 Sofware Geometria do Taxi - Formas Geométricas 64

Figura 32 Distância entre um ponto e uma reta - Métrica Euclidiana 72

Figura 33 Distância entre um ponto e uma reta - Métrica Euclidiana 72

Figura 34 Distância entre um ponto e uma reta - Métrica do Taxi 73

Figura 35 Distância entre um ponto e uma reta - Métrica do Taxi 73

Figura 36 Distância entre um ponto e uma reta - Métrica do Taxi 74

\section{Lista de Tabela}

Tabela 1 Relação das proposições com as definições, postulados e axiomas 
Se quer realmente buscar a verdade, deve pelo menos uma vez na vida, e tão completamente quanto possível, duvidar de tudo.

René Descartes (1596 - 1650) 


\section{Introdução}

O físico Eugene Wigner, em 1960, nos trouxe uma noção de como a matemática e o mundo real podem estar vinculados declarando:

A linguagem da matemática revela-se desrazoavelmente eficaz nas ciências naturais. É um presente misterioso que nem compreendemos e nem merecemos. Devemos estar agradecidos por ele e esperamos que continue a ser válido na investigação futura e que até mesmo se estenda, para o melhor e para o pior, para nosso prazer e apesar talvez de nossa admiração, a ramos mais vastos do conhecimento. ${ }^{1}$

Antes dele Einstein havia escrito:

Há um enigma que desde sempre tem perturbado as mentes. Como pode a matemática, ao fim e ao cabo um produto do pensamento humano independente da experiência ser tão admiravelmente apropriada aos objetos da realidade? ${ }^{2}$

Bem antes desses dois eminentes físicos, há cerca de 2400 anos, Aristóteles deve ter passado muito tempo observando os navios que se distanciavam do cais e desapareciam no horizonte. E num daqueles momentos que se perdem na história deve ter se perguntado o motivo pelo qual os navios iam sumindo primeiramente os cascos e depois as velas. Em uma Terra plana os navios deveriam diminuir por igual. Só havia uma explicação para tal evidência: a Terra é redonda. Em relação a esse fato Mlodinow nos afirma que para observar a estrutura de nosso planeta em grande escala, Aristóteles tinha olhado através da janela da Geometria.

Ao estudar geometria, ou melhor, ao olhar pela janela da geometria, como diria Mlodinow, nossos alunos tem a oportunidade de apreciar e interagir com o ambiente ao seu redor podendo relacionar as ideias geométricas com números e medições, e desse modo ampliar o seu horizonte de conhecimento. A geometria

\footnotetext{
${ }^{1}$ Disponível em <HTTP://nautilus.fis.uc.pt/personal/cfiolhais/extra/artigos/artletras140600. htm

${ }^{2}$ Disponível em < HTTP://nautilus.fis.uc.pt/personal/cfiolhais/extra/artigos/artletras140600. htm
} 
pode agir como tema integrador na Matemática do Ensino Médio uma vez que a intuição e o formalismo, a abstração e a dedução fazem parte de sua estrutura.

Por outro lado, os Parâmetros Curriculares Nacionais estabelecem que a Matemática no Ensino Médio deva não só ter um aspecto formativo e instrumental, mas também ser apresentada como uma ciência.

A Matemática no Ensino Médio tem um valor formativo, que ajuda a estruturar o pensamento e o raciocínio dedutivo, porém também desempenha um papel instrumental, pois é uma ferramenta que serve para a vida cotidiana e para muitas tarefas específicas em quase todas as atividades humanas.

Contudo a Matemática no Ensino Médio deve ser vista como uma ciência, com suas características estruturais específicas. É importante que o aluno perceba que as definições, demonstrações e encadeamentos conceituais e lógicos tem a função de construir novos conceitos e estruturas a partir de outros e que servem para validar intuições e dar sentido às técnicas aplicadas. (PCN Parte - III, 1998, pg.40)

Em continuidade os Parâmetros Curriculares Nacionais afirmam que:

Cabe à Matemática do Ensino Médio apresentar ao aluno conhecimento de novas informações e instrumentos necessários para que seja possível a ele continuar aprendendo. Saber aprender é condição básica para prosseguir aperfeiçoando-se ao longo da vida. (PCN Parte - III, 1998, pg.41)

Especificamente com relação à Geometria os Parâmetros Curriculares

Nacionais nos informam que:

As habilidades de visualização, desenho, argumentação lógica e de aplicação na busca de soluções para problemas podem ser desenvolvidas com um trabalho adequado de Geometria, para que o aluno possa usar formas e propriedades geométricas na representação e visualização do mundo que o cerca.

Essas competências são importantes na compreensão e ampliação da percepção de espaço e construção de modelos para interpretar questões da Matemática e de outras áreas do conhecimento. (PCN Parte - III, 1998, pg.44)

De acordo com as considerações expostas acima apresentamos um texto que nos possibilita não só acompanhar a evolução do pensamento matemático que permitiu a criação e compreensão das Geometrias Não Euclidianas, mas a interação com uma delas a chamada Geometria do Taxi que no nosso entendimento se adéqua as propostas dos Parâmetros Curriculares Nacionais e pode ser facilmente trabalhada com alunos do Ensino Médio.

O estudo e conhecimento da evolução do pensamento matemático que permitiu a criação e desenvolvimento das Geometrias Não Euclidianas é uma 
excelente fonte para o professor compreender o funcionamento e criação das ideias matemáticas e como se estruturaram os novos conhecimentos ao longo do tempo. Uma vez que os Parâmetros Curriculares Nacionais orientam que a atividade matemática escolar não é olhar para coisas prontas e definitivas, mas que esse conhecimento deve ser apresentado ao aluno como historicamente construído e em permanente evolução.

Por outro lado, a Geometria do Taxi é um ótimo modelo para a geografia urbana. Sendo assim, ela pode interagir de modo natural com o cotidiano do discente, permitindo ao professor integrar conceitos e definições na solução de problemas e situações reais envolvendo o bairro e ruas conhecidas por seus alunos. Apresentado a esse modelo geométrico, o aluno é levado naturalmente ao conhecimento da existência de outras geometrias, diferentes da Geometria Euclidiana, ampliando sua visão para novos rumos e setores da Matemática.

A Geometria do Taxi e a Geometria Euclidiana diferem de modo conceitual apenas pela métrica. A distância euclidiana é a medida do segmento de reta que une dois pontos quaisquer, sendo determinada pelo Teorema de Pitágoras. A distância do taxi é obtida pela soma das medidas dos trajetos horizontais ou verticais entre dois pontos quaisquer dados. Entretanto, sob o olhar da Matemática, essa diferença conceitual ocasiona uma grande distinção, e quando observado do ponto de vista educacional possibilita os discentes confrontarem definições e conceitos com representações geométricas distintas. Tal fato leva a uma saudável discussão dessas definições e conceitos possibilitando que os alunos se apropriem desse conhecimento naturalmente.

Sugerimos, ao professor, uma dinâmica que pode ser realizada com alunos do Ensino Médio e que aplicamos a uma turma do $3^{\circ}$ Ano do Ensino Médio do C.E Professor Ney Cidade Palmeiro, localizado na cidade de Itaguaí, estado do Rio de Janeiro. A dinâmica Caminhando pelas Ruas da Minha Cidade que está dividida em dois módulos, um direcionado ao professor e outro para o aluno, procura sintetizar os seguintes objetivos:

- Fazer o aluno se apropriar da noção de que podemos medir uma distância de forma distinta dependendo dos impedimentos apresentados.

- Apresentar a Geometria do Taxi

- Mostrar que a Geometria do Taxi é um modelo mais apropriado que a Geometria Euclidiana para a geografia urbana. 
- Utilizar os conhecimentos matemáticos como modelo de se melhor compreender o ambiente cotidiano.

- Explorar a comparação entre a distância euclidiana e a distância do taxi utilizando coordenadas cartesianas.

- Explorar o conceito de círculo e circunferência e suas representações gráficas na Geometria do Taxi e na Geometria Euclidiana. 


\section{Euclides}

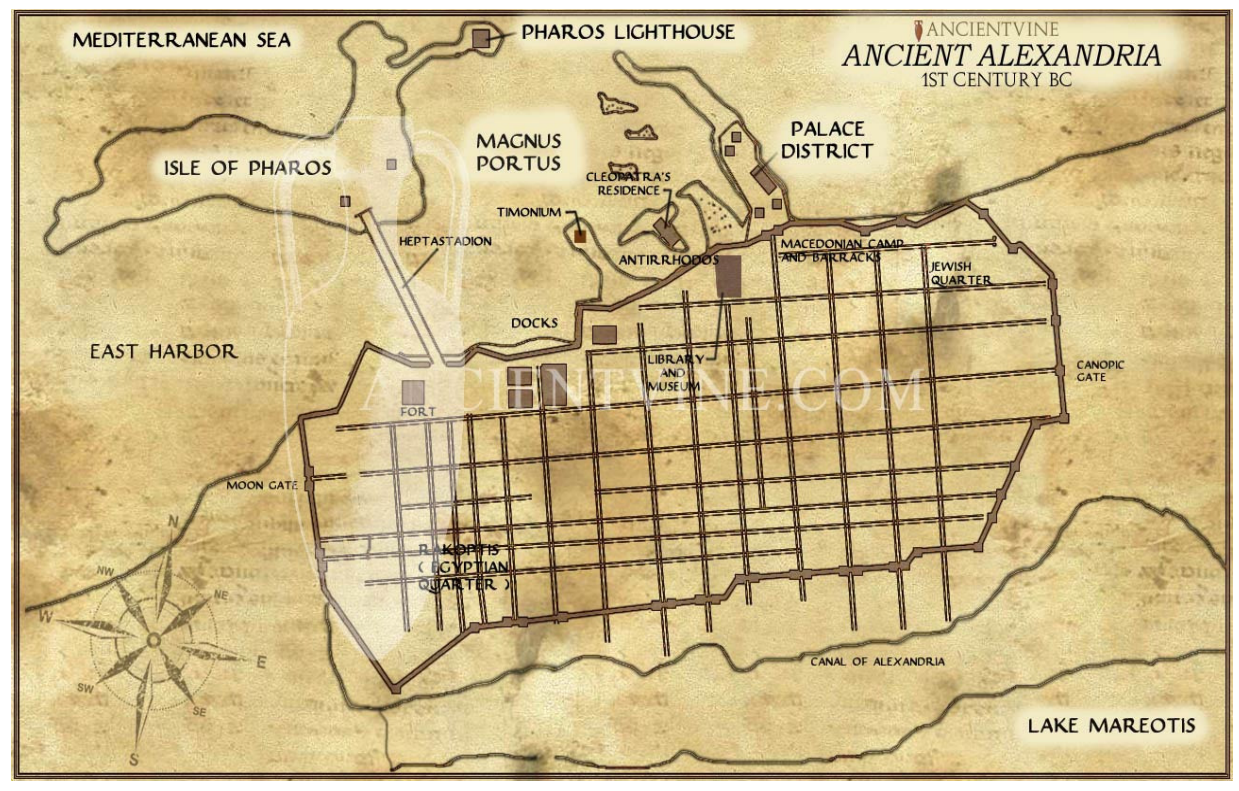

Figura 1 - Mapa de Alexandria ${ }^{3}$

No istmo, entre o mar Mediterrâneo e o Lago Mareótis, a oeste do delta do rio Nilo, em uma antiga aldeia de pescadores e pastores chamada Rhakotis, nasceu a cidade de Alexandria. Em suas geométricas ruas que a tradição atribui ao urbanista Dinócrates ${ }^{4}$ a sua planificação, um homem caminhou por volta de 300 a.E.C. e escreveu um livro que rivaliza com a Bíblia em número de edições. Segundo Mlodinow o modo como ele abordou sua obra acabou dando à filosofia uma nova forma e definiu a natureza da matemática até o século 19:

Sua obra integrou a educação superior durante a maior parte desse tempo, e continua sendo assim até hoje. A redescoberta de sua obra foi uma chave para a

${ }^{3}$ Disponível em: <http://www.ancientvine.com/alexandria_map.html>. Acesso em 22 de novembro de 2013.

${ }^{4}$ Arquiteto e urbanista originário de Rodes ou Macedônia, viveu na época de Alexandre o Grande, e também construiu a grande pira funerária em Hefestion. 
renovação da civilização europeia na Idade Média. Spinoza ${ }^{5}$ tentou imitá-lo. Abraham Lincoln ${ }^{6}$ o estudou. $\mathrm{Kant}^{7}$ o defendeu. (Mlodinow, 2008, pg.39)

Esse homem, cuja vida pouco se conhece, chamava-se Euclides e o seu livro, os Elementos. Artmann no prefácio do seu livro, Euclid the Creation of Mathematic, apresenta Os Elementos do seguinte modo:

Este livro é para todos os amantes da matemática. É uma tentativa de entender a natureza da matemática do ponto de vista da sua fonte antiga mais importante.

Mesmo que o material coberto possa ser considerado elementar na sua maior parte, o modo como ele o apresenta estabeleceu o padrão por mais de dois mil anos. Conhecer Os Elementos pode ser da mesma importância para o matemático hoje que o conhecimento da arquitetura grega para um arquiteto.

É claro que nenhum arquiteto contemporâneo construirá um templo dórico, muito menos organizará um local de construção como os antigos o faziam. Mas, para o treino do julgamento estético de um arquiteto, um conhecimento da herança grega é indispensável. Concordo com Peter Hilton ${ }^{8}$ quando diz que a matemática genuína constitui uma das mais finas expressões do espírito humano, e posso acrescentar aqui, como em outros tantos casos, aprendemos dos gregos aquela linguagem de expressão.

Enquanto apresenta a geometria e a aritmética, Euclides ensina-nos aspectos essenciais da matemática em um sentido muito mais geral. Exibe o fundamento axiomático de uma teoria matemática e seu desenvolvimento consciente rumo à solução de um problema específico. Vemos como a abstração trabalha e impõe a apresentação estritamente dedutiva de uma teoria.

Aprendemos o que são definições criativas e como a compreensão conceitual leva à classificação dos objetos relevantes. Euclides criou o famoso algoritmo que leva o seu nome para a solução de problemas específicos na aritmética e mostrounos como dominar o infinito nas suas várias manifestações.

Um dos poderes maiores do pensamento científico é a habilidade de desvelar verdades que são visíveis somente "aos olhos da mente", como diz Platão, e de desenvolver modos e meios de lidar com elas. É isso que Euclides faz no caso das magnitudes irracionais ou incomensuráveis. E, finalmente, nos Elementos encontramos tantas amostras da bela matemática que são facilmente acessíveis e

${ }^{5}$ Escreveu sua obra principal Ética no estilo de Os Elementos, começando com definições e axiomas, a partir dos quais ele alegava ter demonstrado teoremas rigorosos.

${ }^{6}$ Enquanto era ainda um obscuro advogado, estudou os Elementos de Euclides para melhorar suas habilidades lógicas.

${ }^{7}$ Acreditava que a geometria euclidiana está estruturada no cérebro humano. Escreveu em 1783, na introdução à sua filosofia sob o título "Afinal, é a metafísica possível?": "Não há absolutamente livro na metafísica como temos na matemática. Se quiserdes conhecer o que é a matemática, basta olhardes os Elementos de Euclides".

${ }^{8}$ Matemático, fez grandes contribuições para a topologia algébrica e álgebra homological. Também foi uma figura importante na Educação Matemática, especialmente na Europa Continental. 
que podem ser minuciosamente estudadas por qualquer um que possua um treino mínimo em matemática. (Artmann, 1999)

Apesar da importância e influência da obra de Euclides, o que sabemos dele não é muito diferente do que conhecemos de outros matemáticos da Grécia Antiga: as informações que temos são poucas ou nenhuma sobre sua vida e personalidade. Tatiana Roque afirma que muito pouco se sabe sobre a vida de Euclides; nem mesmo é comprovado que tenha nascido em Alexandria, como se afirma com frequência. Evidências existem de que Euclides, além dos Elementos, tenha escrito outras obras de matemática, sobre lugares geométricos, cônicas, perspectiva e geometria esférica. Mlodinow de modo bem humorado nos diz que virtualmente, nada de sua vida é conhecido. Ele comia azeitonas? Assistia a peças teatrais? Era alto ou baixo? A história não responde a nenhuma dessas perguntas.

Alguns fatos, no entanto, da vida de Euclides são aceitos pela tradição apesar de serem frutos de suposições e inferências. Proclus ${ }^{9}$ no seu livro Comentários sobre os Elementos de Euclides preserva uma parte da História da Geometria de Eudemo ${ }^{10}$, conhecido como o Sumário de Eudemo, ele relaciona os nomes daqueles que mais contribuíram para o estudo e desenvolvimento da matemática grega antiga e chama a atenção para o fato que Euclides não foi o primeiro a compilar os Elementos. Em complementação ao Sumário, Proclus escreve:

E não muito mais jovem do que esses é Euclides, o que reuniu os Elementos, tendo também, por outro lado, arranjado muitas das coisas de Eudoxo ${ }^{11}$ e tendo, por outro lado, aperfeiçoado muitas das coisas de Teeteto ${ }^{12}$, e ainda tendo conduzido as coisas demonstradas frouxamente pelos seus predecessores a demonstrações irrefutáveis. E esse homem floresceu no tempo do primeiro Ptolomeu $^{13}$; pois, também Arquimedes, tendo vindo depois do primeiro, menciona Euclides, e, por outro lado, também dizem que Ptolomeu demandou-lhe uma vez se

${ }^{9}$ Filósofo neoplatônico grego do século V. Seu livro é uma fonte importante da matemática grega.

${ }^{10}$ Filósofo da Grécia Antiga, considerado como o primeiro historiador da ciência.

${ }^{11}$ Matemático e astrônomo grego desenvolveu o método da exaustão.

12 Matemático grego a quem é atribuído a construção e demonstração dos poliedros regulares, bem como a descoberta de dois deles (octaedro e icosaedro).

${ }^{13}$ General macedônio que serviu sob o comando de Alexandre, o Grande que se tornou o governante do Egito fundando a dinastia ptolomaica. 
existe algum caminho mais curto que os Elementos para a Geometria e ele respondeu não existir atalho real na Geometria. (Bicudo, 2009, pg.41)

Proclus aparenta não ter conhecimento direto sobre o assunto, usa de um raciocínio de plausibilidade para estabelecer certos fatos sobre o geômetra. Nessa linha nos escreve Irineu Bicudo:

O próprio autor do acréscimo parece não ter conhecimento direto do lugar de nascimento do geômetra ou das datas em que nasceu e em que morreu. Procede antes por inferência:

(1) Arquimedes ${ }^{14}$ viveu imediatamente após o primeiro Ptolomeu;

(2) Arquimedes menciona Euclides;

(3) Há uma história sobre algum Ptolomeu e Euclides; logo Euclides viveu no tempo do primeiro Ptolomeu.

(4) Euclides medeia entre os primeiros discípulos de Platão ${ }^{15}$ e Arquimedes;

(5) Platão morreu em 347/6 a.E.C;

(6) Arquimedes viveu de 287 a 217 a.E.C; logo Euclides deve ter atingido seu acúmen por volta de 300 a.E.C (o que acorda bem com o fato de que o primeiro Ptolomeu reinara de 306 a 283 a.E.C)

(7) Atenas era, à época, o mais importante centro de matemática existente;

(8) Os que escreveram Elementos antes de Euclides viveram e ensinaram em Atenas;

(9) O mesmo vale para os outros matemáticos de cujos trabalhos os Elementos de Euclides dependiam;

logo Euclides recebeu seu treinamento matemático dos discípulos de Platão em Atenas. (Bicudo, 2009, pg.42)

Em a Coleção Matemática no Livro VII Pappus ${ }^{16}$ comentando sobre Apolônio $^{17}$ relata que Euclides ensinou e fundou uma escola em Alexandria:

Pappus, 7.35:

E [Apolônio] pode ajuntar as coisas restantes ao "lugar", tendo antes sido capaz de imaginar pelas coisas já escritas por Euclides sobre o "lugar" e, tendo frequentado

${ }^{14}$ Físico, astrônomo, engenheiro, inventor é considerado como o maior matemático grego da antiguidade.

${ }^{15}$ Filósofo e matemático da Grécia Antiga no período clássico. Fundador da Academia em Atenas primeira instituição de ensino superior do mundo ocidental.

${ }^{16}$ Principal matemático de sua época, conhecido por sua obra A Coleção, na qual ele reúne uma série de obras antigas de importantes matemáticos.

${ }^{17}$ Matemático grego que nos transmitiu oito livros sobre cônicas, tendo ampliado os quatro livros das Cônicas de Euclides e acrescentado mais quatro. 
muito tempo os discípulos de Euclides em Alexandria, por essa razão adquiriu esse hábito não ignorante da mente. (Bicudo, 2009, pg.43)

Finalmente encontramos um episódio relatado por Stobaeus ${ }^{18}$, nos seus Eclogarum physicarum et athicarum Libri $\mathrm{II}^{19}$. Ei-lo:

(...)alguém que começara estudar geometria com Euclides, tendo aprendido o primeiro teorema, perguntou a Euclides: "Mas o que será acrescido por aprender essas coisas?" E Euclides, tendo chamado o escravo: "Dê-lhe três óbulos, porque para ele é preciso lucrar com o que aprende”. (Bicudo, 2009, pg.43)

Tudo o que a tradição nos transmite sobre Euclides está dito, entretanto, como nos alerta Bicudo "a tradição se interessa mais pela verossimilhança do que pela verdade, considerando aquela como uma metáfora desta" e segundo Asger Aaboe devemos levar em conta que "a tradição grega tem a tendência de transformar seus heróis em ídolos". Tais alertas não levam ao total descrédito dos escritos, mas a uma leitura mais atenta e crítica. Nessa linha, ao nos depararmos com o diálogo entre Ptolomeu e Euclides, que o próprio Stobaeus também relata como tendo ocorrido entre Alexandre e Menaechmus, devemos aceitá-lo como uma metáfora, conforme Bicudo, ao fato de a geometria ter de ser aprendida sistematicamente, passo a passo, seguindo o trajeto exposto nos Elementos. Do mesmo modo a história entre Euclides e seu aluno deve ser tomada, segundo Bicudo, como o fato de que Pitágoras mudou a filosofia sobre a matemática "em uma forma de educação liberal”, ou seja, própria dos homens livres, que não se submetem senão aos ganhos intelectuais.

De tudo que dissemos fica a ideia do pouco que conhecemos e ao mesmo tempo necessitando de inferências ou raciocínios de plausibilidade. Podemos dizer que Euclides estudou em Atenas com algum aluno do filósofo Platão, viveu em Alexandria no tempo do primeiro Ptolomeu e lá ensinou e escreveu os Elementos.

18 Natural da Macedônia escreveu uma compilação de importantes autores gregos, abordando assuntos vários (filosofia natural, ética, política, economia, etc).

${ }^{19}$ Coletânea de coisas físicas e éticas 


\section{Os Elementos}

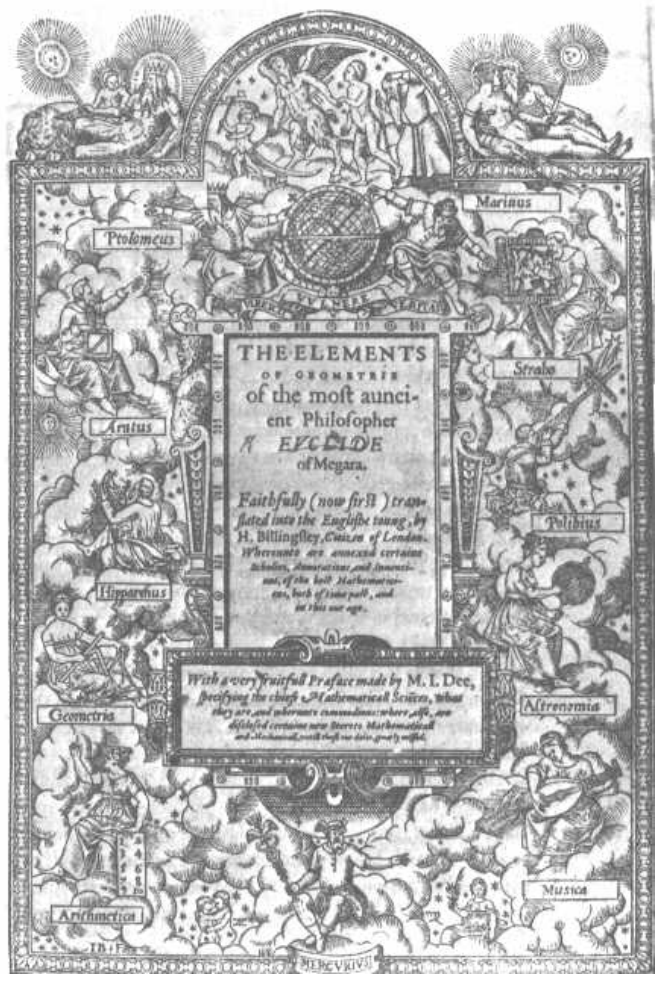

Figura 2 - Capa da primeira edição inglesa de Os Elementos $(1570)^{20}$

Os Elementos foram escritos por volta de 300 a.E.C compondo-se de um conjunto de 13 livros. Não possuímos nenhum registro ou fragmento por menor que seja do texto original escrito por Euclides, temos apenas versões e traduções bem tardias. Para Asger Aaboe os mais antigos manuscritos que contém Os Elementos datam do século dez E.C, ou seja, estão mais próximos de nós do que de Euclides. Tatiana Roque nos informa que um dos mais antigos fragmentos de

\footnotetext{
${ }^{20}$ Disponível em: <http://www.educ.fc.ul.pt/icm/icm2001/icm23/images/elements.jpg>. Acesso em 22 de novembro de 2013.
} 
uma das versões de Os Elementos, foi encontrado entre diversos papiros gregos na cidade de Oxyrhynque no Egito às margens do rio Nilo, datando provavelmente dos anos 100 da Era Comum (Figura - 3). Infelizmente esses fragmentos são poucos e pequenos, impossibilitando termos uma ideia da totalidade da obra, entretanto fornecem comparações valiosas.

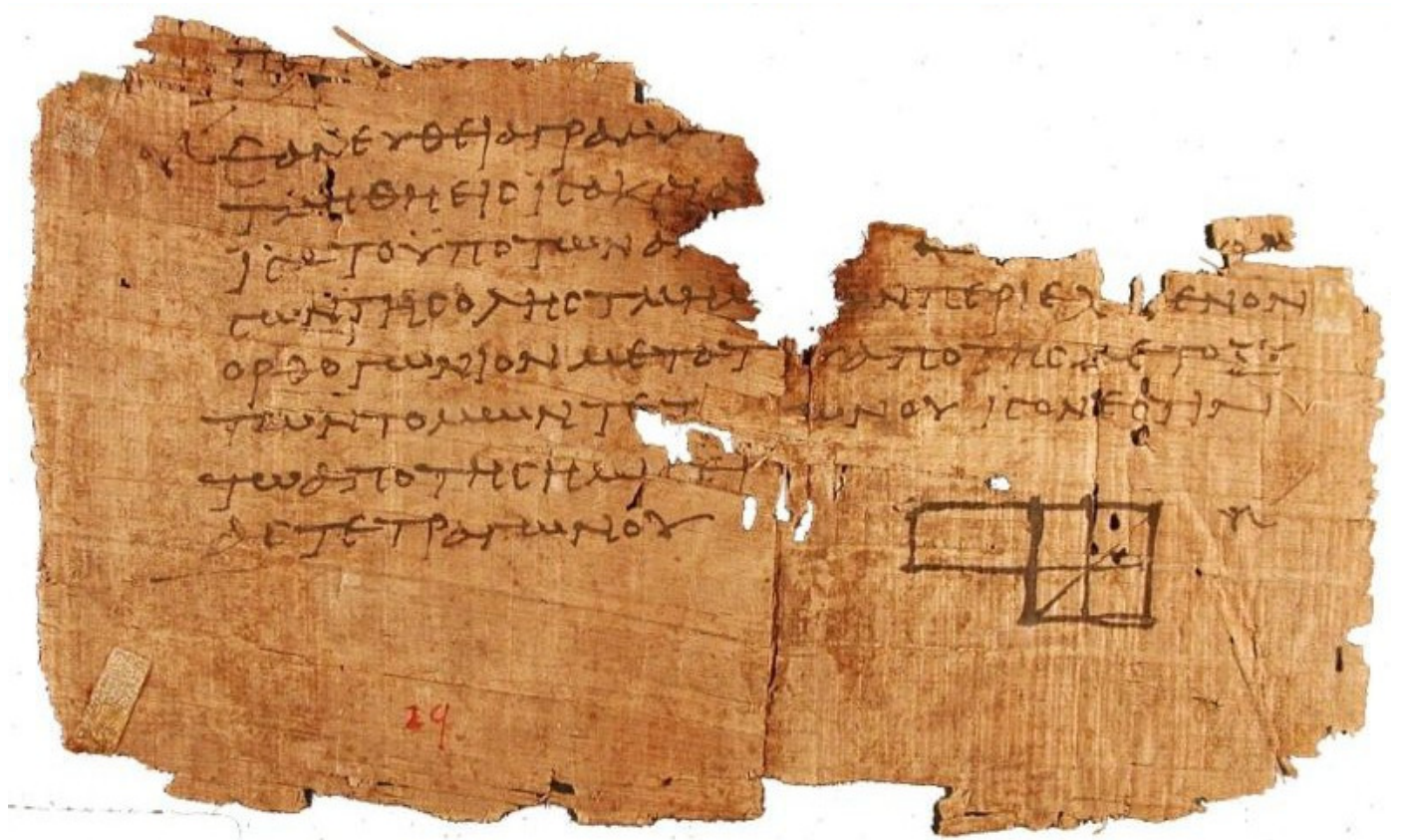

Figura 3 - Fragmento de papiro de Os Elementos ${ }^{21}$

Uma vez que mesmo os textos mais antigos de Os Elementos são transcrições ou traduções de outras transcrições ou traduções que por sua vez foram transcritas ou traduzidas, e assim sucessivamente, resta perguntar como foi possível chegarmos a um texto que se assemelha ao escrito por Euclides? Aaboe de um modo bem simples nos esclarece:

Os estudiosos da antiguidade clássica desenvolveram técnicas refinadas para esse estudo. Em linhas grosseiras o processo é o seguinte:

\footnotetext{
${ }^{21}$ Disponível em: < http://www.educadores.diaadia.pr.gov/arquivos/File/tvmultimidia/imagens/ matematica/2papieuc.jpg >. Acesso em: 5 de dezembro de 2013.
} 
Comparamos os manuscritos $\mathrm{X}$ e $\mathrm{Y}$. Se $\mathrm{Y}$ possui todos os erros e peculiaridades de $\mathrm{X}$ e, além disso, alguns somente seus, é razoável supor que $\mathrm{Y}$ é uma cópia ou cópia de uma cópia, de $\mathrm{X}$. Se $\mathrm{X}$ e $\mathrm{Y}$ tem alguns erros em comuns e cada um deles erros só seus, são provavelmente derivados de um arquétipo Z, talvez perdido, mas que possa ser reconstruído. Desta maneira os manuscritos existentes podem ser dispostos em famílias, cada família representada por um arquétipo. A partir dos arquétipos reconstrói-se o texto original. (Aaboe, 2013, pg.38).

Tomei nos dá uma ideia da grandiosidade e dificuldade do estudo das fontes do texto de Euclides:

A importância dos Elementos faz com que o estudo de suas fontes seja uma tarefa desesperadora. Existem dezenas de manuscritos que partem do texto original, levemente alterado por diversas razões bem intencionadas. Em alguns, por razões didáticas, são acrescentados comentários matemáticos ou históricos, muitas vezes errados. Em outros, aparecem tentativas de corrigir o texto original, apresentando demonstrações mais breves, ou explicitando partes supostamente obscuras do argumento, e mesmo alterando definições. Ironicamente existem estudiosos que encontram erros na versão que tem em mãos, atribuem o erro a estudiosos anteriores, e, ao corrigi-los, apresentam o novo trecho como sendo do próprio Euclides. (Tomei, 2006, pg.21)

O resultado desse refinado e grandioso trabalho descrito por Aaboe e Tomei é que Os Elementos de Euclides são os mais antigos textos matemáticos grego, que nos é possível estudar em sua completude, nos possibilitando entender a importância que essa obra adquiriu ao longo do tempo. Euclides descreve quase todo o conhecimento matemático produzido por seus antecessores corrigindo, dando uma base sólida e acrescentando novos resultados. Isso torna Os Elementos uma verdadeira enciclopédia do conhecimento matemático grego da época relegando os textos anteriores ao esquecimento. Tal fato leva Irineu Bicudo a nos alertar: quem se aproxima descuidadamente dessa história pode ser levado a acreditar que a própria geometria nasceu inteiramente radiante da cabeça de Euclides, como Atenas na de Zeus.

Nos treze livros dos Elementos, Euclides nos apresenta a Geometria Plana, o que hoje chamamos de Teoria dos Números e a Geometria Espacial. Esses conhecimentos foram estruturados do seguinte modo:

Livro I - Os Fundamentos da Geometria. Teoria dos Triângulos, Paralelas e Áreas.

Nesse livro encontramos 23 definições, 5 postulados, 9 axiomas e 48 proposições. Euclides faz uma distinção entre axiomas e postulados, os primeiros 
são considerados as hipóteses básicas a todas as ciências e os postulados são as hipóteses específicas a uma determinada ciência. As 48 proposições podem ser divididas em três partes. As primeiras 26 tratam das propriedades dos triângulos. As proposições de 27 a 32 estabelecem a teoria das paralelas e demonstram que a soma dos ângulos internos de um triângulo é o mesmo que dois ângulos retos. Da proposição 33 a 48 tratam-se dos paralelogramos, triângulos, quadrados, sendo dado uma atenção especial as relações entre áreas. A proposição 47 é o Teorema de Pitágoras e a proposição 48 é a recíproca do Teorema de Pitágoras. O conteúdo desse livro foi desenvolvido provavelmente pelos antigos pitagóricos.

Livro II - Álgebra Geométrica

Nesse livro encontramos duas definições e 14 proposições. É um livro relativamente pequeno que trata das transformações de áreas e da álgebra geométrica grega da Escola Pitagórica. Estabelece as equivalências geométricas de diferentes identidades algébricas e uma generalização do teorema de Pitágoras conhecida como a lei do cosseno.

\section{Livro III - Teoria da Circunferência}

Nesse livro composto de 11 definições e 37 proposições, das quais 5 são problemas e os restantes teoremas, são apresentados os conhecimentos relativos à circunferência, às cordas, secantes, tangentes e medição de ângulos.

Livro IV - Figuras Inscritas e Circunscritas e Construção de Certos Polígonos Regulares.

Esse livro abrange as construções pitagóricas com régua e compasso dos polígonos regulares de 3, 4, 5, 6 e 15 lados. Tem 7 definições e 16 proposições que são todas problemas. São estudados também, as inscrições e circunscrições desses polígonos em um círculo dado e a construção de polígonos regulares, como o pentágono e o hexágono, pelo método da duplicação dos lados.

Livro V - Teoria das Proporções de Eudoxo

Esse livro composto por 18 definições e 25 proposições contém uma exposição da teoria da proporção de Eudoxo aplicável a magnitudes comensuráveis e incomensuráveis resolvendo assim o problema levantado pela descoberta dos pitagóricos dos números irracionais.

Livro VI - Figuras Geométricas Semelhantes e Proporcionais

Esse livro possui 4 definições e 33 proposições onde se estabelecem os Teoremas Fundamentais dos triângulos semelhantes e as construções da terceira, 
da quarta e da média proporcional. Se estabelece também uma solução geométrica para as equações quádricas e a proposição de que a bissetriz do ângulo interno de um triângulo divide o lado oposto em dois segmentos proporcionais aos outros dois lados

Livro VII - Fundamentos da Teoria dos Números

Juntamente com os Livros VIII e IX forma um bloco diferente da estrutura estabelecida nos livros I a VI. Esse bloco compreende no total 102 proposições e trata da teoria elementar dos números.

O Livro VII é composto de 22 definições e 39 proposições. Inicia com a apresentação do hoje denominado Algoritmo de Euclides, para encontrar o máximo divisor comum entre dois números inteiros. Encontramos também a exposição da teoria das proporções numéricas ou pitagóricas.

Livro VIII - Continuação de Proporções e Teoria dos Números

Esse livro possui 27 proposições e trata de séries de números em proporções contínuas e progressão geometrica relacionadas.

Livro IX - Teoria dos Números

Esse livro composto de 36 proposições apresenta demostrações significativas. A proposição 14 é o equivalente ao Teorema Fundamental da Aritmética, a proposição 20 estabele que os números primos são infinitos, a proposição 35 estabelece uma demonstração geométrica da fórmula da soma dos $n$ primeiros termos de uma progressão geométrica e a proposição 36 fornece a fórmula dos números perfeitos. Encontramos também teorias de origem pitagórica que falam dos numeros pares, impares e suas relações.

Livro X - Classificação dos Incomensuráveis

Este volume trata dos números irracionais, ou seja, segmentos que são incomensuráveis com relação a determinado segmento de reta dado. O Livro X é considerado um livro complexo e por muitos especialistas como o mais notável dos Elementos. É composto de 16 definição divididas em três grupos e 115 proposições. Acredita-se que grande parte desse volume corresponde ao trabalho de Teeteto que Euclides ordenou e completou. A proposição I é a base para o método da Exaustão que é empregado no Livro XII.

Livro XI - Geometria Espacial 
Juntamente com os livros XII e XIII forma uma trilogia que apresenta a Geometria Espacial. Nessa trilogia encontramos 75 proposições, 63 das quais são teoremos e as 12 restantes são problemas.

O Livro XI possui 28 definições e 39 proposições, onde encontramos teoremas sobre retas e planos no espaço, e os teoremas sobre paralepípedos.

Livro XII - Medição de Figuras

Esse livro com 18 proposições desenvolve dados básicos para o Livro XIII. Euclides usa o método da exaustão comentado por Arquimedes.

Livro XIII - Sólidos Regulares

Esse livro com 18 proposições apresenta os cinco sólidos platônicos: o tetraedro, o hexaedro, o octaedro, o dodecaedro e o icosaedro.

Não há dúvida quanto a importância do conteúdo apresentado nos Elementos. Entretanto para muitos autores e pesquisadores o grande mérito está na forma com que eles são apresentados. Euclides busca dar a matemática grega uma base sólida utilizando o método axiomático que pela primeira vez pode ser visto atuando em toda a extenção de uma obra. O cuidado de Euclides com a técnica empregada denota provavelmente sua intenção em deixar a obra livre de conjecturas e suposições, livre de noções que se baseiam apenas na intuição sem uma comprovação lógica, livre de observações físicas. Desse modo um caminho que a tradição atribui seu início com Tales encontra seu ponto alto com Euclides.

O método axiomático de um modo geral conciste de um grupo de objetos ou termos não definidos, chamados de objetos ou termos primitivos, em função dos quais todos os demais termos ou objetos são definidos; um conjunto de proposições que se faz sobre os objetos ou termos primitivos e aceitas sem demonstração, que são chamadas de axiomas ou postulados, e finalmente um conjunto de proposições demonstradas utilizando a lógica dedutiva que apresenta a propriedades dos objetos ou termos não definidos, que são denominados de teoremas. Inicialmente pode parecer estranho um sistema lógico ser montado com termos ou objetos não definidos assim como proposições não demonstradas mas observemos o que diz Tomei e Aaboe a esse respeito:

Você deve imaginar qual deve ser um dos problemas básicos de escrever um dicionário. Uma palavra difícil tem de ser explicada com palavras mais fáceis, que por sua vez tem que ser explicadas com palavras ainda mais fáceis. Levado ao pé da letra, o processo não teria fim. Como o número de palavras de uma língua é 
finito, a conclusão é inevitável: algumas palavras não poderão ser definidas. Temos de escolher algumas palavras como ponto de partida e definir todas as outras a partir delas. Claro, não há nada de sagrado nessa escolha inicial de palavras; elas podem ser trocadas por outras. Mas o importante é começar a partir de um conjunto fixo de termos não definidos. (Tomei, 2006, pg.34)

Se eliminarmos as palavras de um tratado matemático, resta uma sequência de teoremas, cada um seguido de sua demonstração. A demonstração consiste em mostrar que o teorema em estudo é uma consequência lógica dos teoremas precedentes. Mas isso significa, naturalmente, que o primeiro "teorema" que enunciamos não pode ser demonstrado, pois não há teoremas precedentes para serem usados em sua demonstração. Os teoremas indemonstráveis que iniciam uma teoria são chamados de axiomas. ( Aaboe, 2013, pg.55)

Além dos fatos explanados por Tomei e Aaboe, o sistema axiomático por lidar com objetos ou termos indefinidos não limita qualquer particular interpretação. Os resultados e propriedades encontradas pela lógica dedutiva podem ser utilizados em qualquer conjunto de termos que se identificam com os objetos não definidos, é o que nos diz Aaboe:

...do ponto de vista da matemática pura, não faz diferença o que são os objetos que figuram nos axiomas, tais como pontos, retas e círculos; o que importa são as relações entre tais objetos não definidos, como por exemplo, duas retas distintas tem no máximo um ponto em comum. Em vez de reduzirem a matemática a uma simples brincadeira inconsequente, essa desistência de definir os objetos com os quais uma teoria se ocupa a torna extremamente útil. Com efeito, sempre que forem encontrados objetos que satisfaçam as relações enunciadas nos axiomas, por exemplo, na física, então todo o corpo de teoria pode ser aplicado a estes objetos. (Aaboe, 2013, pg.55)

Apesar dessa pretensa arbitrariedade que os objetos não definidos e os axiomas possam ter em um sistema axiomático, não é bem assim que as coisas funcionam. Os termos primitivos e os axiomas não são destituídos de significados, os axiomas nos trazem afirmações básicas sobre os objetos não definidos e o raciocínio dedutivo agrega mais e mais proposições e propriedades sobre eles. Além disso, o conjunto de axiomas escolhido para o desenvolvimento de um sistema axiomático deve ter certas propriedades como:

1. Consistência: essa propriedade nos diz que nenhum axioma pode contradizer outro e que com base nesse conjunto de axiomas nenhum teorema será contraditório a outro teorema. 
2. Completude: essa propriedade estabelece que o que será usado no desenvolvimento da teoria está devidamente estabelecido no conjunto de axiomas.

3. Independência: essa propriedade estabelece que nenhum axioma é logicamente deduzido de outro, ou seja, nenhum axioma é derivado de outro.

\section{Aaboe nos esclarece que:}

Não é tão simples quanto parece ter-se certeza que um sistema de axiomas é completo, Mas se procedermos, passo a passo, examinando cada raciocínio nos mínimos detalhes, poderemos ter certeza que não foram feitas hipóteses tácitas.

A consistência de um conjunto de axiomas é extremamente difícil de decidir. Demonstra-se geralmente que um certo conjunto de axiomas, por exemplo os das geometria plana, é consistente, se outro conjunto de axiomas, por exemplo o dos números reais, for consistente. No exemplo dado, a ponte entre os dois conjuntos de axiomas é a geometria analítica.

A independência diz que não deveríamos escrever mais axiomas do que os absolutamente necessários. Se um sistema de axiomas é consistente e completo mas não independente isso não causará nenhum problema sério; significa simplesmente que um ou mais dos axiomas estão erroneamente designados, e deveriam em vez disso serem chamados de teoremas, pois podem ser demonstrados usando outros axiomas. (Aaboe, 2013, pg.56)

Essas poucas observações sobre o método axiomático são suficientes para entendermos a grandiosidade do trabalho de Euclides, entretanto por ser pioneiro em uma região tão vasta e nova, lançando mão de ideias tão densas e profundas, Euclides cometeu enganos, mas que de modo algum diminuem sua importância histórica na construção de alicerces sólidos para o desenvolvimento da matemática. 


\section{O Quinto Postulado}

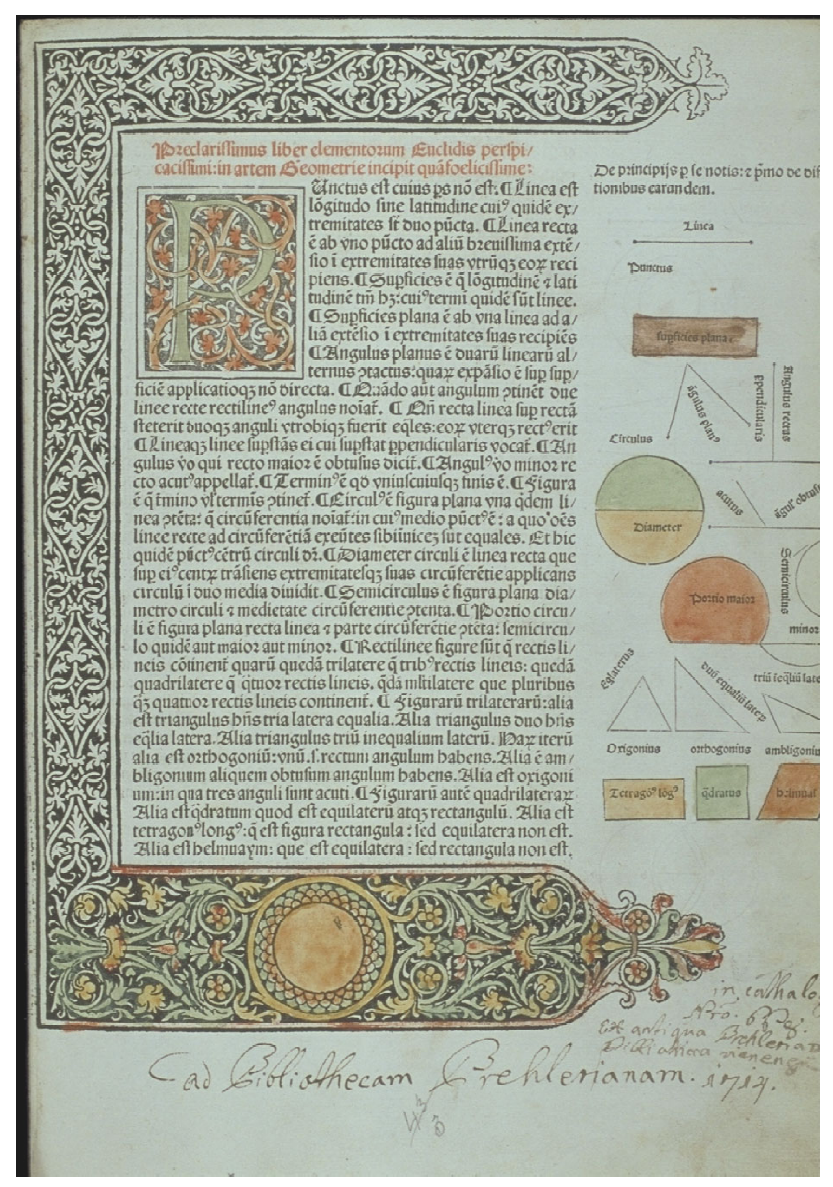

Figura 4 - Página da primeira edição impressa em latim $(1482)^{22}$

Euclides inicia o Livro I dos Elementos citando 23 definições em que procura deixar a compreensão dos objetos e termos, que terão suas propriedades estudadas e estabelecidas no decorrer de sua obra, de forma bem clara e precisa.

\footnotetext{
${ }^{22}$ Disponível em: <http://www.prof2000.pt/users/amma/af18/t1/t1.htm>. Acesso em 26 de novembro de 2013.
} 
Vejamos algumas definições elencadas por Euclides, por tradução de Irineu Bicudo:

1. Ponto é aquilo de que nada é parte.

2. E linha é comprimento sem largura.

3. E extremidade de uma linha são pontos.

4. E uma linha reta é a que está posta por igual com os pontos sobre si mesma.

...

10. E quando uma reta, tendo sido alteada sobre uma reta, faça os ângulos adjacentes iguais, cada um dos ângulos é reto, a a reta que se alteou é chamada uma perpendicular àquela sobre a qual se alteou.

15. Círculo é uma figura plana contida por uma linha, em relação à qual todas as retas que a encontram, a partir de um ponto dos postos no interior da figura, são iguais entre si.

16. E o ponto é chamado centro do círculo.(Bicudo, 2009, pg.97/98)

Em seguida, Euclides escreve os postulados e axiomas delimitando assim as hipóteses que são utilizadas nas demonstrações dos teoremas e no desenvolvimento de toda a teoria. Eis os postulados e axiomas estabelecidos por Euclides, por tradução de Irineu Bicudo:

Postulados:

1. Fique postulado traçar uma reta ${ }^{23}$ a partir de todo ponto até todo ponto.

2. Também prolongar uma reta limitada, continuamente, sobre uma reta.

3. E, com todo centro e distância, descrever um círculo.

4. E serem iguais entre si todos os ângulos retos.

5. E caso uma reta, caindo sobre duas retas, faça os ângulos interiores e do mesmo lado menores do que dois retos, sendo prolongadas, as duas retas, encontram-se no mesmo lado no qual estão os menores do que dois retos.

Axiomas ou Noções Comuns:

1. As coisas iguais às mesmas coisas são também iguais entre si.

2. E, caso sejam adcionados coisas iguais a coisas iguais, os todos são iguais.

3. E, caso de iguais sejam subtraídas iguais, os restantes são iguais.

4. E, caso iguais sejam adcionados a desiguais, os todos são desiguais.

5. E os dobros da mesma coisa são iguais entre si.

6. E as metades da mesma coisa são iguais entre si.

7. E as coisas que se ajustam uma à outra são iguais entre si.

8. E o todo é maior do que a parte.

9. E duas retas não contêm uma área. (Bicudo, 2009, pg.98/99)

É evidente que a luz de nossa moderna visão do sistema axiomático iremos encontrar falhas e enganos cometidos por Euclides na elaboração de suas

\footnotetext{
${ }^{23}$ Euclides não faz distinção entre reta e segmento de reta.
} 
definições, postulados e axiomas. Entretanto o questionamento mais importante da obra de Euclides gira em torno do Quinto Postulado, permitindo que a matemática expandisse e abrisse novos caminhos e áreas de estudo.

Hoje em dia é quase um consenso entre os historiadores da matemática que o próprio Euclides tinha certas restrições quanto ao Quinto Postulado, uma vez que só foi utilizado a partir da proposição 29 do Livro I, contribuindo com a tese que ele só foi utilizado quando se tornou imprecindível. Tal fato pode ser observado na Tabela 1 (Bongiovanni, Jahn, 2010, pg.43) que apresenta a relação de cada proposição do Livro I dos Elementos com as definições, postulados e axiomas.

\begin{tabular}{|c|c|c|c|c|c|c|c|c|c|}
\hline \multirow[b]{2}{*}{ 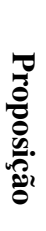 } & \multicolumn{4}{|c|}{ Uso } & \multirow[b]{2}{*}{ 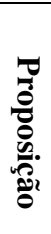 } & \multicolumn{4}{|c|}{ Uso } \\
\hline & 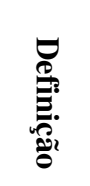 & $\begin{array}{l}\overrightarrow{0} \\
\stackrel{0}{2} \\
\stackrel{0}{0} \\
\stackrel{0}{0}\end{array}$ & 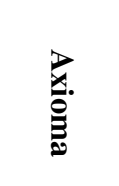 & 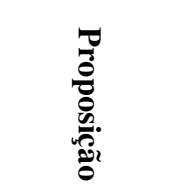 & & 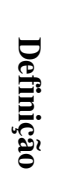 & 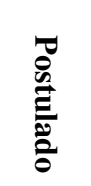 & . & 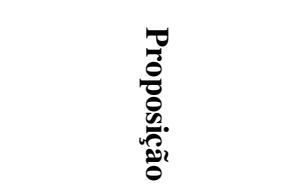 \\
\hline 1 & 15,20 & 1,3 & 1 & & 25 & & & & 4,24 \\
\hline 2 & 15,20 & $1,2,3$ & 1,3 & 1 & 26 & & 1 & 1,8 & $3,4,16$ \\
\hline 3 & 15 & 3 & 1 & 2 & 27 & 23 & 2 & & 16 \\
\hline 4 & & & 7,9 & & 28 & & 4 & $1,2,3$ & $13,15,27$ \\
\hline 5 & & 1,2 & 3 & 3,4 & 29 & 23 & 2,5 & $1,2,4$ & 13,15 \\
\hline 6 & & 1 & 8 & 3,4 & 30 & & & 1 & 27,29 \\
\hline 7 & & 1 & 8 & 5 & 31 & & 1,2 & & 23,27 \\
\hline 8 & & & 7 & 7 & 32 & & 2 & 1,2 & $13,29,31$ \\
\hline 9 & 20 & 1 & & $1,3,8$ & 33 & & 1 & & $4,27,29$ \\
\hline 10 & 20 & & & $1,4,9$ & 34 & & 1 & 2 & $4,26,29$ \\
\hline 11 & 10,20 & 1 & & $1,2,3,8$ & 35 & & & $1,2,3$ & $4,29,34$ \\
\hline 12 & 10,15 & 1,3 & & 8,10 & 36 & & 1 & 1 & $33,34,35$ \\
\hline 13 & 10 & & 1,2 & 11 & 37 & & 2 & 6 & $31,34,35$ \\
\hline 14 & & 2,4 & $1,2,3,8$ & 13 & 38 & & 2 & 6 & $31,34,36$ \\
\hline 15 & & 4 & $1,2,3$ & 13 & 39 & & 1 & 1,8 & 31,37 \\
\hline 16 & & 1,2 & 8 & $2,3,4,10,15$ & 40 & & 1 & 1,8 & 31,38 \\
\hline 17 & & 2 & 4 & 13,16 & 41 & & 1 & 1,2 & 34,37 \\
\hline 18 & & 1 & 8 & $3,5,16$ & 42 & & 1 & 1,2 & $10,23,31,38,41$ \\
\hline 19 & & & & 5,18 & 43 & & 1 & 2,3 & 34 \\
\hline 20 & & 1,2 & 8 & $2,5,19$ & 44 & & $1,2,5$ & 1,8 & $15,29,30,31,42,43$ \\
\hline 21 & & 2 & 4 & 16,20 & 45 & & 1 & 1,2 & $14,29,30,33,34,42,44$ \\
\hline 22 & 15 & 1,3 & 1 & $1,3,20$ & 46 & 22 & 4 & 1,3 & $2,3,11,29,31,34$ \\
\hline 23 & & 1 & & 8,22 & 47 & & 1,4 & $1,2,5$ & $4,14,30,31,41,46$ \\
\hline 24 & & 1 & 1,8 & $2,4,5,19,23$ & 48 & & 1 & 1,2 & $2,3,8,11,47$ \\
\hline
\end{tabular}

Tabela 1 - Relação das proposições com as definições, postulados e axiomas

Aaboe reforça essa hipótese quando nos afirma: 
A decisão de usar o postulado das paralelas como um de seus axiomas não lhe fora fácil e pode ser deduzido da maneira como ele usou este postulado devemos aqui como sempre acontece ao tratar de Euclides, fazer deduções a partir do texto, pois os Elementos não contem prefácio nem comentários ou justificações, mas somente definições, postulados, teoremas e demonstrações. No livro I, não usou o postulado das paralelas até atingir a demonstração da proposição 29, a qual afirma que, quando duas retas paralelas são cortadas por uma terceira, então os ângulos interiores do mesmo lado são iguais a dois retos. Ele tinha tido uma ocasião tentadora para usar o quinto postulado, imediatamente após I, 17 e se o tivesse feito poderia ter encurtado e mesmo tornado mais penetrantes muitos dos raciocínios posteriores. Fica assim claro que o adiamento é deliberado, e que Euclides decidiu demonstrar o máximo possível sem usar o postulado das paralelas, embora isso significasse progresso mais lento. (Aaboe, 2013, pg.60).

Pesquisadores da matemática de diferentes épocas e diferentes lugares tentaram mostrar que na realidade o Quinto Postulado utilizado por Euclides em seu sistema axiomático poderia ser demonstrado pelos outros quatro, ou seja, na realidade o Quinto Postulado seria um teorema. Essa discussão não traz nenhum dano à validade do sistema axiomático utilizado por Euclides nos Elementos, uma vez que o que se discute é a independência do Quinto Postulado, novamente Aaboe nos esclarece:

Os axiomas de Euclides são tão consistentes quanto à aritmética, pois podemos construir um modelo aritmético que os satisfaz. Este modelo é chamado de geometria Analítica.

O problema axiomático que mais preocupou os matemáticos, desde a antiguidade até meados do século passado, foi o da independência do sistema de Euclides, especificamente do quinto postulado de Euclides. Isso parece algo curioso pois, como vimos, a independência dos axiomas não tem impacto sobre a validez lógica da teoria como um todo, mas esta atividade reflete a atitude dos matemáticos mais antigos com relação à axiomática.(Aaboe, 2013, pg.57/58)

Todas as tentativas de demonstração do Quinto Postulado dos Elementos não resistem a uma análise rigorosa, em geral se observa que de forma inadvertida ou tácita o pesquisador utiliza uma proposição que é equivalente ao Postulado das Paralelas, como também é conhecido o Quinto Postulado. A mais antiga tentativa de demonstração que sabemos foi de Ptolomeu, é o que nos informa Proclus em seu livro Comentários sobre os Elementos de Euclides:

Este deve ser retirado do conjunto dos postulados. Pois é um teorema teorema este que coloca muitas questões que Ptolomeu se propôs resolver num dos seus livros e requer, para a sua demonstração, várias definições assim como teoremas. E a sua recíproca é provada pelo próprio Euclides como um teorema. (proposição 17 do Livro 1). 
[...] Estas considerações tornam claro que devemos procurar uma demonstração do teorema com que nos deparamos e que lhe falta o caráter especial de um postulado".( Proclus, séc V, 191.21-193.3) ${ }^{24}$

Importante se faz ressaltar que Proclus em seguida afirma que outros também compartilham da ideia que o Quinto Postulado é na verdade um teorema, embora não mencione os seus nomes:

Como eu disse na parte da minha exposição que precede os teoremas, nem todos admitem que esta proposição geralmente aceite seja indemonstrável...

...outros antes de nós classificaram-no entre os teoremas e exigiram uma demonstração disto que foi tomado como um postulado pelo autor dos Elementos. (Proclus, séc V, 364.18-365.6) ${ }^{25}$

Proclus também apresenta uma tentativa de demonstração do Quinto Postulado de Euclides. Ele analisou diversas tentativas, desqualificando-as, mostrando falhas nas argumentações que na maioria das vezes era aceitar a hipótese que retas paralelas são retas equidistantes, um argumento equivalente ao Quinto Postulado. Proclus afirma que podem existir retas não concorrentes que não são equidistantes, portanto é preciso demonstrar essa hipótese. Entretanto para provar tal fato tem-se que necessariamente admitir o Quinto Postulado ou uma afirmação que lhe é equivalente.

Com a mudança do eixo do saber e cultura para o mundo árabe, com a queda de Alexandria em 641 E.C, a discussão em torno do Postulado das Paralelas também teve contribuições de seus matemáticos. Ibn-al-Haytham e Omar Khayyam, apesar de falharem na demonstração, introduziram uma nova abordagem, utilizaram o método de redução ao absurdo. Ibn-al-Haytham na sua tentativa de demonstração toma um quadrilátero com três ângulos retos e tenta provar que o quarto ângulo também é reto e daí procura deduzir o quinto postulado. Ibn-al-Haytham falha ao admitir que o ponto $\mathrm{A}$ ao percorrer a reta $\mathrm{AB}$, faz o ponto $\mathrm{C}$ descrever uma reta, se o segmento $\mathrm{AC}$ permanecer perpenticular ao segmento $\mathrm{AB}$, pois tal fato é equivalente ao quinto postulado.

\footnotetext{
${ }^{24}$ Disponível em:< htpp://www.educ.fc.ul.pt/docentes/opombo/seminário/quintoposteucl/ proclus.htm>, acessado em 12/12/2013

${ }^{25}$ Disponível em:< htpp://www.educ.fc.ul.pt/docentes/opombo/seminário/quintoposteucl/ proclus.htm>, acessado em 12/12/2013
} 


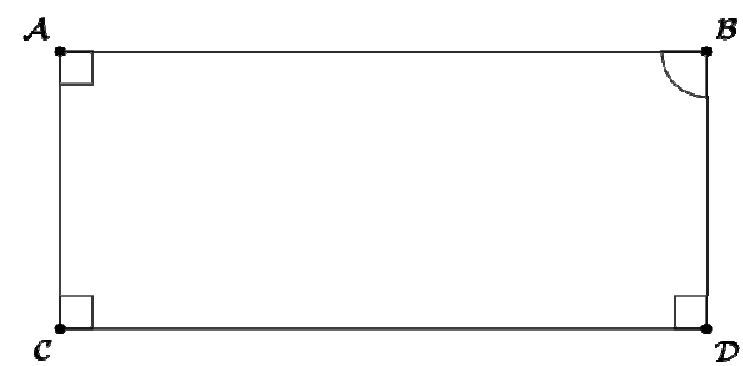

\section{Figura 5 - Quadrilátero usado por Ibn-al-Haytham na tentativa de demonstração do Quinto Postulado}

Por sua vez Omar Khayyam utiliza na sua tentativa um quadrilátero em que os dois ângulos da base são retos e os lados adjacentes a base possuen dimensões iguais.

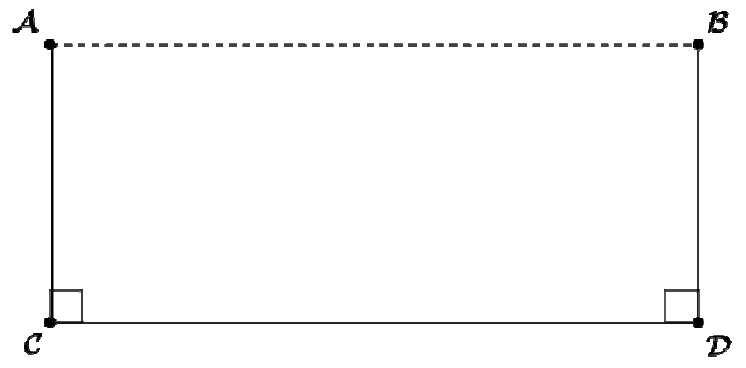

Figura 6 - Quadrilátero usado por Omar Khayyam na tentativa de demonstração do Quinto Postulado

Utilizando agora o fato que a distância entre duas paralelas permanece constante, Omar Khayyam mostra que o segmento AB é maior, menor ou igual ao segmento CD conforme os ângulos A e B sejam respectivamente obtusos, agudos ou retos. Entretanto o argumento utilizado por Khayyam já havia sido refutado por Proclus de que a distância entre duas retas paralelas é constante.

Nasir Eddin al-Tusi que escreveu uma versão em árabe dos Elementos de Euclides apresentou também a sua tentativa de demosntração do Quinto Postulado. Ela baseava-se no seguinte argumento tomado como óbvio: 
Se duas retas $\mathrm{AB}$ e $\mathrm{CD}$ são cortadas por uma terceira reta $\mathrm{PQ}$, que é perpendicular apenas a uma delas (considere-se que seja CD), então, as distâncias medidas nas perpendiculares de $\mathrm{AB}$ para $\mathrm{CD}$ são menores do que $\mathrm{PQ}$ no lado em que $\mathrm{AB}$ faz um ângulo agudo com $\mathrm{PQ}$, e são maiores no lado onde $\mathrm{AB}$ faz um ângulo obtuso. ${ }^{26}$

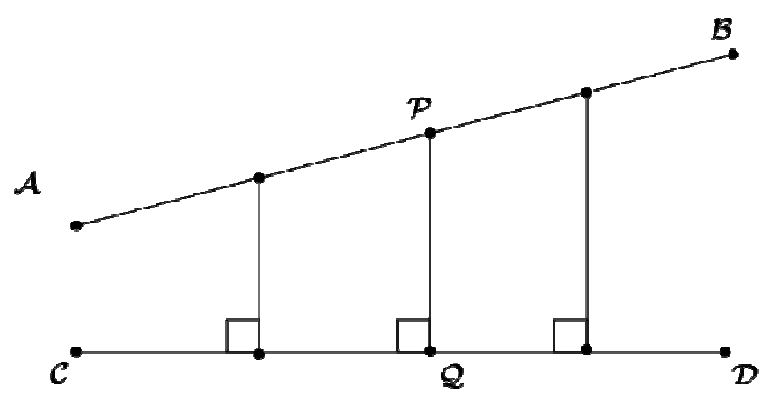

\section{Figura 7 - Argumento usado por Nasir Eddin al-Tusi na tentativa de demosntração do Quinto Postulado}

O erro de Nasir Eddin al-Tusi foi tomar uma argumentação como óbvia equivalente ao Quinto Postulado de Euclides invalidando assim a sua tentativa de demonstração.

Com a tradução para o latim da obra de Euclides em 1142 por Adelard de Bath, retoma novamente o interesse do ocidente pelo problema que envolve o Quinto Postulado.

O matemático John Wallis abandonou a noção da equidistância das retas paralelas utilizando o axioma que toda figura possui uma semelhante de qualquer tamanho, ou seja dada uma figura podemos ampliá-la ou reduzí-la sem que ela sofra distorções. Wallis utilizou esse axioma especificamente para triângulos afirmando que dados um triângulo e um segmento existe um triângulo, tendo o seguimento dado como um dos seus lados, que é semelhante ao triângulo dado.

A tentativa de John Wallis é falha na sua essência o seu axioma é equivalente ao Quinto Postulado de Euclides.

\footnotetext{
${ }^{26}$ http:www. educ.fc.ul.pt/docentes/opombo/seminário/quintoposteucl/postulado

1.htm. Acesso em 12/12/2013
} 
Os esforços foram muitos na tentativa de demonstrar o Quinto Postulado de Euclides, entretanto nenhuma tentativa passa por um exame mais acurado levando sempre a um erro lógico. Desse modo, pouco se evoluiu na discussão em torno do problema das paralelas. Por um lado se procurava demonstrar o Quinto Postulado utilizando os outros quatro, ou seja de forma direta. Por outro lado acreditava-se que a única e verdadeira geometria era a que hoje chamamos como Geometria Euclidiana. Essa crença era tão forte que o matemático Isaac Barrow (1630$1677)^{27}$ afirmou certa vez que os princípios da Geometria Euclidiana se aplicavam ao espaço físico por razões inatas, querendo dizer que nasce com o homem a capacidade de entender o espaço na forma da Geometria Euclidiana.

Nesse ambiente surje Giovanni Girolamo Saccheri (1667-1733) um padre jesuíta, professor de teologia, filosofia e matemática que ensinou em Turim e Pávia. Hoje é considerado como um precursor de uma nova geometria, mas infelizmente influenciado pela noções de sua época, que a única e verdadeira geometria existente era a Euclidiana, deixou de adiantar em um século a descoberta de novas geometrias. Na sua obra "Euclides ab Omni Naevo Vindicatus" ${ }^{\text {"28 }}$ de 1773 que tem como foco a demonstração do Quinto Postulado de Euclides pode-se dizer que praticamente descobriu uma nova geometria ou a primeira Geometria Não Euclidiana, sem ter-se apercebido de tal fato.

A abordagem de Saccheri era negar o Postulado das Paralelas, ou seja, ele tomava como falso o Quinto Postulado e aceitava como premissas verdadeiras as 28 primeiras proposições do Livro I de Euclides. A partir daí começou a procurar alguma evidência de que o Quinto Postalado era de fato verdadeiro. Ele utilizou um quadrilátero com dois lados opostos congruentes e perpendiculares a base que hoje conhecemos como quadrilátero de Saccheri estudando assim as suas propriedades.

Infelizmente Saccheri analisa seus feitos sob uma ótica mais voltada na crença existente na época de que a verdadeira e única geometria era a Euclidiana, do que naquilo que a lógica estava lhe mostrando, deixando assim de caminhar na direção de uma nova e interessante área da matemática.

\footnotetext{
${ }^{27}$ Teólogo e matemático inglês, nascido em Londres. Teve como aluno Isaac Newton.

${ }^{28}$ Euclides Livre de Todos os Erros
} 


\section{Uma Primeira Geometria Não Euclidiana}

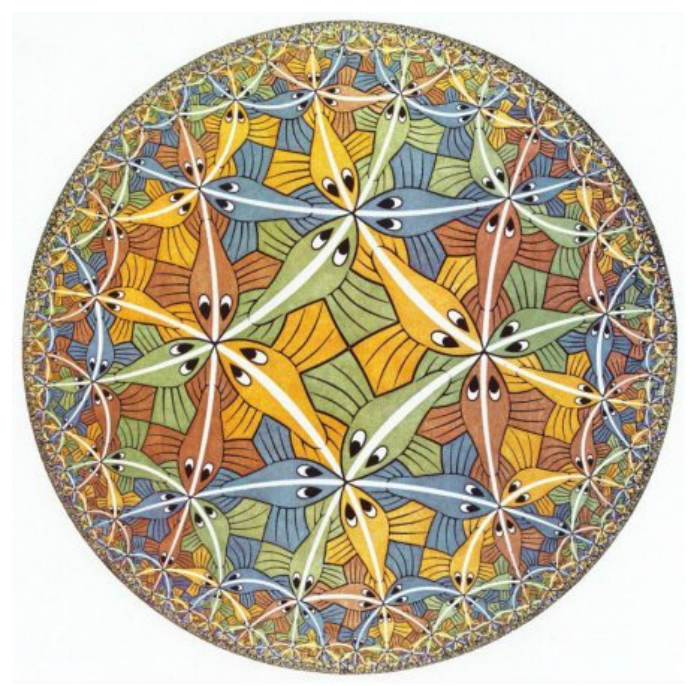

Figura 8 - Circle Limited III (1959) - M.C.Escher ${ }^{29}$

Em 1820 um preocupado pai com o futuro profissional do filho lhe dá um conselho por carta: "Não desperdices uma hora no problema. Em vez de ser recompensador, envenenará toda a tua vida”. Esse zeloso pai ainda continua tentando dissuadir o filho para outros interesses escrevendo: "os maiores geômetras ponderaram o problema durante centenas de anos e não conseguiram provar o postulado das paralelas sem um novo axioma." E colocando a autoridade de pai: “ Acredito que eu mesmo investiguei todas as ideias possíveis...”.

Apesar dos apelos de Farkas Wolfgang Bolyai, esse preocupado e zeloso pai, o jovem de 21 anos Janos Bolyai, nascido em Kolozsvár, Hungria (atualmente Cluj, Romenia), escreve ao seu pai em 3 de novembro de 1823 relatando: "resolvi publicar um trabalho sobre as paralelas, mal arranje o material e as minhas circunstâncias o permitam. Não completei o meu trabalho, mas o caminho que segui torna quase certo que o objetivo será alcançado". Prossegue de um modo

\footnotetext{
${ }^{29}$ Disponível em: http://www.mcescher.com/. Acesso em 05 de dezembro de 2013.
} 
eufórico escrevendo: "Efetuei descobertas maravilhosas que me deixaram extasiados e seria motivo de lamento se as perdesse. Quando as vires, querido pai, também perceberás.”. Na mesma carta Janos Bolyai escreve uma conhecida frase "Criei um universo do nada". E como que se desculpando pelo fato de não ter seguido o conselho do pai afirma: " tenho certeza que me trará honra, tal como se já tivesse completado a descoberta".

Uma vez que novas e boas ideias não é privilégio de uma única pessoa, podendo ocorrer de modo simultâneo entre personagens que nunca se conheceram, Farkas Bolyai agora aconselha o seu filho a agir com rapidez: "primeiro porque as ideias passam facilmente de uns para os outros, que as podem de imediato publicar, e, segundo, há alguma verdade no fato de muitas coisas terem uma época para serem descobertas ao mesmo tempo em vários sítios”.

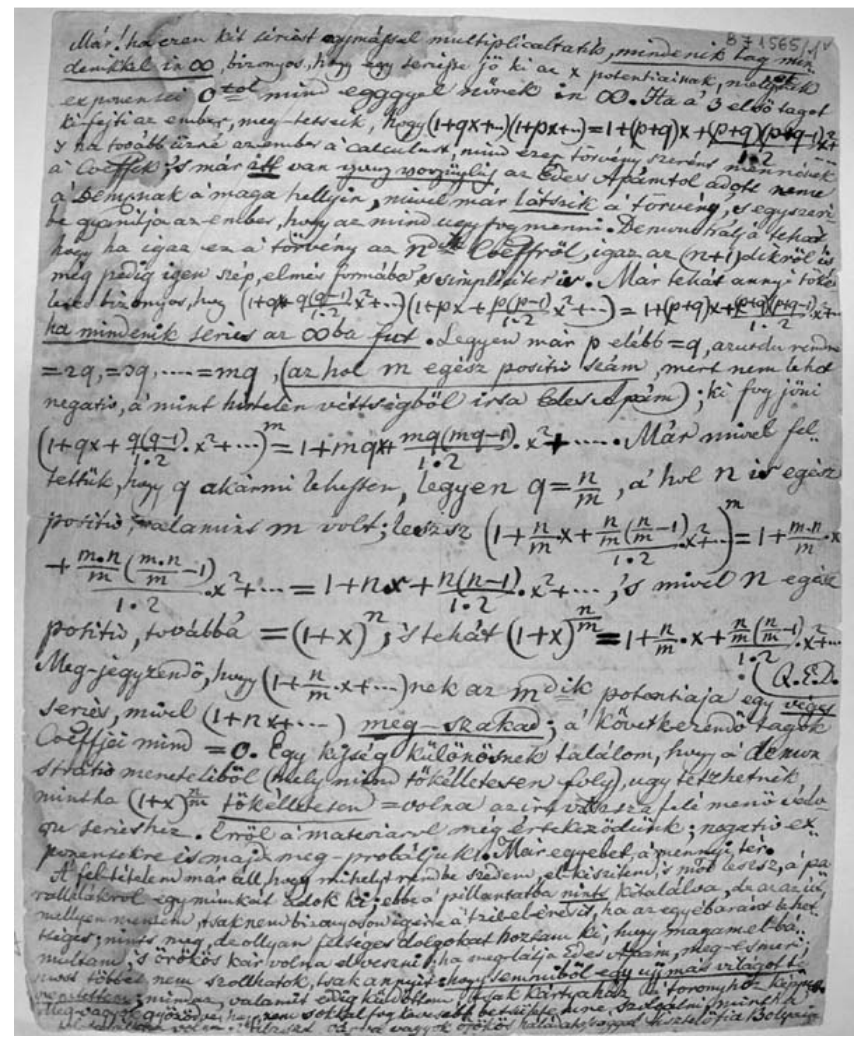

Figura 9 - Carta de Janos Bolyai a seu pai ${ }^{30}$

${ }^{30}$ Disponível em: http://www.termeszetvilaga.hu/kulonsz/k011/eukleidesz.html. Acesso em 12 de dezembro de 2013. 
Nessa época Farkas Bolyai trabalhava em seu livro Ensaios sobre os Elementos de Matemática para Jovens Estudiosos e imediatamente convidou Janos Bolyai para incluir em seu livro esses estudos. Desse modo em 1823 Janos Bolyai descobre a primeira Geometria Não Euclidiana.

Nessa época o outro personagem dessa história, Nikolay Ivanovich Lobachevsky, talvez ainda não tivesse iniciado o seu estudo do problema das paralelas, entretanto foi ele o primeiro a publicar um trabalho que apresenta uma nova geometria, que hoje conhecemos como a Geometria Hiperbólica. Em 1829 em uma desconhecida revista científica russa, O Mensageiro de Kazam, Lobachevsky apresenta um artigo intitulado Sobre os Fundamentos da Geometria. Nesse artigo, escrito em russo, ele apresenta todo o desenvolvimento do que chamou de Geometria Imaginária.

Somente em 1832 Janos Bolyai consegue publicar os seus estudos, e mesmo assim em um apêndice do $1^{\circ}$ volume dos Ensaios de Farkas Bolyai, com o pomposo título "A ciência do espaço absoluto com uma demonstração da independência da verdade ou falsidade do axioma XI de Euclides (que não pode ser decidido a priori) e também a quadratura do círculo no caso de sua falsidade".

Tanto Bolyai quanto Lobachevsky não conheciam o trabalho um do outro e como afirma Mlodinow “... infelizmente, ninguém tampouco sabia. Matemáticos essencialmente obscuros, quando falaram ninguém deu ouvidos". Bolyai nunca mais publicou nenhum outro trabalho e Lobachevsky se tornou reitor da Universidade de Kazam. Mlodinow ainda completa afirmando:

... poderiam ambos ter sumido no limbo desconhecido, não fosse o seu contato com Gauss. Ironicamente, foi a morte de Gauss que finalmente levou à revolução não euclidiana.

Gauss foi um cronista meticuloso das coisas à sua volta. Tinha o prazer de colecionar dados bizarros, tais como a duração da vida de seus amigos mortos, ou o número de passos desde o laboratório onde trabalhava até vários lugares que gostava de visitar. Ele também fazia registros de seu trabalho. Após a sua morte, especialistas estudaram com atenção suas anotações e correspondências. Lá, descobriram a sua pesquisa sobre o espaço não euclidiano, bem como os trabalhos de Bolyai e Lobachevsky. (Mlodinow,2008 , pg.125). 
Somente em 1862 quando Richard Baltzer, na segunda edição do seu livro Element der Mathmatik incluiu os trabalhos de Bolyai e Lobachevsky, tornou-os referências padrão para aqueles que estudam essas novas geometrias.

Assim de Euclides por volta de 300 a.E.C até Bolyai e Lobachevsky no século XIX, muito tempo se passou para que a matemática consolidasse as ideias e considerações em torno do Quinto Postulado dos Elementos e abrisse caminho para o estudo de novas geometrias que hoje conhecemos como as Geometrias Não Euclidiana. Tais geometrias são assim chamadas, pois contrariam o Quinto Postulado dos Elementos ou algumas de suas consequências.

Hoje em dia chamamos de Geometria Euclidiana, Geometria Hiperbólica e Geometria Elíptica aquela que adota como o Quinto Postulado respectivamente a afirmação que por um ponto exterior a uma reta podemos traçar uma única reta paralela, infinitas retas paralelas ou nenhuma reta paralela a reta dada.

A seguir apresentamos uma Geometria Não Euclidiana que por sua simplicidade de compreensão e uso pode ser inserida e trabalhada para contextualizar tópicos do Ensino Básico. 


\section{A Geometria do Taxi}

\subsection{Métrica}

Quando perguntamos a alguém qual a distância entre dois lugares, podemos ter respostas diversas e até certo ponto surpreendentes. Muitos, talvez, dirão que depende da hora, pois pode ser uma hora e meia a duas horas dependendo do trânsito. Outros que depende do meio de transporte que se está utilizando para se deslocar, associando assim distância a tempo. Muitas vezes o desconhecimento do caminho pode influenciar em nossa percepção de distância. Quantas vezes já não dissemos que a volta parece ser mais perto. Se estiver no interior de Minas Gerais responderam a sua pergunta dizendo que é logo ali e no interior do nordeste que pode ser daqui a três cachimbos.

A ciência, no entanto, não pode ficar a mercê de nossa intuição e regionalismos. Assim a matemática define distância como uma função D: $\mathrm{HxH} \rightarrow$ $\mathrm{R}$, que associa a cada par ordenado $(\mathrm{x}, \mathrm{y})$ pertencentes ao conjunto $\mathrm{H}$ um número real $\mathrm{D}(\mathrm{x}, \mathrm{y})$, chamado a distância de x a y, de modo que tal função, que chamamos de métrica deve satisfazer as seguintes condições:

$$
\begin{aligned}
& \text { 1. } D(x, x)=0 \\
& \text { 2. se } x \neq y, \text { então } D(x, y)>0 \\
& \text { 3. } D(x, y)=D(y, x) \\
& \text { 4. } D(x, z) \leq D(x, y)+D(y, z)
\end{aligned}
$$

O conjunto $\mathrm{H}$ ao qual associamos uma métrica $\mathrm{D}: \mathrm{HxH} \rightarrow \mathrm{R}, \mathrm{D}(\mathrm{x}, \mathrm{y})=\mathrm{k}$, é o que chamamos de espaço métrico e representamos pelo par (H, D).

$\mathrm{O}$ espaço euclidiano $\mathrm{R}^{\mathrm{n}}$ cujos elementos são $\mathrm{x}=\left(x_{1}, x_{2}, \ldots, x_{n}\right)$ onde $\mathrm{x}_{\mathrm{i}}$ é um número real, é um exemplo de espaço métrico com as seguintes métricas (Demonstrações no anexo - 9.1): 


$$
\begin{gathered}
D_{E}(x, y)=\left[\sum_{i=1}^{n}\left(x_{i}-y_{i}\right)^{2}\right]^{1 / 2} \\
D_{T}(x, y)=\sum_{i=1}^{n}\left|x_{i}-y_{i}\right|
\end{gathered}
$$

A métrica $\mathrm{D}_{\mathrm{E}}$ é a que chamamos de Métrica Euclidiana e a $\mathrm{D}_{\mathrm{T}}$ denominamos de Métrica do Taxi.

No particular caso do Plano Euclidiano $\left(\mathrm{R}^{2}\right)$ teríamos a Métrica Euclidiana e a Métrica do Taxi descritas do seguinte modo:

Métrica Euclidiana:

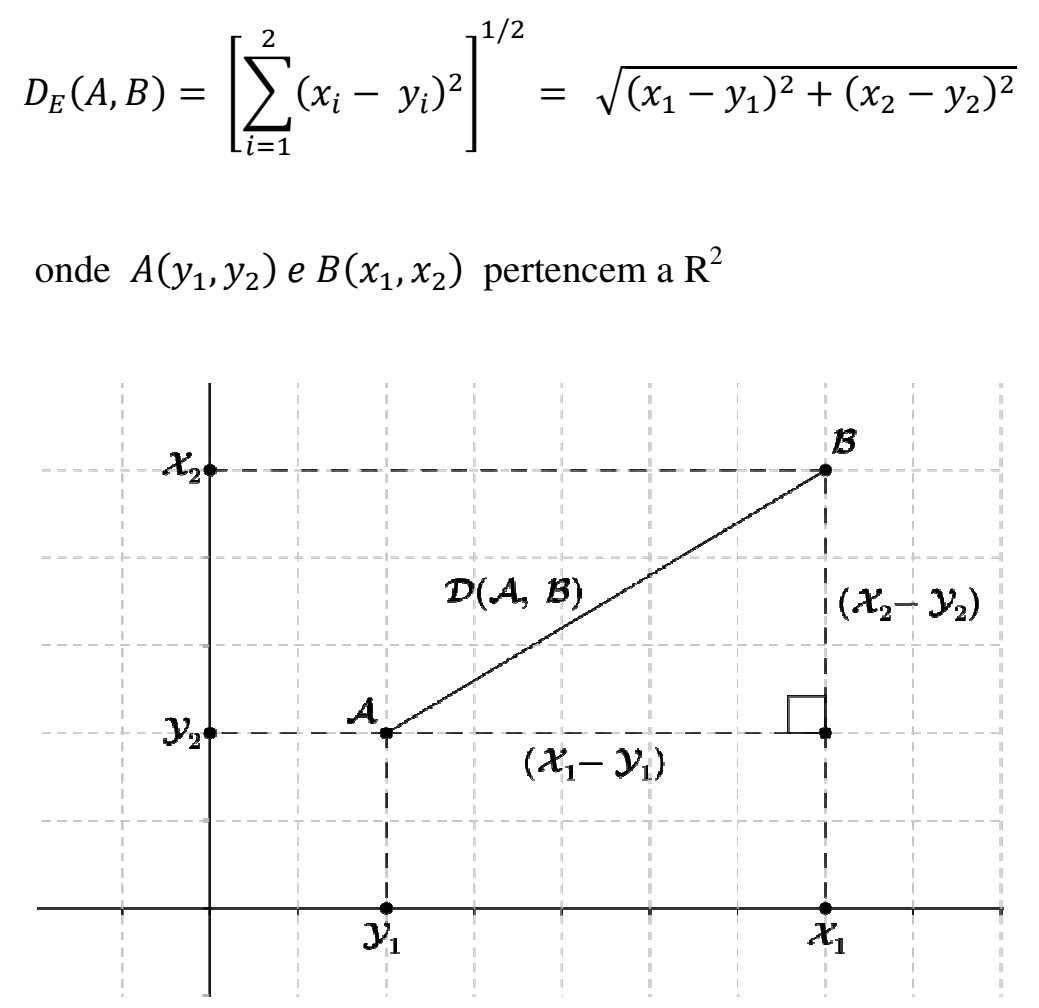

Figura 10 - Métrica Euclidiana

Métrica do Taxi: 


$$
D_{T}(A, B)=\sum_{i=1}^{n}\left|x_{i}-y_{i}\right|=\left|x_{1}-y_{1}\right|+\left|x_{2}-y_{2}\right|
$$

onde $A\left(y_{1}, y_{2}\right)$ e $B\left(x_{1}, x_{2}\right)$ pertencem a $\mathrm{R}^{2}$

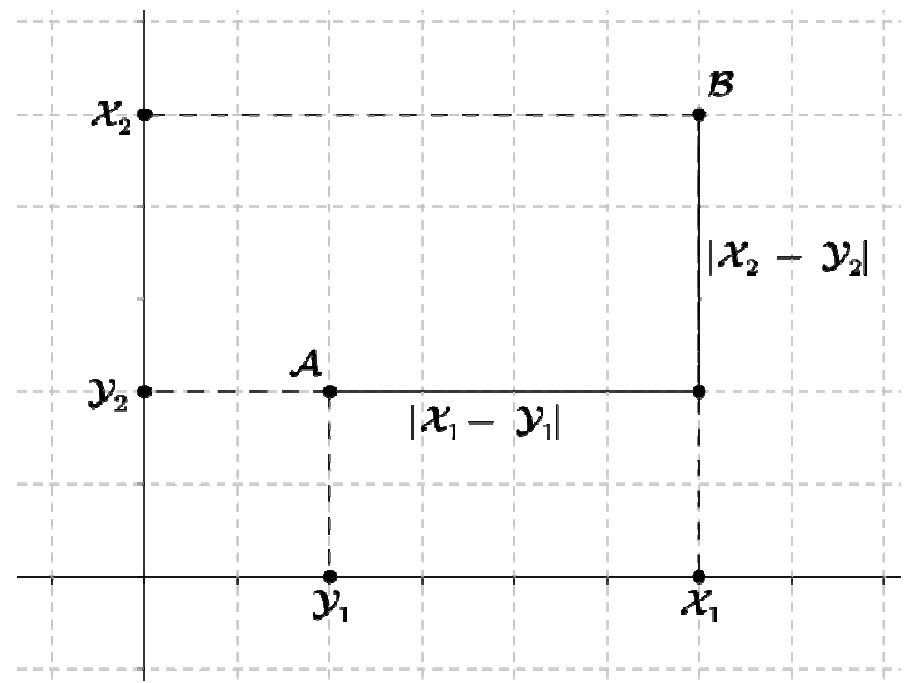

Figura 11 - Métrica do Taxi

Na Métrica Euclidiana a distância entre dois pontos é um segmento de reta que une esses dois pontos, já na Métrica do Taxi a distância entre dois pontos é determinada de forma distinta, por intermédio de linhas quebradas que vão unir esses dois pontos. A Métrica do Taxi irá induzir uma nova geometria, onde retas e pontos são os mesmos da Geometria Euclidiana e os ângulos são medidos da mesma forma, entretanto os objetos que dependem do conceito de distância se apresentam de forma distinta. Essa nova geometria não euclidiana recebe hoje o nome de Geometria do Taxi, ou Geometria Urbana ou ainda Geometria de Manhattan, e teve como precursor o matemático russo Hermann Minkowski (1884 - 1909) responsável pela definição da métrica do taxi. O termo Geometria do Taxi ou Taxicab Geometry surge pela primeira vez em 1952 quando Karl Menger em uma exibição no Museum of Science and Industry of Chicago apresenta um folheto com o nome You Will Like Geometry em que o termo Taxicab Geometry é usado. 
Podemos observar que a Geometria do Taxi é uma Geometria Não Euclidiana no fato que o postulado de congruência do triângulo LAL $^{31}$ (lado ângulo- lado) da Geometria Euclidiana, não é válido na Geometria do Taxi. Como evidencia a Figura - 12. Nela temos que os triângulos $A B C$ e A'B'C' têm respectivamente os lados $\mathrm{AB}, \mathrm{AC}$ e A'B', $\mathrm{A}^{\prime} \mathrm{C}^{\prime}$ congruentes, pela métrica do taxi, e o ângulo A congruente com o ângulo A', entretanto os triângulos não são congruentes.

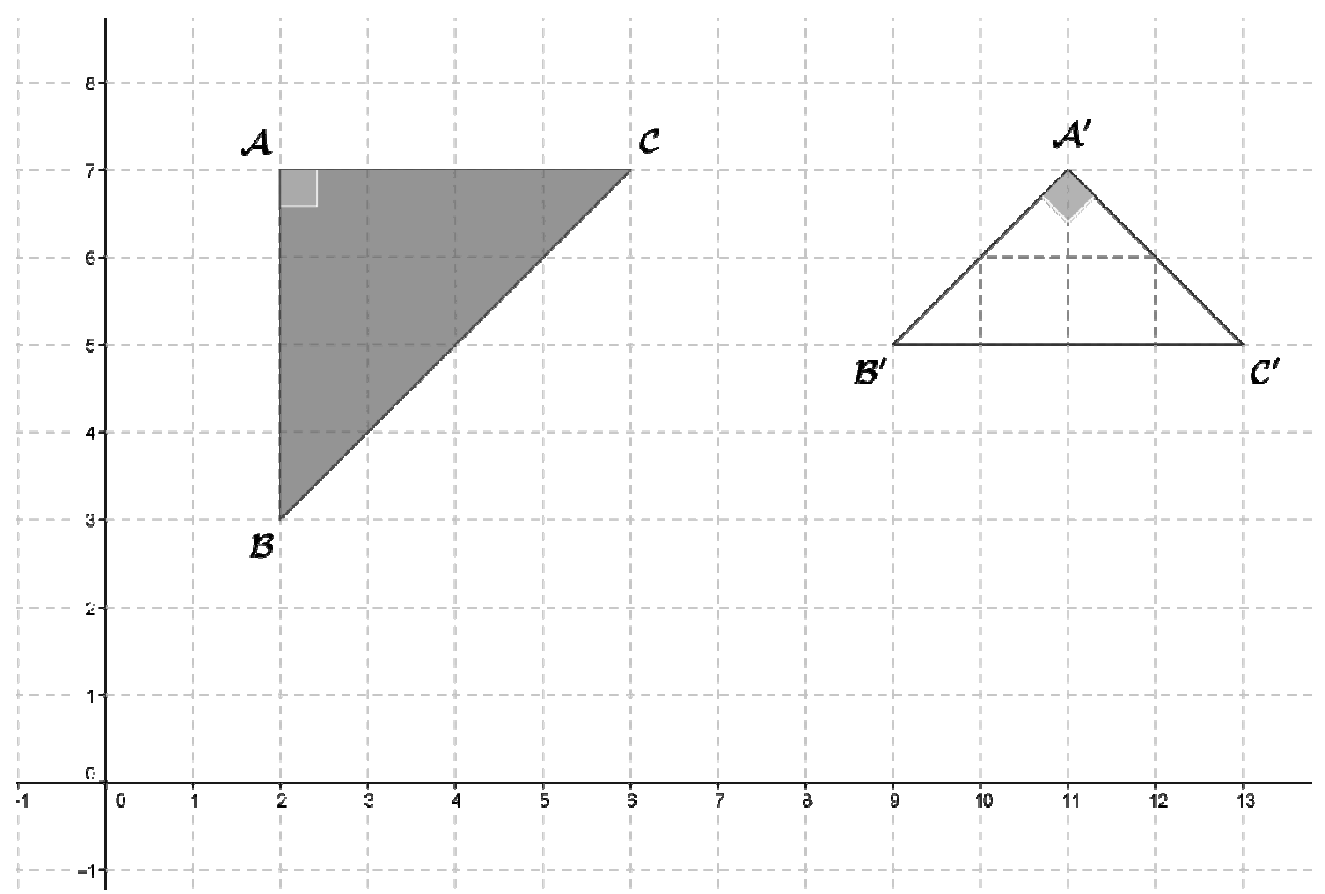

Figura 12 - Negação da congruência LAL

\subsection{Comparações da Geometria do Taxi com a Euclidiana no $\mathbf{R}^{2}$}

Apresentaremos agora algumas considerações a respeito da Geometria do Taxi em comparação com a Geometria Euclidiana, sem a intenção de ser exaustivo, mas tornando possível uma melhor compreensão do modelo do taxi.

${ }^{31}$ Se dois triângulos têm ordenadamente congruentes dois lados e o ângulo compreendido, então eles são congruentes. 


\subsubsection{Distância}

Dados os pontos $A\left(y_{1}, y_{2}\right)$ e $B\left(x_{1}, x_{2}\right)$ temos que:

$$
\begin{aligned}
& D_{E}(A, B)=\left[\sum_{i=1}^{2}\left(x_{i}-y_{i}\right)^{2}\right]^{1 / 2}=\sqrt{\left(x_{1}-y_{1}\right)^{2}+\left(x_{2}-y_{2}\right)^{2}} \\
& D_{T}(A, B)=\sum_{i=1}^{n}\left|x_{i}-y_{i}\right|=\left|x_{1}-y_{1}\right|+\left|x_{2}-y_{2}\right|
\end{aligned}
$$

Observando o fato que:

$$
0 \leq 2\left|x_{1}-y_{1}\right| \cdot\left|x_{2}-y_{2}\right|
$$

$$
\begin{aligned}
& \text { E somando em ambos os lados da desigualdade }\left(x_{1}-y_{1}\right)^{2}+\left(x_{2}-y_{2}\right)^{2} \\
& \text { teremos: } \\
& \begin{array}{c}
\left(x_{1}-y_{1}\right)^{2}+\left(x_{2}-y_{2}\right)^{2} \leq\left(x_{1}-y_{1}\right)^{2}+\left(x_{2}-y_{2}\right)^{2}+2\left|x_{1}-y_{1}\right| \cdot\left|x_{2}-y_{2}\right| \\
\left(x_{1}-y_{1}\right)^{2}+\left(x_{2}-y_{2}\right)^{2} \leq\left(\left|x_{1}-y_{1}\right|+\left|x_{2}-y_{2}\right|\right)^{2} \\
\text { Podemos agora elevar ambos os lados da desigualdade a } 1 / 2, \operatorname{logo}: \\
{\left[\left(x_{1}-y_{1}\right)^{2}+\left(x_{2}-y_{2}\right)^{2}\right]^{1 / 2} \leq\left[\left(\left|x_{1}-y_{1}\right|+\left|x_{2}-y_{2}\right|\right)^{2}\right]^{1 / 2}} \\
\sqrt{\left(x_{1}-y_{1}\right)^{2}+\left(x_{2}-y_{2}\right)^{2}} \leq\left|x_{1}-y_{1}\right|+\left|x_{2}-y_{2}\right|
\end{array}
\end{aligned}
$$

Logo podemos afirmar que: $D_{E}(x, y) \leq D_{T}(x, y)$

\subsubsection{Menores Caminhos entre Dois Pontos}

No modelo euclidiano a distância entre dois pontos é fornecida como a medida de um segmento de reta que une esses dois pontos, desse modo existe um único caminho para percorrer essa distância. Já no modelo do taxi podemos ter vários caminhos que fornecem a mesma medida de distância entre dois pontos. 


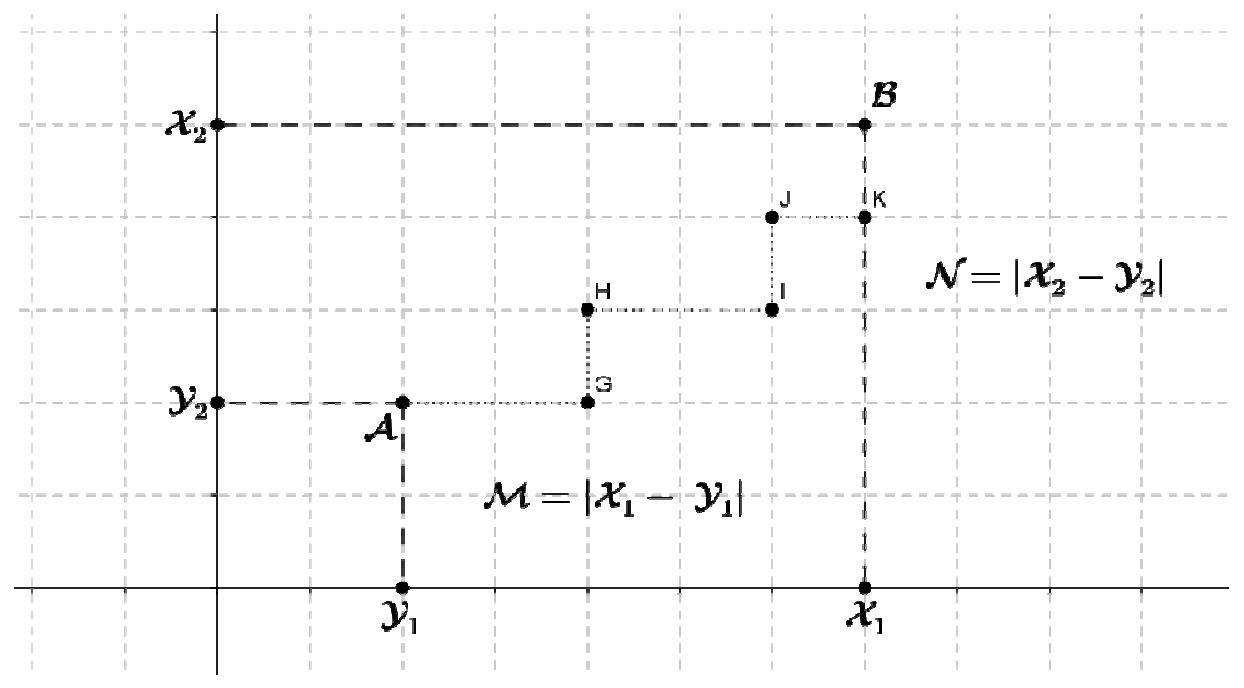

Figura 13 - Trajetória do taxi entre os pontos A e B

Observando a Figura - 13, onde apresentamos um dos possíveis caminhos que nos permitem determinar a distância entre A e B (AGHIJKB), para determinar quantos possíveis caminhos podemos ter entre A e B, vamos raciocinar da seguinte maneira:

Como para nos deslocar de A até B realizaremos movimentos horizontais e verticais, respectivamente, paralelos ao eixo $\mathrm{x}$ e ao eixo y e como todos os movimentos são unitários necessitamos de $\mathrm{M}$ movimentos horizontais e $\mathrm{N}$ movimentos verticais que totaliza $\mathrm{M}+\mathrm{N}$ movimentos. Certo caminho fica totalmente determinado se dissermos quantos desses $\mathrm{M}+\mathrm{N}$ caminhos são horizontais. Assim queremos saber de quantas maneiras iremos escolher M movimentos horizontais em $\mathrm{M}+\mathrm{N}$ movimentos o que podemos determinar calculando:

$$
C_{M+N}^{M}=\frac{(M+N) !}{M !(M+N-M) !}=\frac{(M+N) !}{N ! M !}
$$

Por outro lado também poderíamos querer saber de quantas maneiras iremos escolher $\mathrm{N}$ movimentos verticais em $\mathrm{M}+\mathrm{N}$ movimentos o que podemos determinar calculando: 


$$
C_{M+N}^{N}=\frac{(M+N) !}{N !(M+N-N) !}=\frac{(M+N) !}{N ! M !}
$$

\subsubsection{Circunferência}

Conceituamos a circunferência como sendo o lugar geométrico dos pontos do plano que estão a mesma distância de um ponto fixo chamado centro. Desse modo temos:

Dados os pontos $\mathrm{M}(\mathrm{x}, \mathrm{y})$ e $\mathrm{O}(\mathrm{a}, \mathrm{b})$, tal que $\mathrm{M}$ pertence a circunferência e $\mathrm{O}$ seu centro, e $\mathrm{D}(\mathrm{M}, \mathrm{O})=\mathrm{r}$, temos que:

$$
\begin{aligned}
& C_{E}=\left\{M(x, y) \in R^{2} / D_{E}(O, M)=r\right\} \\
& C_{T}=\left\{M(x, y) \in R^{2} / D_{T}(O, M)=r\right\}
\end{aligned}
$$

Desse modo:

$$
\begin{gathered}
C_{E} \equiv \sqrt{(x-a)^{2}+(y-b)^{2}}=r \\
C_{T} \equiv|x-a|+|y-b|=r
\end{gathered}
$$

Onde $C_{E}$ e $C_{T}$ representam de modo algébrico a circunferência no modelo euclidiano e no modelo do taxi, respectivamente. A equação $C_{E}$ representada em um sistema de eixos cartesianos nos fornece a seguinte visualização gráfica da circunferência:

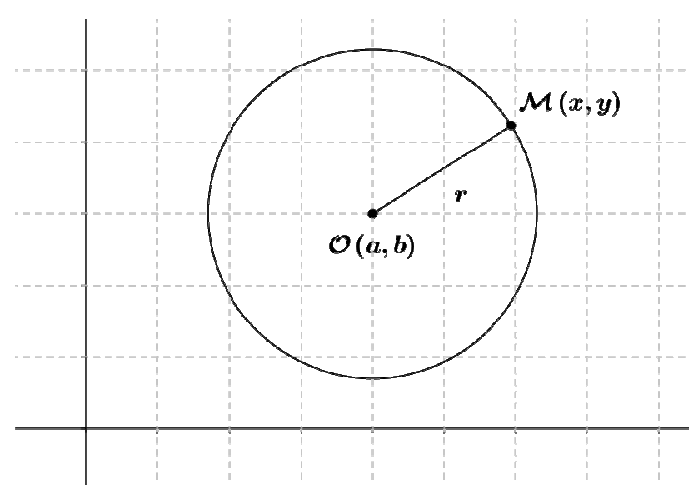

Figura 14 - Circunferência Euclidiana 
Analisemos agora a equação $C_{T} \equiv|x-a|+|y-b|=r$ :

Para $x<$ a e $y \geq b \rightarrow y=x+(r-a+b)(1)$

Para $x \geq$ a e $y<b \rightarrow y=-x+(r+a+b)(2)$

Para $x>$ a e $y \leq b \rightarrow y=x+(-r-a+b)(3)$

Para $x \leq$ a e $y<b \rightarrow y=-x+(-r+a+b)(4)$

Da Geometria Analítica sabemos que as equações (1), (2), (3), e (4) são equações de retas e que os pares de retas (1) e (2), (1) e (4), (3) e (4), (3) e (2) são retas perpendiculares concorrentes nos pontos $\mathrm{A}(\mathrm{a}, \mathrm{b}+\mathrm{r}), \mathrm{B}(\mathrm{a}-\mathrm{r}, \mathrm{b}), \mathrm{C}(\mathrm{a}, \mathrm{b}-\mathrm{r})$, $\mathrm{D}(\mathrm{a}+\mathrm{r}, \mathrm{b})$, respectivamente. Uma vez que $\mathrm{D}_{\mathrm{T}}(\mathrm{A}, \mathrm{B})=\mathrm{D}_{\mathrm{T}}(\mathrm{B}, \mathrm{C})=\mathrm{D}_{\mathrm{T}}(\mathrm{C}, \mathrm{D})=$ $\mathrm{D}_{\mathrm{T}}(\mathrm{D}, \mathrm{A})=2 \mathrm{r}$, o quadrilátero $\mathrm{ABCD}$ é um quadrado. Dessa forma a circunferência na Geometria do Taxi tem como representação gráfica um quadrado, conforme Figura - 15 .

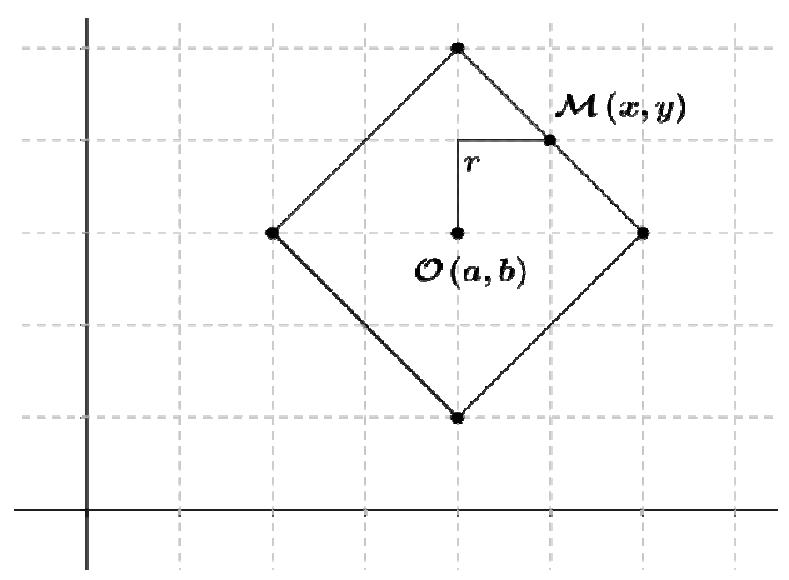

Figura 15 - Circunferência do Taxi

É fácil de ver que o comprimento da circunferência na Geometria do Taxi é dado por $c_{t}=8 r$ e uma vez que o valor de $\pi$ é a razão entre o comprimento da circunferência e o diâmetro, temos que:

$$
\pi_{t}=8 r / 2 r=4
$$


Com as observações acima podemos afirmar que o comprimento da circunferência na Geometria do Taxi pode ser calculado pela fórmula $c_{t}=2 \pi_{t} r$ que é virtualmente semelhante a que utilizamos na Geometria Euclidiana.

Sendo na Geometria do Taxi a circunferência representada graficamente por um quadrado, cujas diagonais são paralelas aos eixos coordenados, ela pode ser dividida em quatro triângulos retângulos isósceles cujos lados iguais medem r, conforme a Figura - 16. É importante observar que para calcularmos a área de um triângulo na Geometria do Taxi usamos a mesma fórmula da Geometria Euclidiana, no caso em que tanto a base quanto a altura são medidas horizontais ou verticais, de modo que esses segmentos são os mesmos tanto para a Métrica do Taxi quanto para a Métrica Euclidiana.

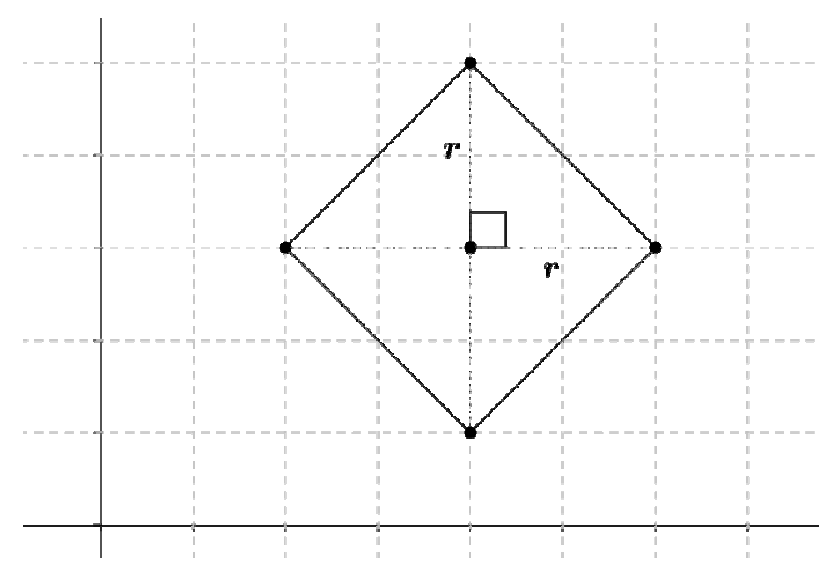

Figura 16 - Cálculo da área do Círculo do Taxi

Desse modo podemos calcular a área da circunferência do taxi do seguinte modo:

$$
A_{c_{t}}=\frac{r \cdot r}{2} \cdot 4=\frac{\pi_{t}}{2} \cdot r^{2}
$$

\subsubsection{Elipse}

Definimos elipse como sendo o lugar geométrico dos pontos do plano cuja soma das distâncias a dois pontos fixos, chamados focos, é igual a uma constante, maior do que a distância entre os focos.

Desse modo, dados os pontos $F_{1}(a, b), F_{2}(c, d)$ e $M(x, y)$ e a constante $a \in R$, temos: 


$$
\begin{aligned}
& E_{E}=\left\{M(x, y), \in R^{2} / D_{E}\left(M, F_{1}\right)+D_{E}\left(M, F_{2}\right)=2 a\right\} \\
& E_{T}=\left\{M(x, y) \in R^{2} / D_{T}\left(M, F_{1}\right)+D_{T}\left(M, F_{2}\right)=2 a\right\}
\end{aligned}
$$

Desse modo:

$$
\begin{gathered}
E_{E} \equiv \sqrt{(x-a)^{2}+(y-b)^{2}}+\sqrt{(x-c)^{2}+(y-d)^{2}}=2 a \\
E_{T} \equiv|x-a|+|y-b|+|x-c|+|y-d|=2 a
\end{gathered}
$$

Onde $E_{E}$ e $E_{T}$ representam de modo algébrico a elipse no modelo euclidiano e no modelo do taxi, respectivamente. A equação $E_{E}$ representada em um sistema de eixos cartesianos nos fornece a seguinte visualização gráfica da elipse:

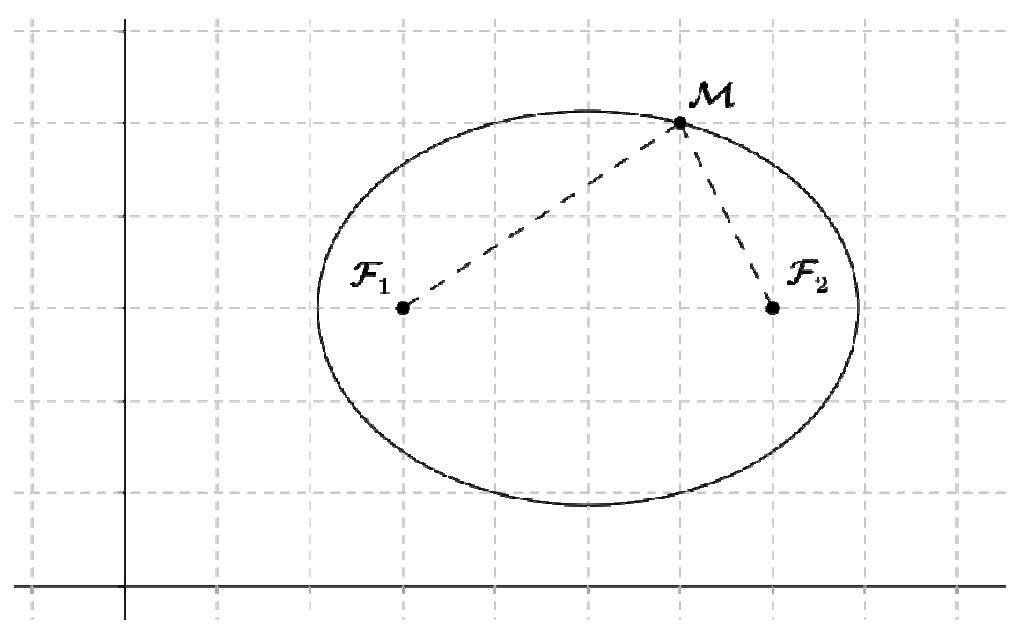

Figura 17 - Elipse Euclidiana

No caso da elipse apresentaremos um exemplo de como obter a sua representação gráfica.

Exemplo:

Dados os pontos $F_{1}(2,4)$ e $F_{2}(3,6)$, encontre os pontos $M(x, y)$ do plano que atende a equação:

$$
D_{T}\left(M, F_{1}\right)+D_{T}\left(M, F_{2}\right)=5
$$

Solução: 
Sendo:

$$
D_{T}\left(M, F_{1}\right)+D_{T}\left(M, F_{2}\right)=5
$$

Temos que:

$$
|x-2|+|y-4|+|x-3|+|y-6|=5
$$

Analisando essa equação, teremos:

Para $x \leq 2$ e $y<4 \rightarrow x+y=5$ (a)

Para $x<2$ e $4 \leq y<6 \rightarrow x=1$ (b)

Para $x<2$ e $y \geq 6 \rightarrow-x+y=5$ (c)

Para $2<x \leq 3$ e $y<4 \rightarrow y=3$ (d)

Para $2<x<3$ e $4<y<6 \rightarrow 3=5$ não tem solução

Para $2<x \leq 3$ e $y>6 \rightarrow y=7$ (e)

Para $x>3$ e $y \leq 4 \rightarrow x-y=0$ (f)

Para $x>3$ e $4<y \leq 6 \rightarrow x=4(\mathrm{~g})$

Para $x>3$ e $y>6 \rightarrow x+y=10(h)$

Tomando agora as soluções das equações acima com suas respectivas condições e traçando em um sistema de eixos cartesianos teremos a representação gráfica dessa elipse no modelo do taxi.

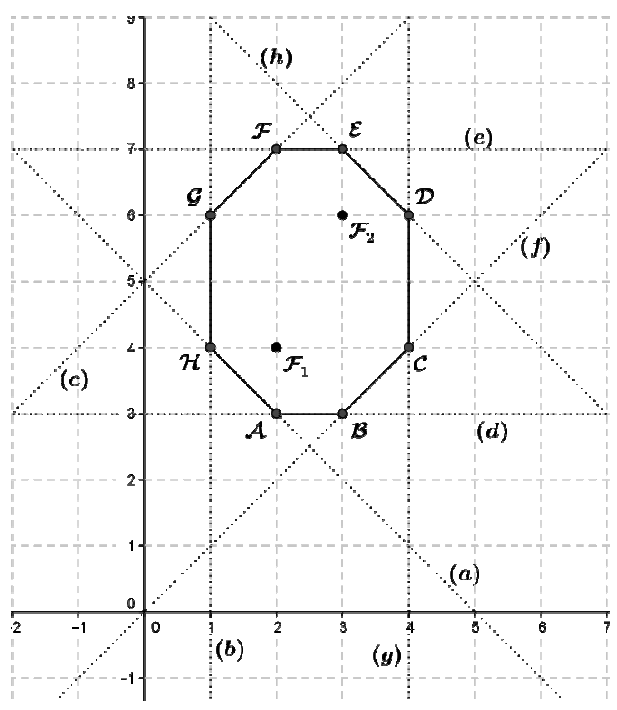

Figura 18 - Elipse do Taxi 


\subsubsection{Parábola}

Dados uma reta $\mathrm{L}$ e um ponto $\mathrm{F} \notin \mathrm{L}$, que chamamos de diretriz e foco, respectivamente, definimos uma parábola como sendo o lugar geométrico dos pontos do plano cuja distância à $\mathrm{F}$ e a L são iguais.

Desse modo dado $\mathrm{L} \equiv m x+n y+c=0$ e $\mathrm{F}(\mathrm{a}, \mathrm{b}) \notin \mathrm{L}$, temos que:

$$
\begin{aligned}
& P_{E}=\left\{M(x, y) \in R^{2} / D_{E}(M, F)=D_{E}(M, L)\right\} \\
& P_{T}=\left\{M(x, y) \in R^{2} / D_{T}(M, F)=D_{T}(M, L)\right\}
\end{aligned}
$$

Uma vez que dado um ponto $A\left(x_{a}, y_{a}\right)$ e uma reta $\mathrm{L} \equiv m x+n y+c=0$ podemos escrever:

$$
\begin{aligned}
D_{E}(P, L) & =\frac{\left|m x_{a}+n y_{a}+c\right|}{\sqrt{m^{2}+n^{2}}} \\
D_{T}(P, L)^{32} & =\frac{\left|m x_{a}+n y_{a}+c\right|}{\operatorname{Max}\{|m|,|n|\}}
\end{aligned}
$$

Assim, teremos que:

$$
\begin{gathered}
P_{E} \equiv \sqrt{(x-a)^{2}+(y-b)^{2}}=\frac{\left|m x_{a}+n y_{a}+c\right|}{\sqrt{m^{2}+n^{2}}} \\
P_{T} \equiv|x-a|+|y-b|=\frac{\left|m x_{a}+n y_{a}+c\right|}{\operatorname{Max}\{|m|,|n|\}}
\end{gathered}
$$

Onde $P_{E}$ e $P_{T}$ representam de modo algébrico a parábola no modelo euclidiano e no modelo do taxi, respectivamente. A equação $P_{E}$ representada em um sistema de eixos cartesianos nos fornece a seguinte visualização gráfica da parábola:

\footnotetext{
${ }^{32}$ A demonstração encontra-se no anexo 9.2
} 


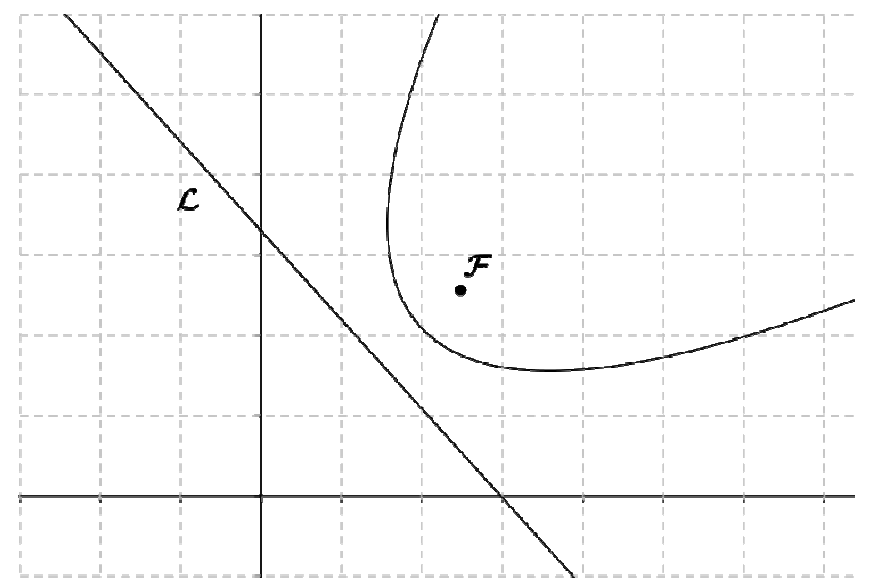

Figura 19 - Parábola Euclidiana

Apresentamos agora um exemplo como obter a representação gráfica de uma parábola no modelo do taxi.

Exemplo:

Dados o ponto $F(0,2)$ e a reta $L \equiv y=-3$, determine os pontos $M(x, y)$ do plano que atendem a equação:

$$
D_{T}(M, F)=D_{T}(M, L)
$$

Solução:

Uma vez que:

$$
D_{T}(M, F)=D_{T}(M, L)
$$

Temos então:

$$
|x-0|+|y-2|=|y+3|
$$

Analisando essa equação, temos:

Para $x<0$ e $y<-3 \rightarrow x=5$ não é uma solução.

Para $x<0 e-3 \leq y<2 \rightarrow x+2 y=-1$ (a)

Para $x<0$ e $y \geq 2 \rightarrow x=-5$ (b)

Para $x \geq 0$ e $y \leq-3 \rightarrow x=-5$ não é uma solução

Para $x \geq 0 e-3 \leq y<2 \rightarrow x-2 y=1$ (c)

Para $x \geq 0$ e $y \geq 2 \rightarrow x=5$ (d) 
Desse modo podemos traçar a parábola no modelo do taxi:

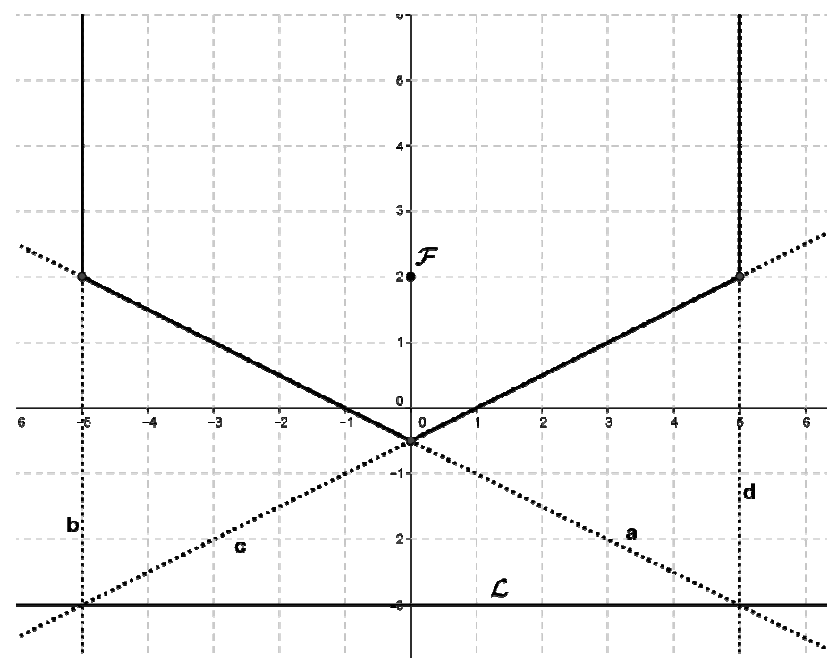

Figura 20 - Parábola do Taxi

\subsubsection{Hipérbole}

Dados dois pontos do plano $F_{1} e F_{2}$, que chamamos de focos, definimos hipérbole como sendo o lugar geométrico dos pontos $M(x, y)$ para os quais o módulo da diferença de suas distâncias a $F_{1} e F_{2}$ é igual a um valor constante.

Desse modo, dados os pontos $F_{1}(a, b)$ e $F_{2}(c, d)$ e $k \in R$, temos que:

$$
\begin{aligned}
& H_{E}=\left\{M(x, y) \in R^{2} /\left|D_{E}\left(M, F_{1}\right)-D_{E}\left(M, F_{2}\right)\right|=2 k\right\} \\
& H_{T}=\left\{M(x, y) \in R^{2} /\left|D_{T}\left(M, F_{1}\right)-D_{T}\left(M, F_{2}\right)\right|=2 k\right\}
\end{aligned}
$$

Assim, teremos:

$$
\begin{gathered}
H_{E} \equiv\left|\sqrt{(x-a)^{2}+(y-b)^{2}}-\sqrt{(x-c)^{2}+(y-d)^{2}}\right|=2 k \\
H_{T} \equiv|| x-a|+| y-b|-(|x-c|+|y-d|)|=2 k
\end{gathered}
$$

Onde $H_{E}$ e $H_{T}$ representam de modo algébrico a hipérbole no modelo euclidiano e no modelo do taxi, respectivamente. A equação $H_{E}$ representada em 
um sistema de eixos cartesianos nos fornece a seguinte visualização gráfica da hipérbole:

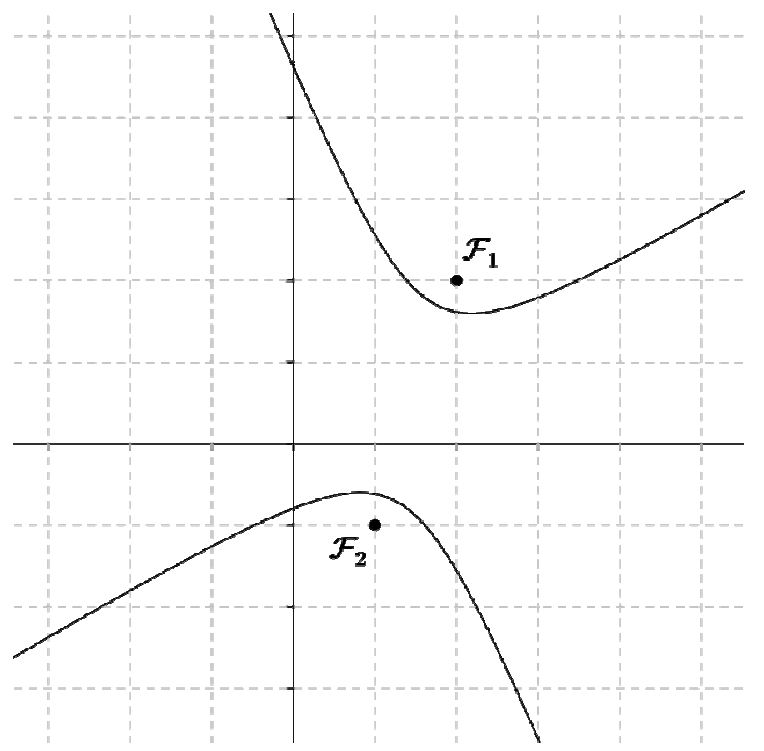

Figura 21 - Hipérbole Euclidiana

Apresentaremos um exemplo de como obter a sua representação gráfica no modelo do taxi.

Exemplo:

Dados os pontos $F_{1}(0,0)$ e $F_{2}(2,-3)$ determine os pontos $M(x, y)$ do plano que atendem a equação:

$$
\left|D_{T}\left(M, F_{1}\right)-D_{T}\left(M, F_{2}\right)\right|=2
$$

Solução:

Uma vez que:

$$
\left|D_{T}\left(M, F_{1}\right)-D_{T}\left(M, F_{2}\right)\right|=2
$$

Temos então:

$$
|| x|+| y|-| x-2|-| y+3||=2
$$

Analisando essa equação temos: 
Para $x<0$ e $y<-3 \rightarrow$ não existe solução

Para $x<0 e-3 \leq y<0 \rightarrow y=-7 / 2$ ou $y=-3 / 2 \rightarrow y=-3 / 2$ (a)

Para $x<0$ e $y \geq 0 \rightarrow$ não existe solução

Para $0 \leq x<2$ e $y \leq-3 \rightarrow x=1 / 2$ ou $x=-3 / 2 \rightarrow x=1 / 2$ (b)

Para $0 \leq x<2 e-3 \leq y<0 \rightarrow x-y=7 / 2(c)$ ou $x-y=3 / 2(d)$

Para $0 \leq x<2$ e $y \geq 0 \rightarrow x=7 / 2$ ou $x=3 / 2 \rightarrow x=3 / 2(\mathrm{e})$

Para $x \geq 2$ e $y<-3 \rightarrow$ não existe solução

Para $x \geq 2 e-3 \leq y<0 \rightarrow y=-3 / 2$ ou $y=1 / 2 \rightarrow y=-3 / 2$ (a)

Para $x \geq 2$ e $y \geq 0 \rightarrow$ não existe solução

Tomando agora as soluções das equações acima com suas respectivas condições e traçando em um sistema de eixos cartesianos teremos a representação gráfica dessa hipérbole no modelo do taxi.

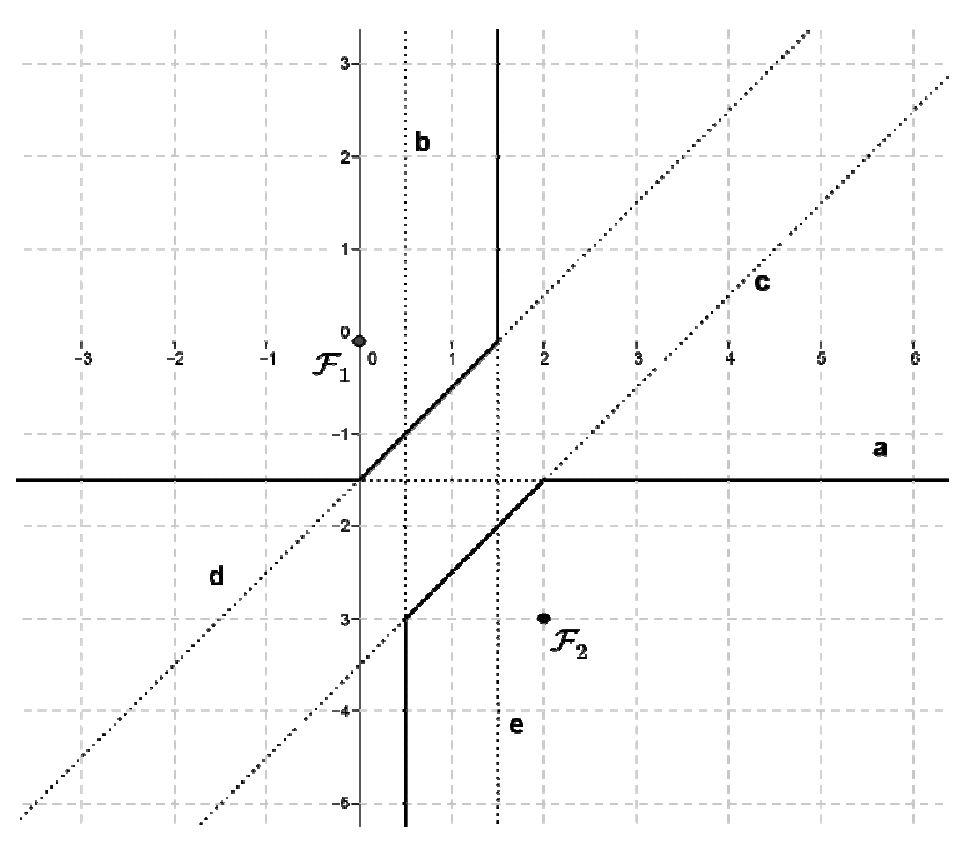

Figura 22 - Hipérbole do Taxi 


\section{Dinâmica: Caminhando Pelas Ruas da Minha Cidade}

A atividade apresentada no Anexo - 9.3 e que vamos detalhar nesse capítulo, foi trabalhada com uma turma do $3^{\circ}$ ano do ensino médio do C.E. Professor Ney Cidade Palmeiro localizado na cidade de Itaguaí, estado do Rio de Janeiro. A turma em questão era composta por 31 alunos e as atividades foram realizadas nos meses de outubro e novembro de 2013 em cinco etapas, em dias não consecutivos, do seguinte modo:

Primeira Etapa: realizamos uma pequena palestra com os alunos sobre a importância do estudo e conhecimento dos diferentes modelos geométricos como representação do espaço em que vivemos, com apresentação dos vídeos História da Geometria ${ }^{33}$ e A Geometria Não Euclidiana ${ }^{34}$.

Segunda Etapa: realizamos as atividades Caminhando e Navegando.

Terceira Etapa: realizamos a atividade Distância.

Quarta Etapa: realizamos as atividades Cálculo da Distância Euclidiana e Cálculo da Distância do Taxi.

Quinta Etapa: realizamos a atividade Círculo e Circunferência.

$\mathrm{Na}$ primeira etapa durante a palestra fornecemos aos alunos uma folha de papel e perguntamos o que eles entendiam por circunferência, solicitando inicialmente que escrevessem esse entendimento e a seguir nos dessem uma representação gráfica da circunferência. As respostas dadas por essa pequena amostra de alunos podem evidenciar, mesmo após passarem pelo ensino fundamental e estarem no final do ensino médio, que esses alunos não distinguem o conceito de um objeto matemático de sua representação ou do seu modelo gráfico. O que dizer então a respeito do conhecimento ou entendimento da existência de diferentes modelos geométricos que podem em determinadas situações representar um conceito ou definição matemática, na realidade para esses alunos só existe um tipo de geometria a Geometria Euclidiana. Na Figura -

\footnotetext{
${ }^{33}$ Disponível em <http://www.youtube.com/watch?v=6ebMePGYIf8>

${ }^{34}$ Disponível em <http://www.youtube.com/watch?v=gqyY_vSQWEw>
} 
23 e na Figura - 24 podemos ver um tipo de resposta que é comumente dada por esses alunos.

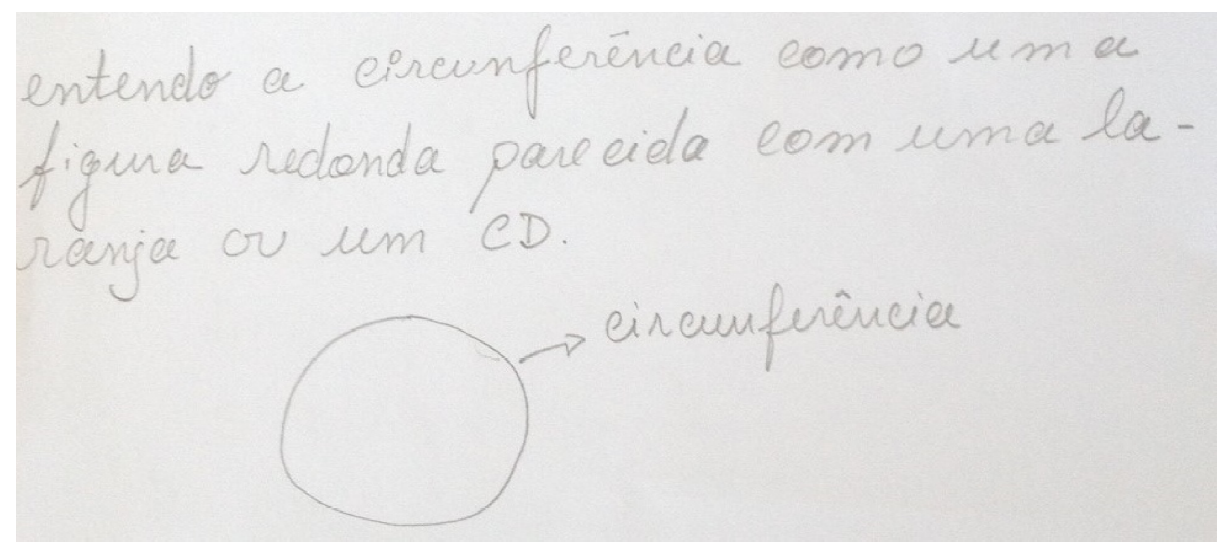

Figura 23 - Resposta dos alunos a atividade proposta

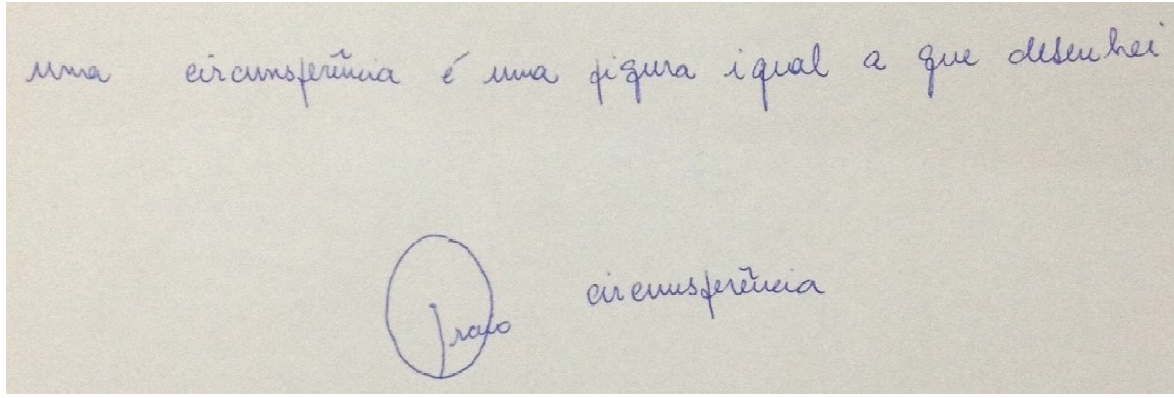

Figura 24 - Resposta dos alunos a atividade proposta

Fornecemos também aos alunos durante a palestra uma folha conforme a Figura - 25 e solicitamos que eles determinassem a distância entre os dois pontos marcados. Em todas as respostas os alunos usaram uma régua para determinar a distância, não usando em nenhum momento nem a Métrica Euclidiana para o cálculo da distância e nem mesmo cogitando se haveria algum impedimento para se medir a distância com um segmento de reta que unisse os dois pontos. 


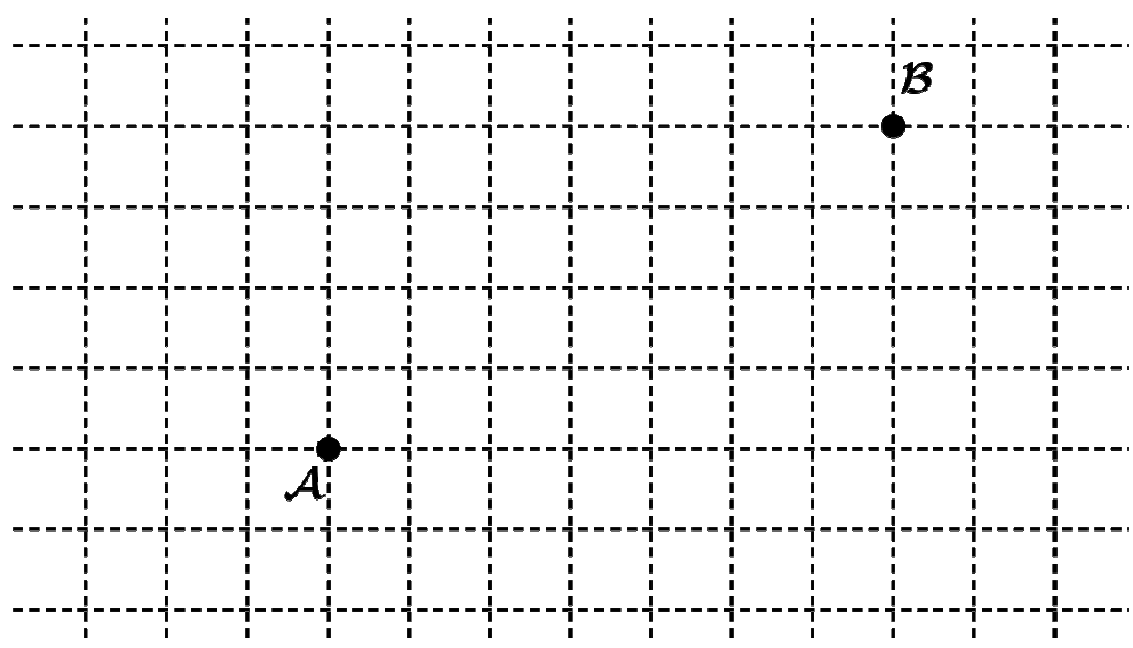

Figura 25 - Folha distribuída aos alunos

Desse modo a aplicação da dinâmica Caminhando pelas Ruas da Minha Cidade tem como objetivos básicos a apresentação de um novo modelo geométrico distinto da geometria euclidiana, a Geometria do Taxi, e ao mesmo tempo procura consolidar a definição de circunferência e círculo, independente do modelo (Euclidiano ou do Taxi) que se adote e do modo pelo qual se representa graficamente tal conceito. A escolha da Geometria do Taxi se dá pelo fato que esse tipo de Geometria Não Euclidiana não é de difícil compreensão para um aluno do Ensino Médio e sua representação gráfica pode ser feita utilizando o sistema de eixos cartesianos que é do conhecimento dos alunos desde o ensino fundamental. Entretanto o fato que mais contribui com a escolha da Geometria do Taxi é que com ela podemos modelar o espaço urbano, o que nos permite de modo bem natural integrar ao dia a dia do aluno esse modelo geométrico, confrontando-o com uma nova geometria que não a euclidiana. Tal fato possibilita ao professor utilizar um modelo geométrico não euclidiano a fim de contextualizar situações de aprendizagens que permitem ao aluno ampliar sua visão crítica aplicando e exercitando seus conhecimentos na solução de problemas integrados ao seu cotidiano.

$\mathrm{Na}$ segunda etapa aplicamos as atividades Caminhando e Navegando que procuram evidenciar o conceito de distância como sendo a menor trajetória que une dois pontos entre as várias possíveis. Além disso, o aluno tem a oportunidade de observar que dependendo das condições impostas pelo ambiente o modo como 
se determina essa menor trajetória é distinto. Na atividade Caminhando usamos a Métrica do Táxi e na atividade Navegando é usado a Métrica Euclidiana.

$\mathrm{Na}$ atividade Caminhando podemos observar que as três trajetórias escolhidas são sempre buscando o menor caminho entre A e B, como mostra a figura - 26, e na atividade Navegando a trajetória reta entre A e B está presente em praticamente todas as respostas, como podemos ver na figura -27 . Podemos assim observar que de modo intuitivo o conceito de distância está presente nas respostas desses alunos.

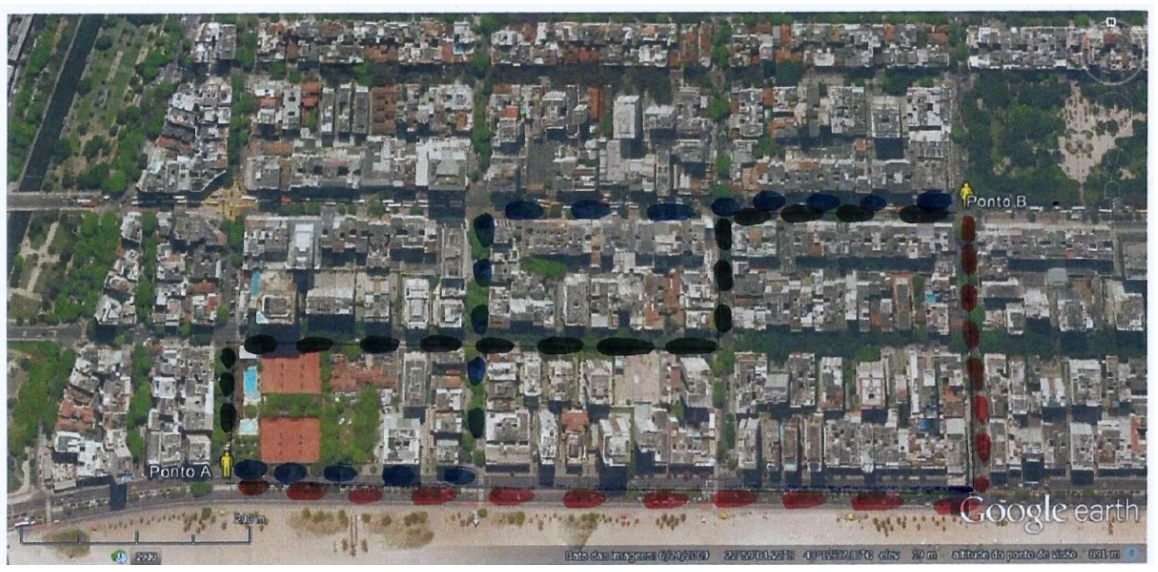

Figura 26 - Resposta dos alunos a atividade proposta

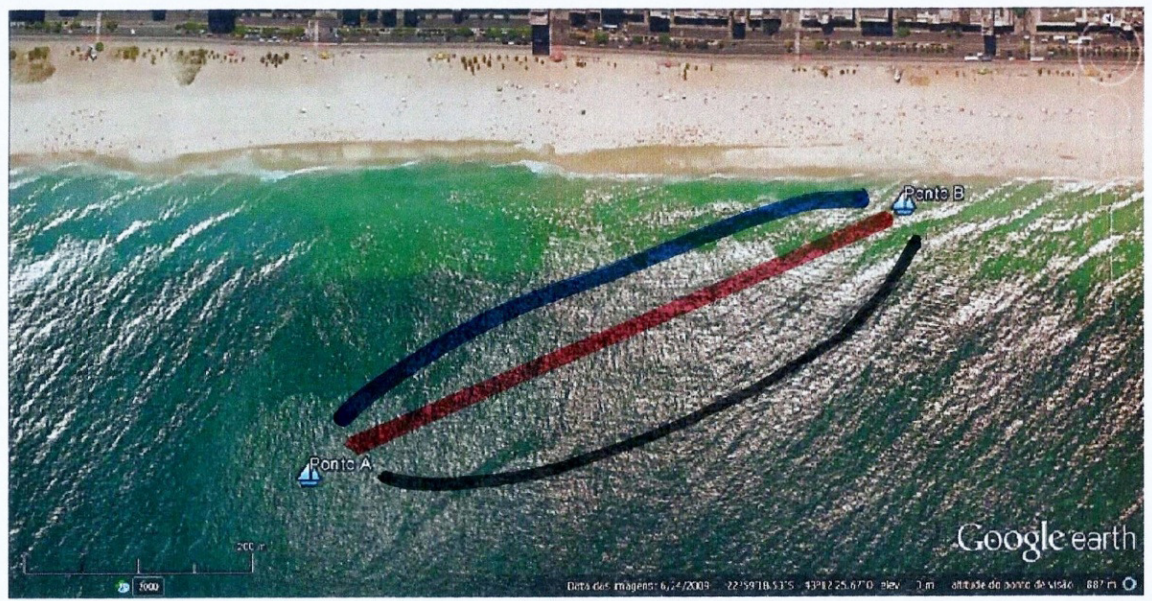

Figura 27 - Resposta dos alunos a atividade proposta

Com as respostas dadas ao questionamento (b) das atividades Navegando e Caminhando podemos consolidar a afirmação que o conceito de distância entre 
dois pontos está bem definido entre os alunos como sendo a menor trajetória entre esses pontos, conforme Figura - 28(Navegando) e Figura - 29(Caminhando).

b) Se você fosse medir a distância entre a localidade $A$ e a localidade $B$ que trajeto escolheria para fazê-lo? Explique porque escolheu tal trajeto para fazer a medição da distância entre a localidade $A$ e a localidade B.

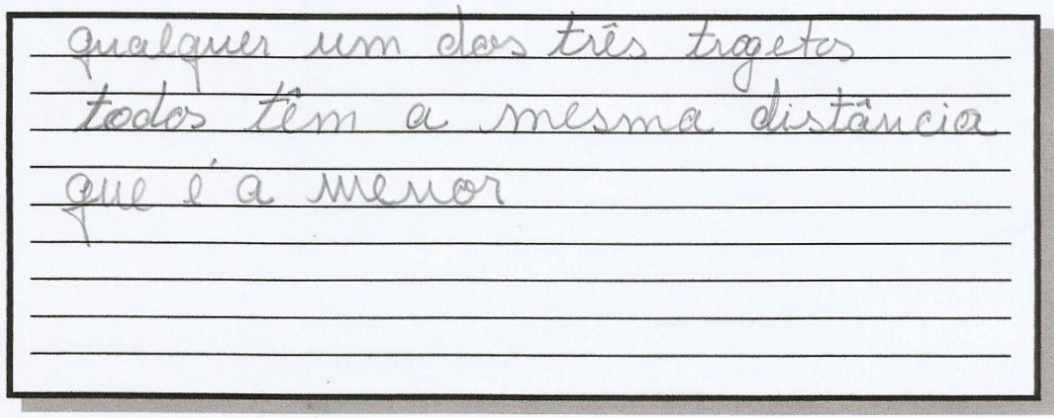

Figura 28 - Resposta dos alunos a atividade proposta

b) Se você fosse medir a distância entre a localidade $A$ e a localidade B que trajeto escolheria para fazê-lo? Explique porque escolheu tal trajeto para fazer a medição da distância entre a localidade $A$ e a localidade B.

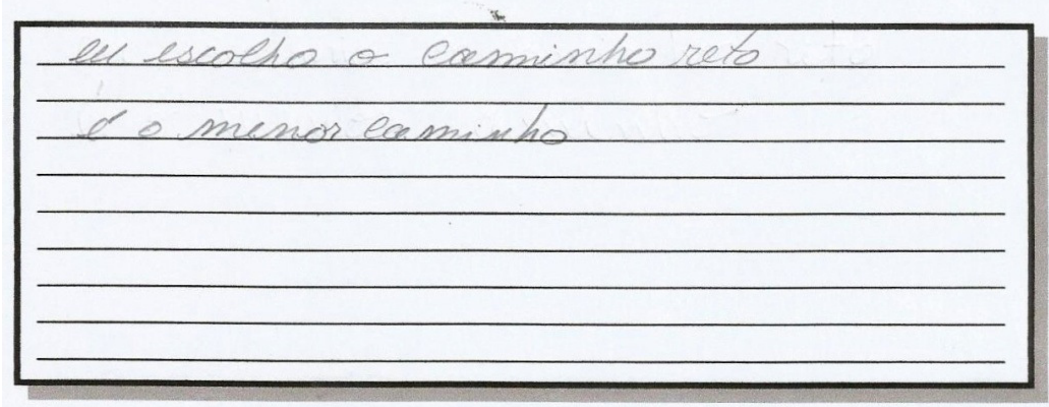

Figura 29 - Resposta dos alunos a atividade proposta

Nos questionamentos (c) e (d) das atividades Navegando e Caminhando o aluno tem a oportunidade de se confrontar com duas formas distintas de medir a 
distância entre dois pontos e uma consequência interessante que dependendo da forma como é feita sua determinação podemos ter apenas uma trajetória ou várias trajetórias que podem ser utilizadas para a medição da distância.

Ao final dessa etapa o aluno já passa ter uma quebra de paradigma, naturalmente ele se apropria da noção que a distância entre dois pontos nem sempre é um segmento de reta e que existe outras formas de medir uma distância. O modelo a ser utilizado vai depender das condições impostas pelo problema a ser solucionado, no nosso caso um impedimento físico, ou seja, a obrigatoriedade de se trafegar por ruas.

$\mathrm{Na}$ terceira etapa os alunos foram levados ao Laboratório de Informática da escola onde realizamos a atividade Distância ${ }^{35}$. Os alunos foram distribuídos em duplas para a realização da tarefa. Essa atividade tem como objetivos principais:

(a) - consolidar o uso das coordenadas cartesianas no plano e introduzir uma nova noção de distância onde a função módulo aparece de forma natural;

(b) - explorar a comparação entre a distância euclidiana e a distância do taxi.

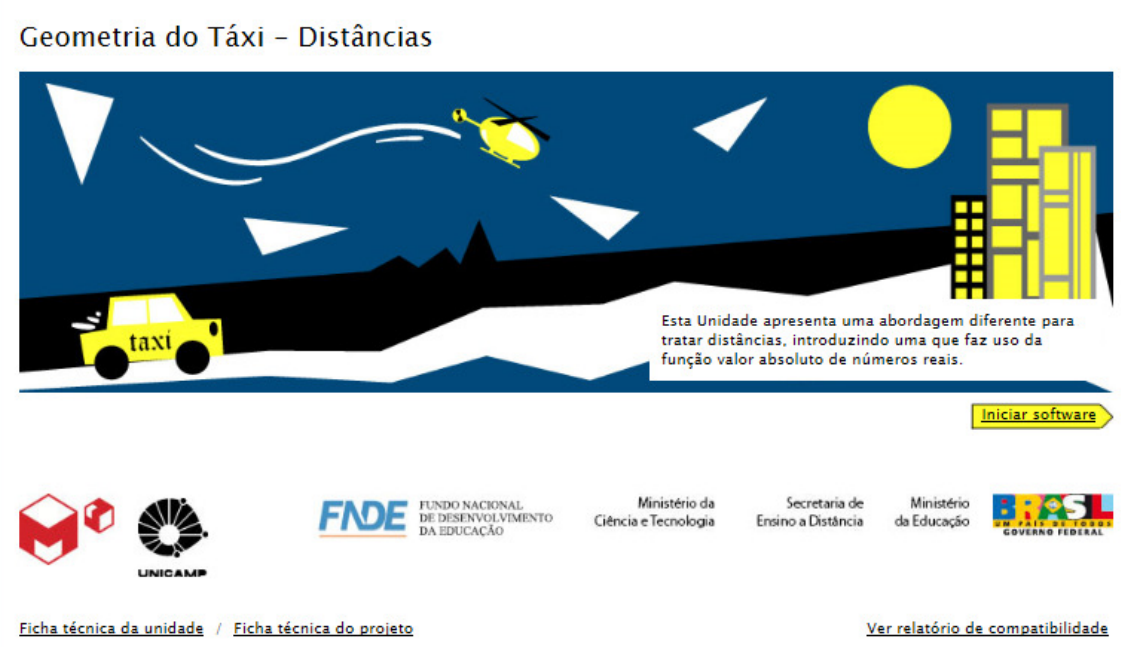

Figura 30 - Sofware Geometria do Taxi - Distância

Na Figura - 30, vemos a tela inicial do software utilizado nessa atividade.

${ }^{35}$ Disponível em <http://m3.ime.unicamp.br/recursos/1231> 
$\mathrm{Na}$ quarta etapa realizamos as atividades Cálculo da Distância Euclidiana e Cálculo da Distância do Taxi que fornece ao aluno a oportunidade de aprofundar seus conhecimentos nessas duas métricas exercitando o cálculo propriamente dito das distâncias em questão. Essas atividades deixam bem claro para o aluno que a forma como medimos distância pode ser distinta dependendo das condições impostas pelo modelo geométrico adotado para modelar certa situação real, como fizemos nas atividades Caminhando e Navegando onde usamos dois modelos geométricos, a Geometria do Taxi e a Geometria Euclidiana, respectivamente, para modelar as duas situações apresentadas.

$\mathrm{Na}$ quinta e última etapa realizamos a atividade Círculo e Circunferência ${ }^{36}$ levamos os alunos novamente para o Laboratório de Informática da escola. Os alunos foram distribuídos em dupla para a realização dessa tarefa. O objetivo principal dessa atividade é, utilizando a Geometria do Taxi, explorar o conceito de círculo e circunferência e a forma desses objetos.

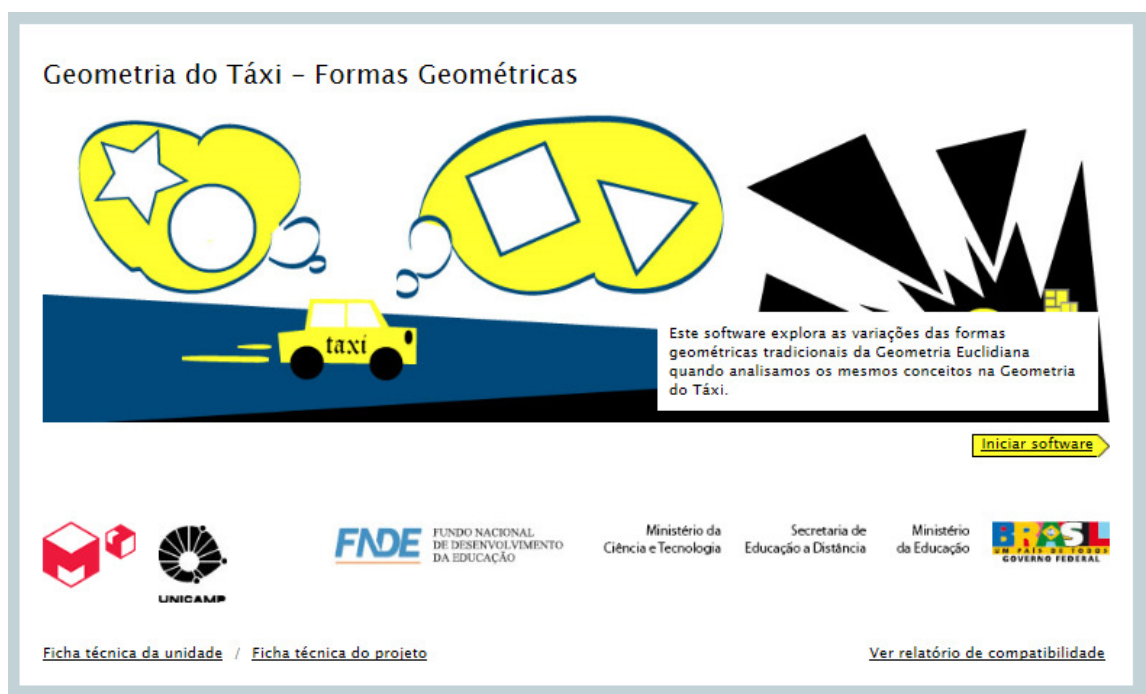

Figura 31 - Sofware Geometria do Taxi - Formas Geométricas

${ }^{36}$ Disponível em <http://m3.ime.unicamp.br/recursos/1248> 


\section{Conclusão}

Mesmo não sendo exaustivo, na apresentação, tanto da Geometria do Taxi quanto no desenvolvimento histórico que possibilitou o aparecimento das Geometrias Não Euclidianas, este trabalho fornece ao professor do Ensino Básico uma forma de observar a matemática sob um aspecto integrador e crítico, possibilitando que o mesmo possa refletir sobre os processos de ensino e as possibilidades que a Geometria fornece como objeto de aprendizagem.

A inegável característica da Geometria em modelar o ambiente cotidiano do aluno, permite o seu uso como objeto de aprendizagem de compreensão natural e lúdica, por outro lado a Geometria do Taxi leva o alunado a uma quebra de paradigma, possibilitando uma abordagem mais crítica e um desenvolvimento mais consistente da aprendizagem.

A Dinâmica que sugerimos é um exemplo de como o professor de matemática pode usar a Geometria, mais especificamente a Geometria do Taxi, no desenvolvimento de conceitos matemáticos, quebrando a monotonia e tornando mais interessante a sua aprendizagem.

Esperamos com esse trabalho, que o professor de matemática do Ensino Básico, abra novos caminhos em sua prática docente e se sinta motivado em criar suas próprias estratégias, pesquisando novos conceitos de aprendizagem. 


\section{Referências Bibliográficas}

AABOE, ASGER. Episódios da História da Matemática; tradução: João Bosco Pitombeira. 3 $3^{\text {a }}$ ed. Rio de Janeiro: SBM, 2013. 191 p. (Coleção Professor de Matemática; 18).

ANCIENT VINE, Journey Back in Time. Disponível em $<$ http://www.ancientvine.com/alexandria_map.html $>$. Acesso em: 22 de novembro de 2013

ARTMANN, BENNO. Euclid: The Creation of Mathematics. Springer, 1999.

BICUDO, IRINEU. Os Elementos/Euclides; tradução e introdução. São Paulo: Editora UNESP, 2009.

BONGIOVANNI, V.; JAHN, A.P. De Euclides às Geometrias Não Euclidianas. Unión: Revista Iberoamericana de Educación Matemática, №22, p.37-51, 2010.

BRASIL, MINISTÉRIO DA EDUCAÇÃO, Parâmetros Curriculares Nacionais para O Ensino Da Matemática, Brasília, 1998.

EVES, HOWARD. Introdução a História da Matemática/Tradução: Hygino H. Domingues. Campinas, SP: Editora Unicamp, 2004.

HEAT, THOMAS L., The thirteen books of Euclid's Elements translated with introduction and commentary (volume 1), New York: Dover Publications Inc, 1956 (edição original 1925).

KALEFF, A.M.; NASCIMENTO, R.S. Atividades Introdutórias às Geometrias Não Euclidianas: o exemplo da Geometria do Taxi, Boletim Gepem, Rio de Janeiro, n44, dezembro 2002, pg.s 11 a 42.

MLODINOW, LEONARD. A Janela de Euclides: a história da geometria das linhas paralelas ao hiperespaço. Tradução de Enézio E. de Almeida Filho. São Paulo: Geração Editorial, 2008.

ROQUE, TATIANA. História da Matemática: uma visão critica, desfazendo mitos e lendas. - Rio de Janeiro: Zahar, 2012.

ROQUE, TATIANA; CARVALHO, J.B.P. Tópicos de História da Matemática. Rio de Janeiro: SBM, 2012. 
SACCHERI, GEROLAMO. Euclides Vindicatus. Tradução de George Halsted.

New York: Dover Publications, 1986

SAMUCO, JOSÉ MARIA E. A Gênese da Geometria Hiperbólica. 2005. 51 f.

Tese (mestrado em Ensino de Matemática)- Departamento de Matemática Pura, Faculdade de Ciências da Universidade do Porto. Porto, 2005.

STANFORD ENCYCLOPEDIA OF PHILOSOPHY. Disponível em <http: //plato.stanford. Edu/entries/proclus>. Acesso em 29 de novembro 2013.

TOMEI, CARLOS. Euclides - A Conquista do Espaço; $2^{a}$ Edição - São Paulo: Odysseus Editora, 2006. (Imortais da Ciência/ Coordenação Marcelo Gleiser).

THE NLAB. Disponível em <http://ncatlab.org/nlab/show/Peter+Hilton>. Acesso em: 25 de novembro de 2013.

UNIVERSITY OF ST ANDREWS. The MacTutor History of Mathematics. Disponível em <http://www-groups.dcs.st-and.ac.uk/ history/Mathematicians/ Proclus.html>. Acesso em: 29 de novembro de 2013.

UNIVERSIDADE DE LISBOA. Docente Olga Maria Pombo Martins. Departamento de Educação da Faculdade de Ciências. Disponível em http://www.educ.fc.ul.pt/docentes/opombo/seminario/quintoposteucl/proclus.htm. Acesso em:12 de dezembro de 2013.

UNIVERSIDADE DE LISBOA. Docente Olga Maria Pombo Martins. Departamento de Educação da Faculdade de Ciências. Disponível em $<$ http://www.educ.fc.ul.pt/docentes/opombo/seminario/quintoposteucl/postulapo1. htm>. Acesso em: 12 de dezembro de 2013.

UNIVERSIDADE DE LISBOA. Docente Olga Maria Pombo Martins. Departamento de Educação da Faculdade de Ciências. Disponível em $<$ http://www.educ.fc.ul.pt/docentes/opombo/hfe/momentos/museu/fundacao.htm> Acesso em: 25 de novembro de 2013. 


\section{Anexo}

\subsection{Espaço Euclidiano $\mathbf{R}^{\mathbf{n}}$}

\subsection{1. $\left(R^{n}, D_{E}\right)$}

O espaço euclidiano $\mathrm{R}^{\mathrm{n}}$ é um espaço métrico com a distância assim definida:

$$
D_{E}(x, y)=\left[\sum_{i}^{n}\left(x_{i}-y_{i}\right)^{2}\right]^{1 / 2}
$$

Demonstração:

Para mostrarmos tal afirmação devemos verificar que a métrica definida atende as seguintes condições:

$$
\begin{aligned}
& \text { 1. } D(x, x)=0 \\
& \text { 2. se } x \neq y, \text { então } D(x, y)>0 \\
& \text { 3. } D(x, y)=D(y, x) \\
& \text { 4. } D(x, z) \leq D(x, y)+D(y, z)
\end{aligned}
$$

1. $\mathrm{D}(\mathrm{x}, \mathrm{x})=0$

Seja $\mathrm{x} \in \mathrm{R}^{\mathrm{n}}$, desse modo:

$$
D_{E}(x, y)=\left[\sum_{i}^{n}\left(x_{i}-y_{i}\right)^{2}\right]^{1 / 2}=\left[\sum_{i}^{n}\left(x_{i}-x_{i}\right)^{2}\right]^{1 / 2}=0
$$

2. Se $x \neq y$, então $D(x, y)>0$

Sejam $x \in R^{n}$ e $y \in R^{n}$, desse modo: 


$$
D_{E}(x, y)=\left[\sum_{i}^{n}\left(x_{i}-y_{i}\right)^{2}\right]^{1 / 2}
$$

Uma vez que para $\mathrm{x} \neq \mathrm{y}$ existe pelo menos $u \mathrm{x}_{\mathrm{i}} \neq \mathrm{y}_{\mathrm{i}}$ e para todo $\mathrm{x}_{\mathrm{i}} \neq \mathrm{y}_{\mathrm{i}}$ temos que $\left(x_{i}-y_{i}\right)^{2}>0$ logo:

$$
D_{E}(x, y)=\left[\sum_{i}^{n}\left(x_{i}-y_{i}\right)^{2}\right]^{1 / 2}>0
$$

3. $\mathrm{D}(\mathrm{x}, \mathrm{y})=\mathrm{D}(\mathrm{y}, \mathrm{x})$

Uma vez que $\left(y_{i}-x_{i}\right)^{2}=\left[-\left(x_{i}-y_{i}\right)\right]^{2}=\left(x_{i}-y_{i}\right)^{2}$ temos:

$$
\begin{aligned}
& D_{E}(y, x)=\left[\sum_{i}^{n}\left(y_{i}-x_{i}\right)^{2}\right]^{\frac{1}{2}}=\left[\sum_{i}^{n}\left[-\left(x_{i}-y_{i}\right)\right]^{2}\right]^{\frac{1}{2}} \\
& D_{E}(y, x)=\left[\sum_{i}^{n}\left(x_{i}-y_{i}\right)^{2}\right]^{1 / 2}=D_{E}(x, y)
\end{aligned}
$$

4. $\mathrm{D}(\mathrm{x}, \mathrm{z}) \leq \mathrm{D}(\mathrm{x}, \mathrm{y})+\mathrm{D}(\mathrm{y}, \mathrm{z})$

Vamos demonstrar tal afirmação denominada de desigualdade triangular, utilizando-se de outra desigualdade chamada desigualdade de Cauchy-Schawarz que nos afirma que:

Dado dois vetores $\mathrm{x}, \mathrm{y}$ pertencentes ao espaço vetorial normado com produto interno $\mathrm{R}^{\mathrm{n}}$, temos que:

$$
|\langle x, y\rangle| \leq|x| \cdot|y|
$$

Desse modo temos que:

$$
\begin{aligned}
|x+y|^{2}= & |\langle x+y ; x+y\rangle|=|x|^{2}+|y|^{2}+2|\langle x+y\rangle| \leq \\
& \leq x^{2}+y^{2}+2|x||y|=(|x|+|y|)^{2}
\end{aligned}
$$

logo: 


$$
|x+y| \leq|x|+|y|
$$

Sendo suficiente para afirmarmos que $D_{E}(x, z) \leq D_{E}(x, y)+D_{E}(y, z)$

\subsection{2. $\left(R^{n}, D_{T}\right)$}

$\mathrm{O}$ espaço euclidiano $\mathrm{R}^{\mathrm{n}}$ é um espaço métrico com a distância assim definida:

$$
D_{T}(x, y)=\sum_{i=1}^{n}\left|x_{i}-y_{i}\right|
$$

Demonstração:

Para mostrarmos tal afirmação devemos verificar que a métrica definida atende as seguintes condições:

1. $\mathrm{D}(\mathrm{x}, \mathrm{x})=0$

2. Se $x \neq y$, então $D(x, y)>0$

3. $\mathrm{D}(\mathrm{x}, \mathrm{y})=\mathrm{D}(\mathrm{y}, \mathrm{x})$

4. $\mathrm{D}(\mathrm{x}, \mathrm{z}) \leq \mathrm{D}(\mathrm{x}, \mathrm{y})+\mathrm{D}(\mathrm{y}, \mathrm{z})$

1. $\mathrm{D}(\mathrm{x}, \mathrm{x})=0$

Seja $\mathrm{x} \in \mathrm{R}^{\mathrm{n}}$, desse modo:

$$
D_{T}(x, x)=\sum_{i=1}^{n}\left|x_{i}-x_{i}\right|=0
$$

2. Se $x \neq y$, então $D(x, y)>0$

Sejam $x \in R^{n}$ e $y \in R^{n}$, desse modo:

$$
D_{T}(x, y)=\sum_{i=1}^{n}\left|x_{i}-y_{i}\right|
$$

Uma vez que para $\mathrm{x} \neq \mathrm{y}$ existe pelo menos um $\mathrm{x}_{\mathrm{i}} \neq \mathrm{y}_{\mathrm{i}}$ e para todo $\mathrm{x}_{\mathrm{i}} \neq \mathrm{y}_{\mathrm{i}}$ temos que $\left|x_{i}-y_{i}\right|>0$, logo: 


$$
D_{T}(x, y)=\sum_{i=1}^{n}\left|x_{i}-y_{i}\right|>0
$$

3. $\mathrm{D}(\mathrm{x}, \mathrm{y})=\mathrm{D}(\mathrm{y}, \mathrm{x})$

Uma vez que:

$$
\left|x_{i}-y_{i}\right|=\left|-\left(y_{i}-x_{i}\right)\right|=\left|y_{i}-x_{i}\right|
$$

Temos que:

$$
\begin{aligned}
D_{T}(x, y) & =\sum_{i=1}^{n}\left|x_{i}-y_{i}\right|=\sum_{i=1}^{n}\left|-\left(y_{i}-x_{i}\right)\right|= \\
& =\sum_{i=1}^{n}\left|y_{i}-x_{i}\right|=D_{T}(y, x)
\end{aligned}
$$

4. $\mathrm{D}(\mathrm{x}, \mathrm{z}) \leq \mathrm{D}(\mathrm{x}, \mathrm{y})+\mathrm{D}(\mathrm{y}, \mathrm{z})$

Uma vez que $|x+y| \leq|x|+|y|$ temos:

$$
\begin{aligned}
& D_{E}(x, y)+D_{E}(y, z)=\sum_{i=1}^{n}\left|x_{i}-y_{i}\right|+\sum_{i=1}^{n}\left|y_{i}-z_{i}\right| \geq \\
& \geq \sum_{i=1}^{n}\left|x_{i}-y_{i}+y_{i}-z_{i}\right|=\sum_{i=1}^{n}\left|x_{i}-z_{i}\right|=D_{E}(x, z)
\end{aligned}
$$

\subsection{Distância de Ponto a Reta}

$\mathrm{Na}$ geometria euclidiana para obter a distância entre um ponto $\mathrm{P}$ e uma reta $\mathrm{h}$ podemos proceder do seguinte modo:

$\mathrm{a}$ - trace a reta s perpendicular a reta $\mathrm{h}$ e que passe pelo ponto $\mathrm{P}$;

$\mathrm{b}$ - marque o ponto A intersecção da reta s com a reta $\mathrm{h}$;

$\mathrm{c}-\mathrm{a}$ distância do ponto $\mathrm{P}$ a reta $\mathrm{h}$ é a medida do segmento de reta PA 


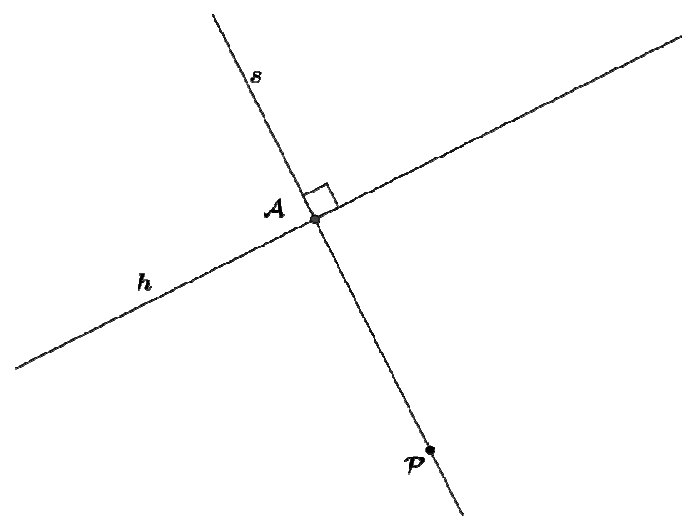

Figura 32 - Distância entre um ponto e uma reta - Métrica Euclidiana

Poderíamos também abordar tal situação do seguinte modo:

$\mathrm{a}$ - tracemos um círculo de centro $\mathrm{P}$ e raio $r<D_{E}(P, h)$;

b - aumente o círculo até o mesmo intersecctar a reta $\mathrm{h}$ em apenas um ponto, ou seja, que o círculo seja tangente à reta;

$\mathrm{c}-\mathrm{a}$ distância do ponto a reta será o raio desse círculo tangente à reta $\mathrm{h}$

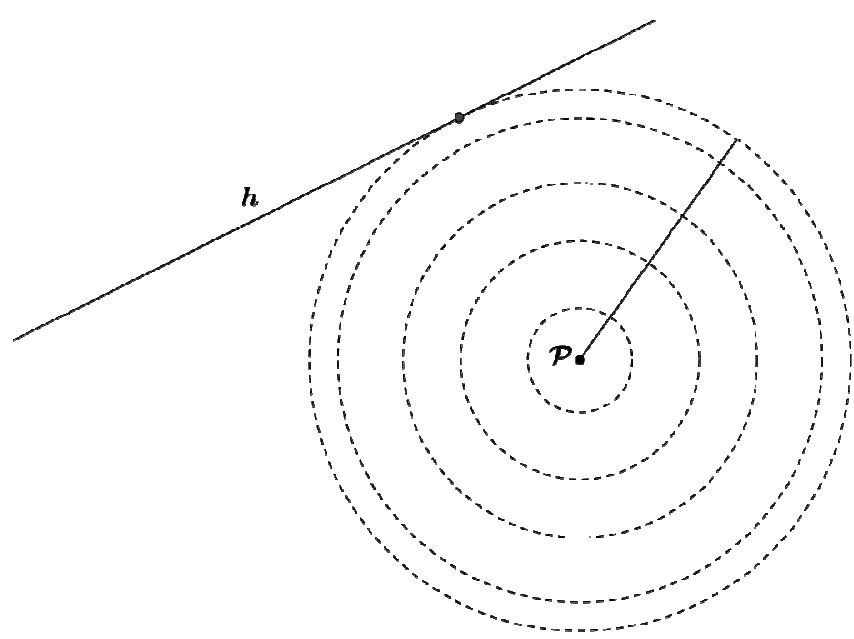

Figura 33 - Distância entre um ponto e uma reta - Métrica Euclidiana

Usaremos esse modo de visualizar a distância entre uma reta e um ponto na geometria euclidiana para explorar conceitualmente a distância entre uma reta e um ponto na geometria do taxi.

Consideremos então uma reta $\mathrm{h}$ e um ponto $\mathrm{P}$ dados, e uma sequência de círculos do taxi concêntricos em P. Três casos podem ocorrer: 
Primeiro Caso:

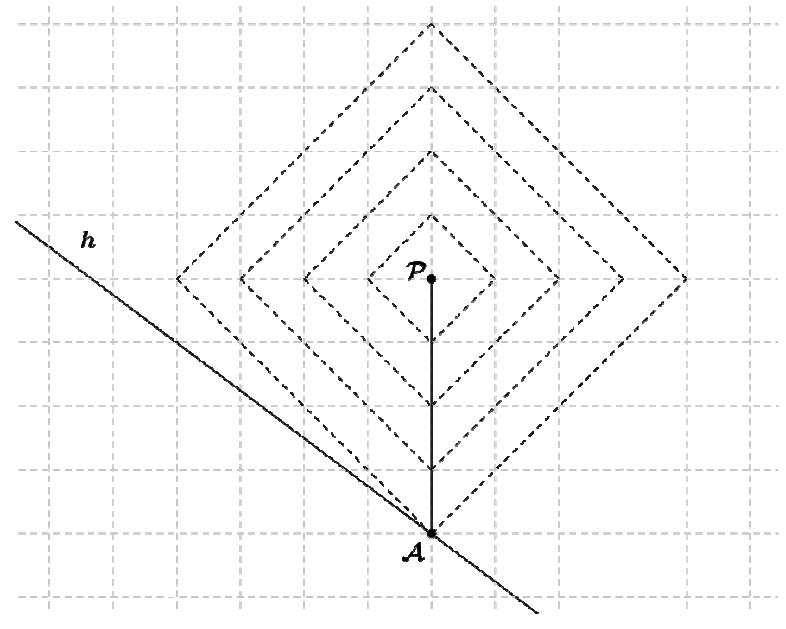

Figura 34 - Distância entre um ponto e uma reta - Métrica do Taxi

A distância do ponto $\mathrm{P}$ a reta h é a distância vertical $D_{T}(P, h)=D_{T}(P, A)$.

Segundo Caso:

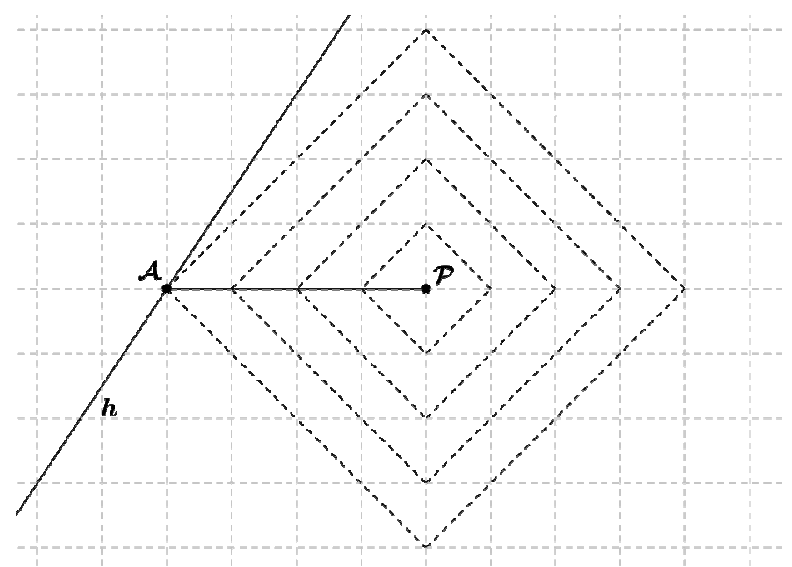

Figura 35 - Distância entre um ponto e uma reta - Métrica do Taxi

A distância do ponto $\mathrm{P}$ a reta $\mathrm{h}$ é a distância horizontal $D_{T}(P, h)=$ $D_{T}(P, A)$.

Terceiro Caso: 


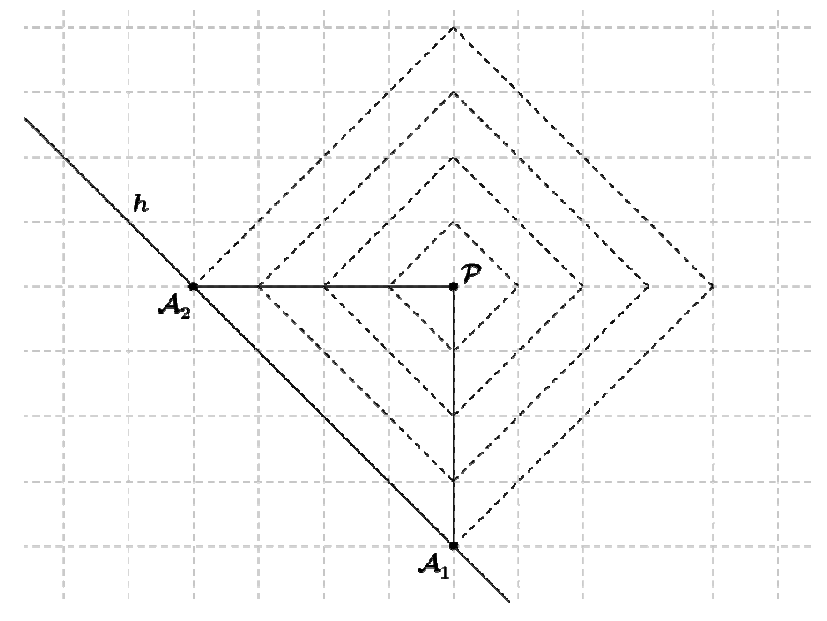

Figura 36 - Distância entre um ponto e uma reta - Métrica do Taxi

A distância do ponto $\mathrm{P}$ a reta $\mathrm{h}$ é dada por: $D_{T}(P, h)=D_{T}(P, X), X \in$ $\overline{A_{1} A_{2}}$

Com essas observações feitas podemos então melhor entender o seguinte teorema:

Dado o ponto $P\left(x_{0}, y_{0}\right)$ e a reta $h: a x+$ by $+\mathrm{c}=0$, na geometria do taxi temos que a distância de $\mathrm{P}$ a reta $\mathrm{h}$ é dada por:

$$
D_{T}(P, h)=\frac{\left|a x_{0}+b y_{0}+c\right|}{\operatorname{Max} .\{|a|,|b|\}}
$$

Demonstração:

Na geometria do taxi a distância de um ponto a uma reta é definida como:

$$
D_{T}(P, h)=\operatorname{Min}_{X \in h} D_{T}(P, X)
$$

Sendo $X_{1}$ e $X_{2}$ o ponto de intersecção da reta h com as retas $x=x_{0}$ ou $y=$ $y_{0}$, respectivamente, temos:

$$
D_{T}(P, h)=\operatorname{Min}\left\{D_{T}\left(P, X_{1}\right), D_{T}\left(P, X_{2}\right)\right\}
$$

Uma vez que $X_{1}$ e $X_{2}$ são dados por: 


$$
\begin{aligned}
& X_{1}\left(x_{0},-\frac{a x_{0}}{b}-\frac{c}{b}\right) \\
& X_{2}\left(-\frac{b y_{0}}{a}-\frac{c}{a}, y_{0}\right)
\end{aligned}
$$

Desse modo, teremos;

$$
\begin{aligned}
& D_{T}\left(P, X_{1}\right)=\left|x_{0}-x_{0}\right|-\left|y_{0}+\frac{a x_{0}}{b}+\frac{c}{b}\right|=\left|\frac{a x_{0}+b y_{0}+c}{b}\right| \\
& D_{T}\left(P, X_{2}\right)=\left|x_{0}+\frac{b y_{0}}{a}+\frac{c}{a}\right|+\left|y_{0}-y_{0}\right|=\left|\frac{a x_{0}+b y_{0}+c}{a}\right|
\end{aligned}
$$

Podemos então escrever que:

$$
\begin{gathered}
D_{T}(P, h)=\operatorname{Min}\left\{\frac{\left|a x_{0}+b y_{0}+c\right|}{|b|} ; \frac{\left|a x_{0}+b y_{0}+c\right|}{|a|}\right\} \text {, se } a \neq 0 \text { e } b \neq 0 \\
D_{T}(P, h)=\left|\frac{b y_{0}+c}{b}\right| \text { se } a=0 \\
D_{T}(P, h)=\left|\frac{a x_{0}+c}{a}\right| \text { se } b=0
\end{gathered}
$$

Assim:

$$
D_{T}(P, h)=\frac{\left|a x_{0}+b y_{0}+c\right|}{\operatorname{Max}\{|a| ;|b|\}}
$$

\subsection{Dinâmica}

A seguir apresentamos os módulos, do professor e do aluno, da dinâmica Caminhando pelas Ruas da Minha Cidade. 


\section{Caminhando Pelas Ruas da}

Matemática

\section{Minha Cidade}

\begin{tabular}{|cll|}
\hline Série & Campo & \multicolumn{1}{c|}{ Conceito } \\
\hline Ensino Médio 3o & Geométrico & Geometria Não \\
& & Euclidiana \\
\hline
\end{tabular}

\section{Geometria do}

Taxi

\section{Professor}


Professor, nessa dinâmica você terá as seguintes atividades para desenvolver com os seus alunos:

\begin{tabular}{|c|c|c|c|c|}
\hline & Atividades & Tempo & Organização & Registro \\
\hline 1 & Caminhando & $15 \mathrm{~min}$ & $\begin{array}{c}\text { Grupo de } 2 \\
\text { alunos }\end{array}$ & Em grupo \\
\hline 2 & Navegando & $15 \mathrm{~min}$ & $\begin{array}{c}\text { Grupo de } 2 \\
\text { alunos }\end{array}$ & Em grupo \\
\hline 3 & Distância & $50 \mathrm{~min}$ & $\begin{array}{c}\text { Grupo de } 2 \\
\text { alunos }\end{array}$ & \\
\hline 4 & $\begin{array}{c}\text { Cálculo da Distância } \\
\text { do Taxi }\end{array}$ & $25 \mathrm{~min}$ & $\begin{array}{c}\text { Grupo de } 2 \\
\text { alunos }\end{array}$ & Individual \\
\hline 5 & $\begin{array}{c}\text { Cálculo da Distância } \\
\text { Euclidiana }\end{array}$ & $25 \mathrm{~min}$ & $\begin{array}{c}\text { Grupos de } 2 \\
\text { alunos }\end{array}$ & Individual \\
\hline 6 & $\begin{array}{c}\text { Círculo e } \\
\text { Circunferência }\end{array}$ & $50 \mathrm{~min}$ & $\begin{array}{c}\text { Grupos de } 2 \\
\text { alunos }\end{array}$ & - \\
\hline
\end{tabular}

\section{Apresentação}

A geometria possibilita que o aluno desenvolva habilidades que permitem a descrição, o reconhecimento, a compreensão e a representação do espaço em que vivem. Com tais habilidades desenvolvidas o aluno está apto a resolver problemas do cotidiano e interagir com seu ambiente de modo organizado e preciso.

A dinâmica foi elaborada com o intuito de fazer o aluno se apropriar de conceitos que o possibilite interagir e representar suas relações com o espaço em que vive utilizando-se de outro tipo de geometria que não a euclidiana.

Nessa dinâmica utilizamos a chamada Geometria do Taxi, ou Geometria do Motorista de Taxi, ou ainda, Geometria Pombalina. Tal geometria criada pelo matemático Hermann Minkowski (1864 - 1909) apresenta uma relação muito estreita com o cotidiano do aluno na cidade descrevendo os caminhos da geografia urbana de um modo mais real que a geometria euclidiana. 


\section{Atividade - 01}

\section{Material}

Lápis, borracha, régua, folha -01 , folha -03 .

\section{Descrição}

Professor forneça ao aluno a folha - 01 e a folha - 03, fazendo algumas considerações a respeito do deslocamento que se deve fazer para sair da localidade A e chegar à localidade B. Informe ao aluno que, ao se deslocar de A para B, ele deve fazer apenas com trajetos horizontais e verticais. Na figura - 01 temos dois exemplos de caminhos que podem ser feitos.

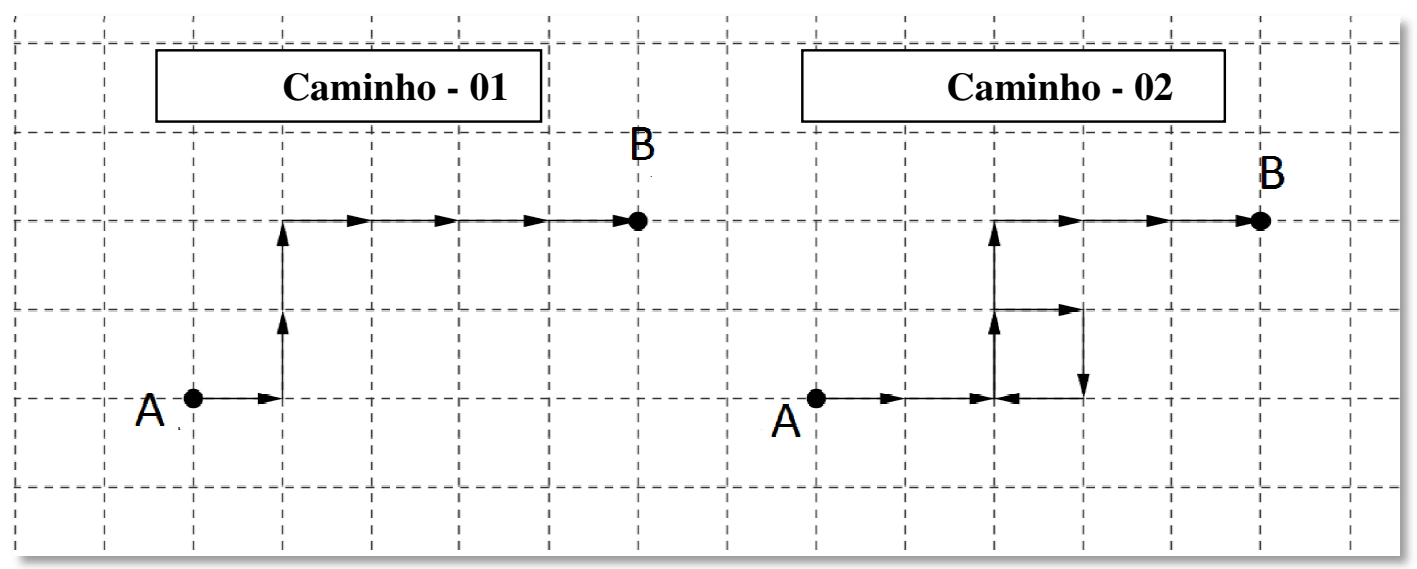

Figura - 01

Incentive o aluno a representar o cenário usando uma malha quadriculada (folha - 03) que irá representar os quarteirões e as ruas. Os trajetos podem ser representados por uma sequência de letras $\mathbf{H}$ (para horizontal) e $\mathbf{V}$ (para vertical) do modo como está exemplificado abaixo na figura -02 . 


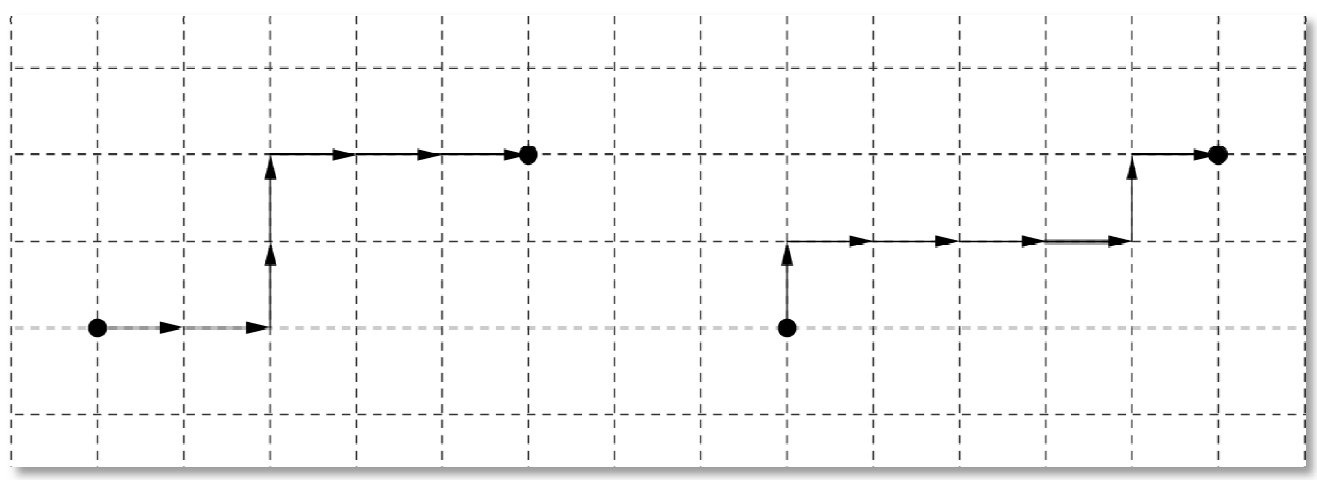

Figura - 02

Isso irá facilitar não só o processo de contagem dos trajetos entre $\mathrm{A}$ e $\mathrm{B}$, mas também a visualização do cenário a ser estudado e a determinação da distância a ser percorrida nos trajetos. Por exemplo, se na figura - 02 estabelecermos que $\mathrm{H}=100 \mathrm{~m}$ e V $=100 \mathrm{~m}$ teremos que no trajeto $\mathbf{H ~ H ~ V ~ V ~ H ~ H ~}$ H a distância percorrida entre os dois pontos será de:

H H V V H H H $=100+100+100+100+100+100+100=700 \mathrm{~m}$

Atividade - 02

Material

Lápis, borracha, régua, folha - 02 .

\section{Descrição}

Professor entregue aos alunos a folha - 02 e solicite que eles registrem os questionamentos feitos no livreto. Observe com seus alunos que agora não existe nenhum impedimento na escolha da trajetória entre A e B.

Ao término das atividades 01 e 02 é importante que os alunos tenham se apropriado da ideia que medir uma distância é algo que pode ser feito de modo distinto conforme as necessidades e condições impostas. É importante promover 
um pequeno debate em sala com os alunos com a intenção de consolidar e avaliar a apropriação dos conceitos e ideias estudadas.

Incentive os alunos a pesquisarem sobre o assunto com perguntas do tipo:

O que é distância?

O que é medir?

Qual o conceito de distância em matemática?

O que é distância euclidiana?

Existem outros tipos de distância?

O que é distância do taxi?

Leves seus alunos ao laboratório de informática e oriente uma pesquisa sobre essas perguntas, finalizando com a apresentação de um trabalho escrito ou um cartaz feito em grupo ou mesmo a apresentação de um vídeo sobre o assunto. Uma sugestão interessante de trabalho é buscar no Google Maps a região em que os alunos moram e o local da escola solicitando aos alunos que tracem no mapa o trajeto que fazem de suas casas até a escola determinando assim as distâncias de percurso 


\section{Folha - 01}

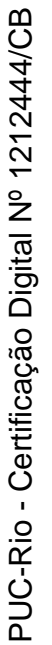

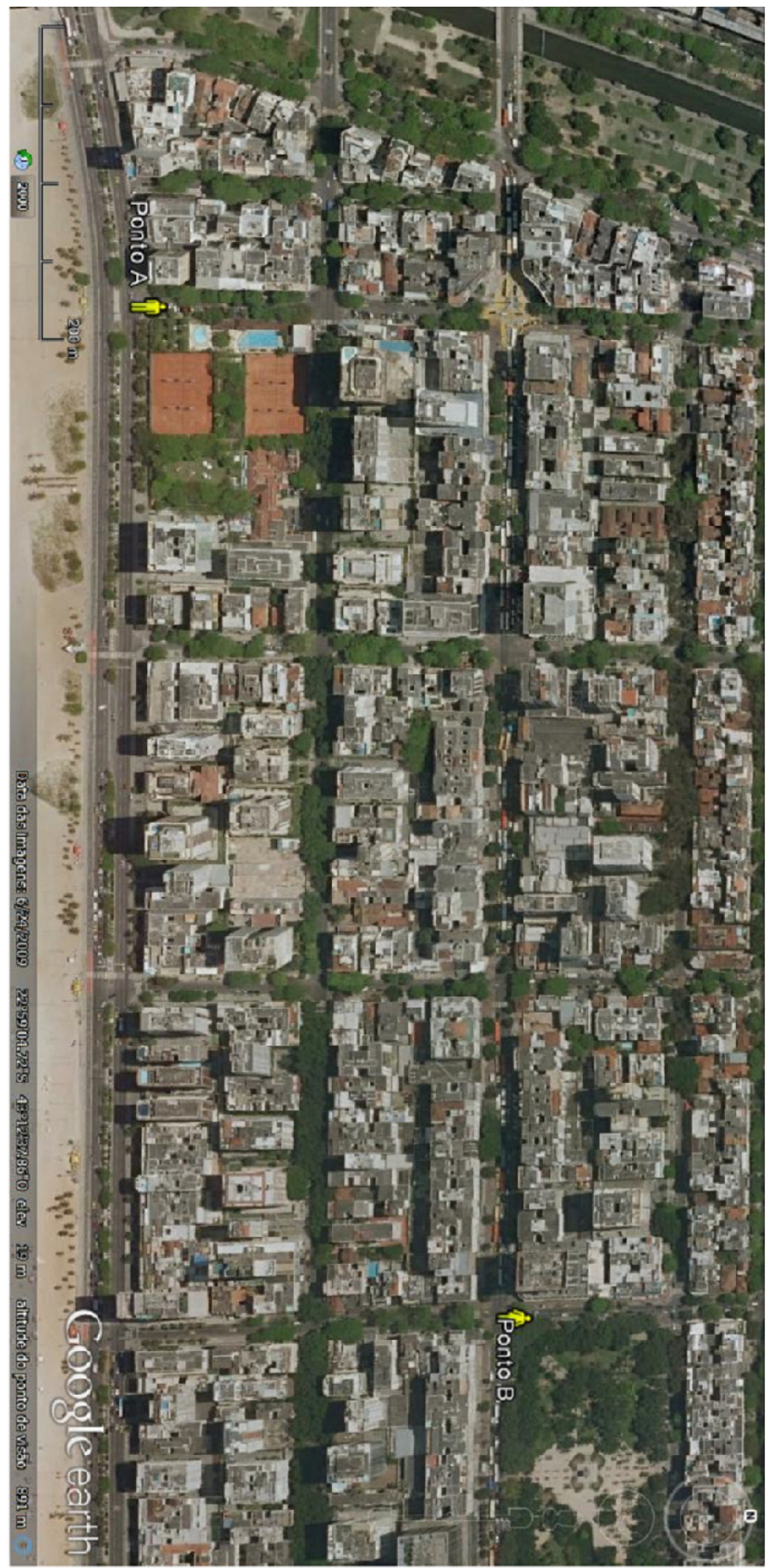




\section{$\underline{\text { Folha }-02}$}

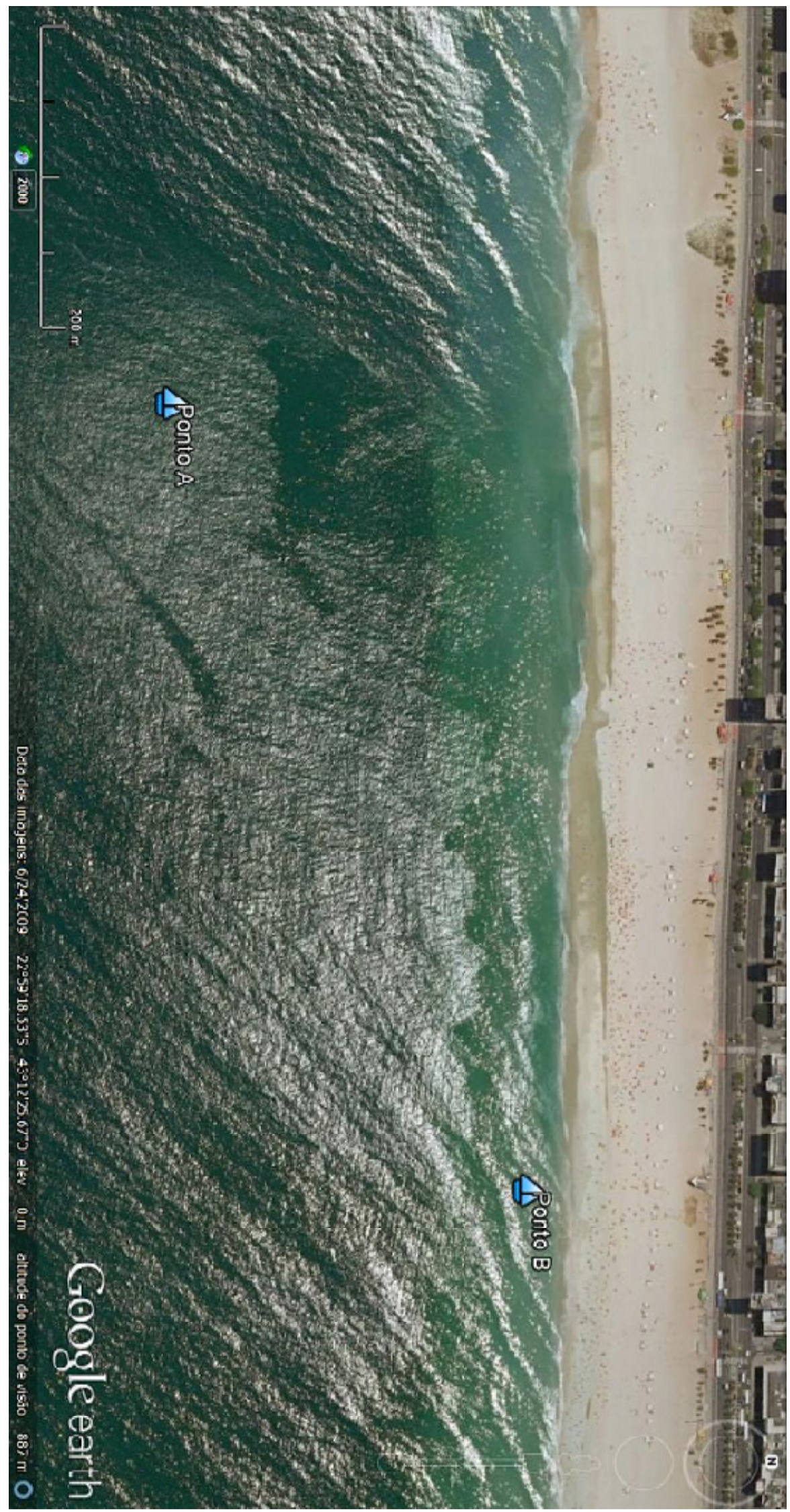




\section{Folha -03}

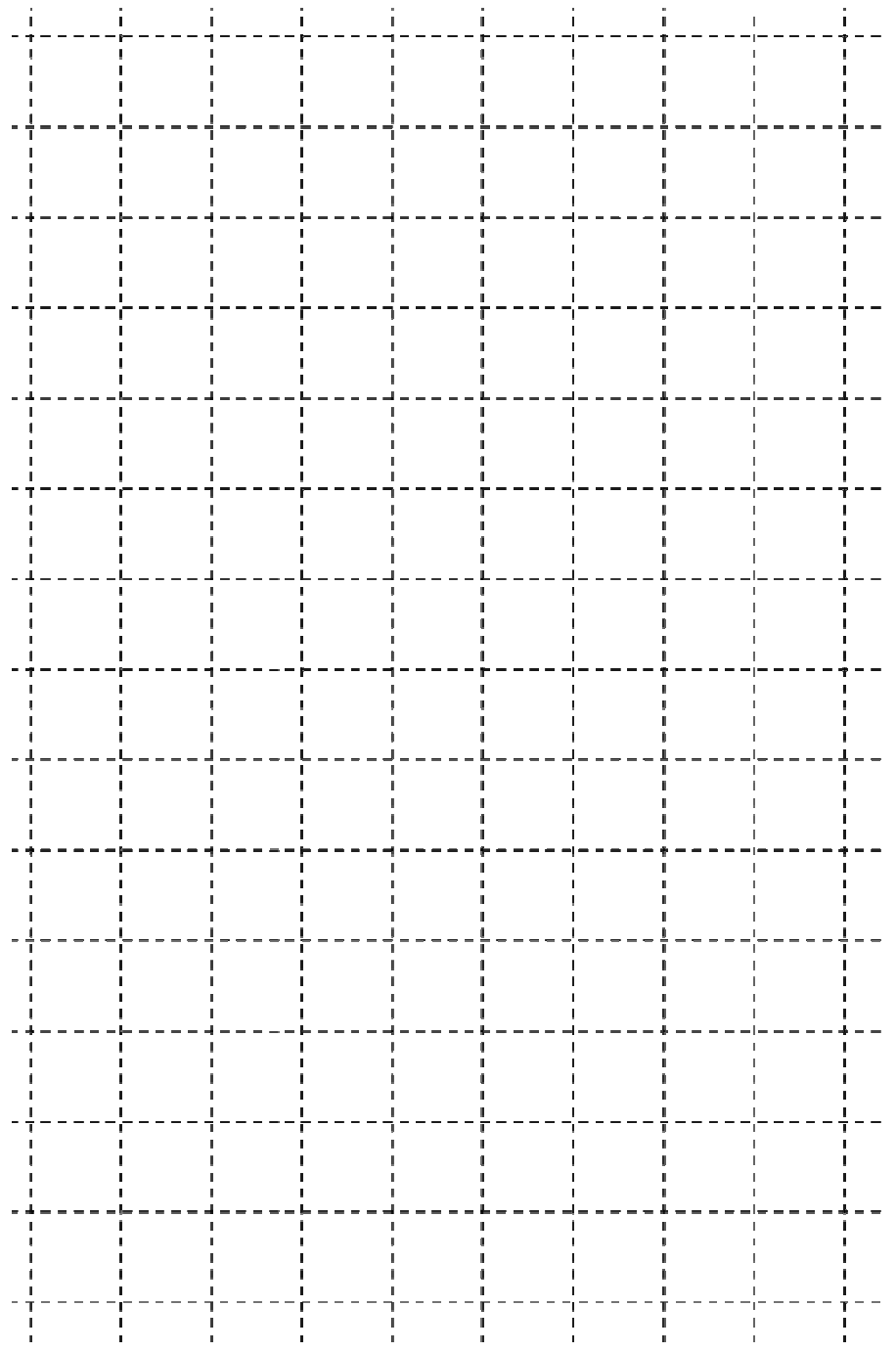


Professor na atividade 3 iremos fazer uso dos recursos educacionais multimídias disponíveis no sitio http://m3.ime.unicamp.br/, que é o portal $\mathrm{M}^{3}$ Matemática e Multimídia. Esse portal "contém recursos educacionais multimídia em formatos digitais desenvolvidos pela Unicamp com financiamento do FNDE, SED, MCT e MEC para o Ensino Médio de Matemática no Brasil. São recursos educacionais no formato de vídeos, áudios, softwares e experimentos, que estão licenciados sob uma licença Creative Commons - é permitido copiar, distribuir, exibir, executar a obra e criar obras derivadas, mas não é permitido o uso comercial ou o relicenciamento sobre uma licença mais restritiva".

Como descrito no sítio as "atividades são realizadas com o uso de computadores para o estudo, aplicação ou formalização de conceitos de matemática do ensino médio. Estes softwares contêm várias informações para os alunos e existe um guia com explicações aprofundadas para o professor”.

Sugerimos que antes da aplicação das atividades que seja lido e executado por você professor todas as etapas da mesma. Todo o processo avaliativo é feito no próprio portal que não passa de uma fase para outro se a anterior não estiver correta.

\section{Atividade - 03}

\section{Material}

Recursos de Informática

\section{Descrição}

Na atividade 3 iremos realizar a dinâmica Geometria do Taxi - Distância que encontramos disponível no sítio http://m3.ime.unicamp.br/recursos/1231 . Tal atividade irá "Consolidar o uso de coordenadas cartesianas no plano e introduzir uma nova noção de distância, na qual a função módulo aparece de forma natural" e "explorar a comparação entre as distâncias euclidiana e do táxi, por meio de coordenadas".

\section{Atividade - 04}




\section{Material}

Lápis, borracha e calculadora, Folha - 04 e Tabela - 01.

\section{Descrição}

Nessa atividade, professor, vamos trabalhar com o aluno o cálculo da distância euclidiana. Inicie passando para o aluno qualquer dos vídeos disponível em:

http://www.youtube.com/watch?v=aIXcuud7QUo

http://www.youtube.com/watch?v=SLGrD9QCitQ

http://www.youtube.com/watch?v=-01oaYJ7RGE

Após o vídeo disponibilize para o aluno a folha - 04 e a tabela - 01, para que o mesmo se aproprie do método de cálculo da distância euclidiana.

Atividade - 05

Material

Lápis, borracha e calculadora, Folha - 05 e Tabela - 02.

\section{Descrição}

Nessa atividade, professor, vamos trabalhar com o aluno o cálculo da distância do taxi. Inicie passando para o aluno o vídeo disponível em:

http://www.youtube.com/watch?v=t4tWboIKG2g

Após o vídeo disponibilize para o aluno a folha - 05 e a tabela - 02, para que o mesmo se aproprie do método de cálculo da distância do taxi 


\section{Folha-04}

\section{Distância Euclidiana}

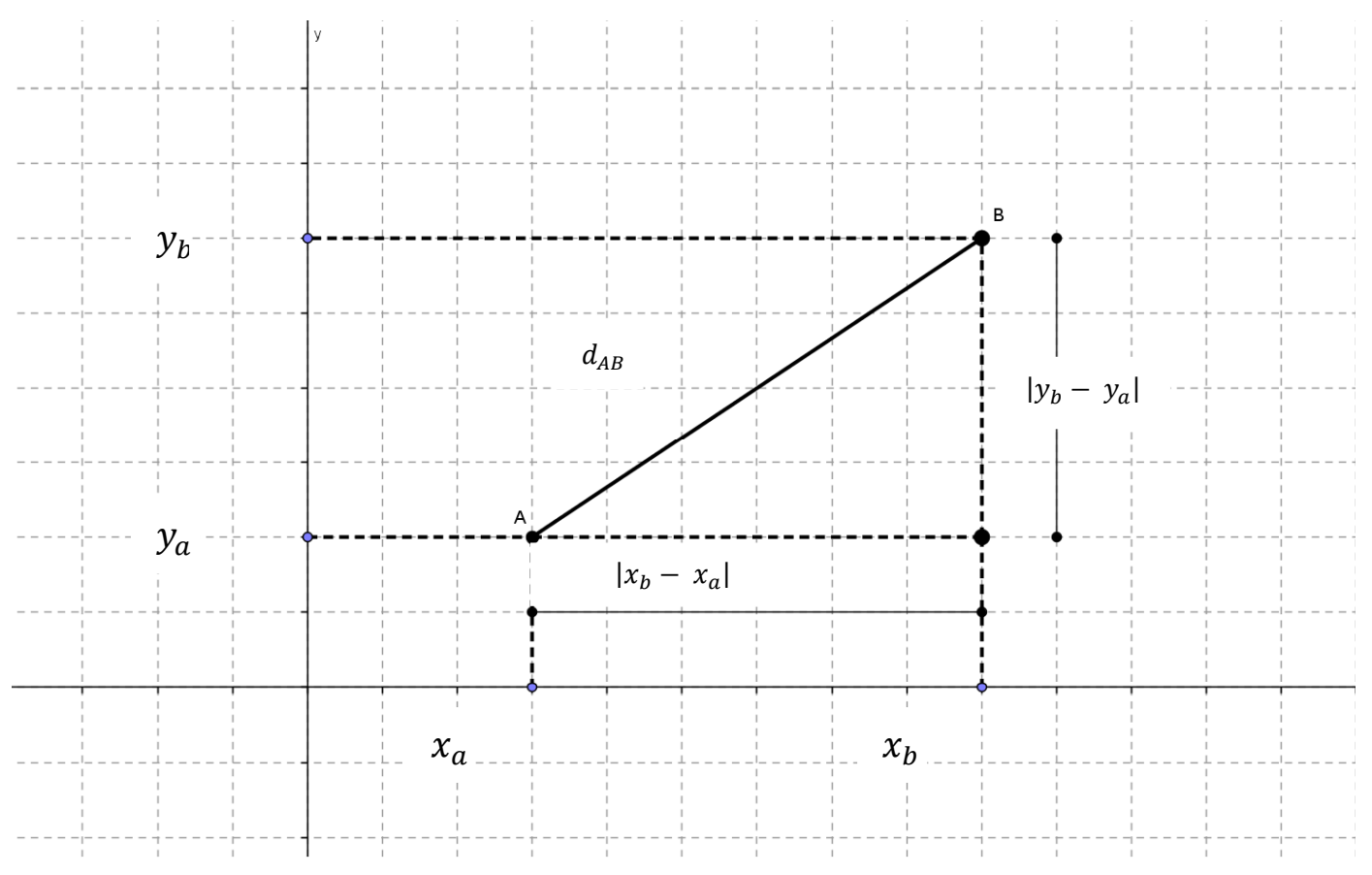

$$
d_{A B}=\sqrt{\left(x_{b}-x_{a}\right)^{2}+\left(y_{b}-y_{a}\right)^{2}}
$$




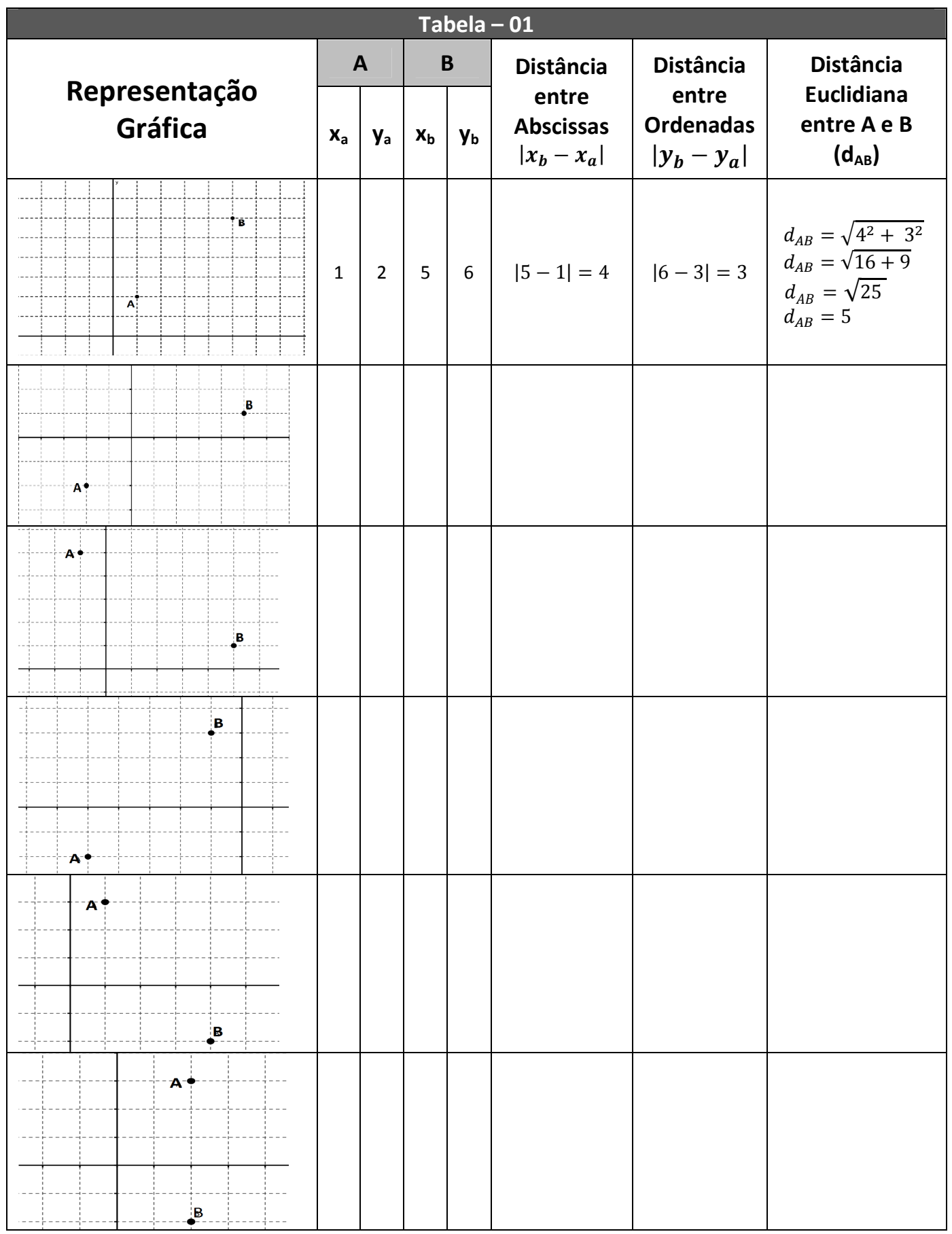


$\underline{\text { Folha }-05}$

\section{Distância do Táxi}

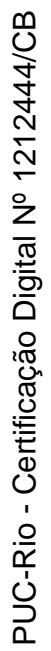

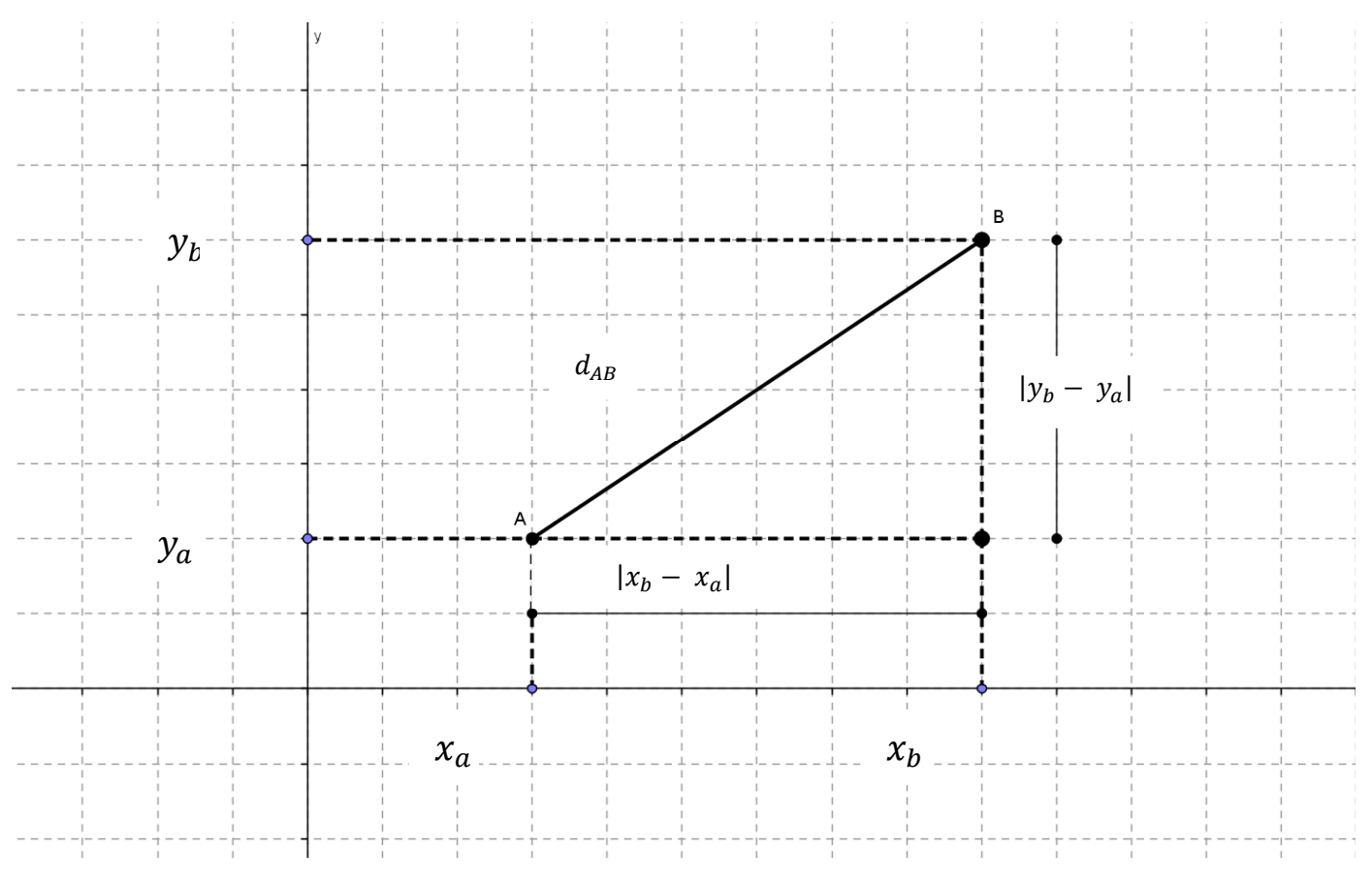

$$
d t_{A B}=\left|x_{b}-x_{a}\right|+\left|y_{b}-y_{a}\right|
$$




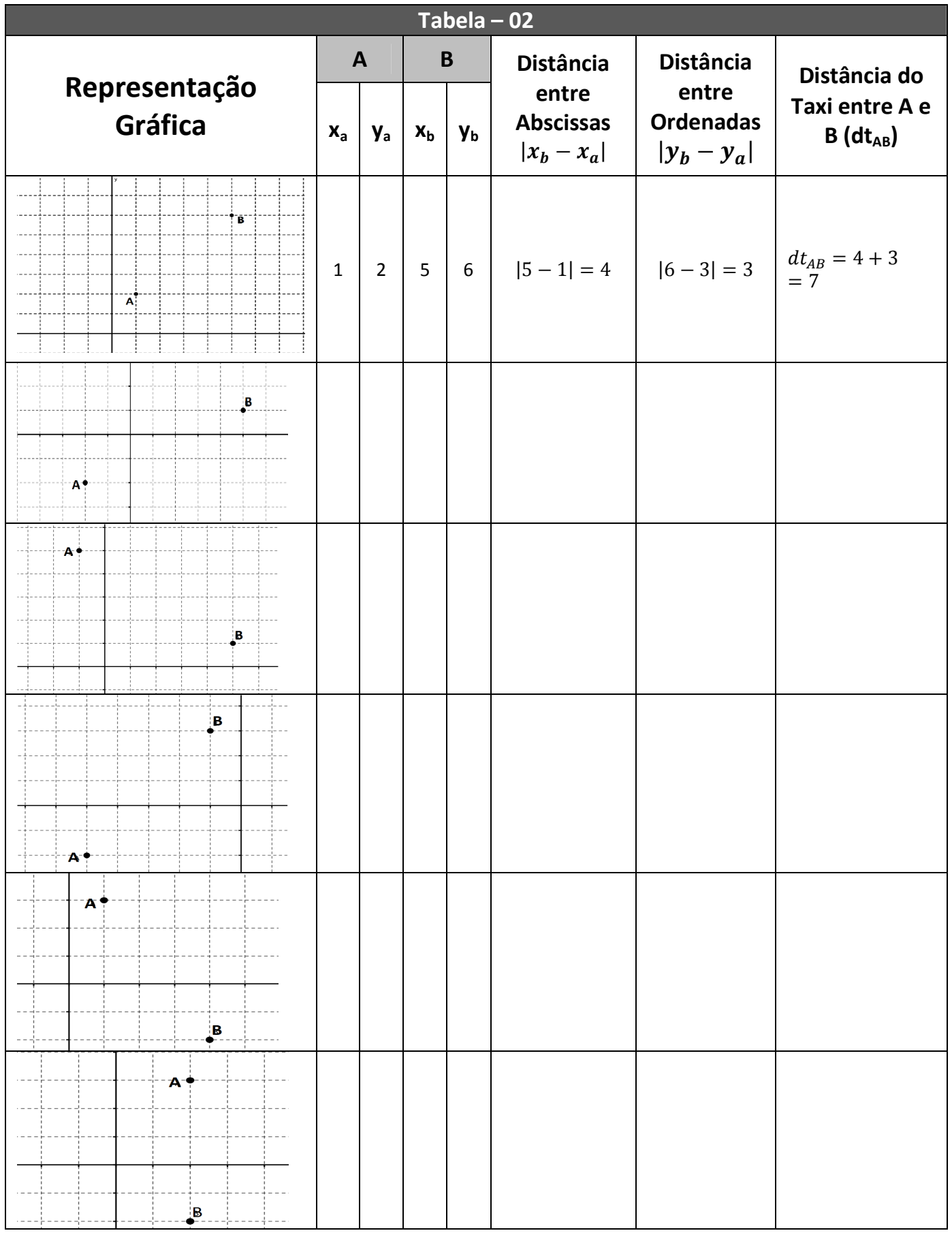


Professor na atividade 6 iremos fazer uso dos recursos educacionais multimídias disponíveis no sitio http://m3.ime.unicamp.br/, que é o portal $\mathrm{M}^{3}$ Matemática e Multimídia. Esse portal "contém recursos educacionais multimídia em formatos digitais desenvolvidos pela Unicamp com financiamento do FNDE, SED, MCT e MEC para o Ensino Médio de Matemática no Brasil. São recursos educacionais no formato de vídeos, áudios, softwares e experimentos, que estão licenciados sob uma licença Creative Commons - é permitido copiar, distribuir, exibir, executar a obra e criar obras derivadas, mas não é permitido o uso comercial ou o relicenciamento sobre uma licença mais restritiva".

Como descrito no sítio as "atividades são realizadas com o uso de computadores para o estudo, aplicação ou formalização de conceitos de matemática do ensino médio. Estes softwares contêm várias informações para os alunos e existe um guia com explicações aprofundadas para o professor”.

Sugerimos que antes da aplicação das atividades que seja lido e executado por você professor todas as etapas da mesma. Todo o processo avaliativo é feito no próprio portal que não passa de uma fase para outro se a anterior não estiver correta.

\section{Atividade 6}

\section{Material}

Recursos de Informática

\section{Descrição}

$\mathrm{Na}$ atividade 6 iremos realizar a dinâmica Geometria do Taxi - Formas Geométricas no sítio http://m3.ime.unicamp.br/recursos/1248 . Nessa atividade "o aluno escolhe no mapa as "esquinas" onde colocar quatro pontos de referência (sua casa, a escola, a casa de um amigo e a lanchonete) e é solicitado a considerar distância como o número mínimo de quadras a serem percorridas para se ir de um ponto a outro (distância do táxi). Depois é convidado a pensar no que corresponde aos conceitos de circunferência e círculo na geometria do táxi”. 


\section{Caminhando Pelas Ruas}

Matemática

\section{da Minha Cidade}

\begin{tabular}{|c|c|c|}
\hline Série & Campo & Conceito \\
\hline Ensino Médio 3 & Geométrico & $\begin{array}{c}\text { Geometria Não } \\
\text { Euclidiana }\end{array}$ \\
\hline
\end{tabular}

\section{Geometria do}

\section{Taxi}

\section{Aluno}


$\underline{\text { Atividade }-01}$

Seu professor entregou uma foto aérea de certa região da cidade.

Observando essa foto responda aos questionamentos feitos abaixo:

a) Queremos caminhar da localidade A para a localidade B. Trace pelo menos três trajetos que sejam possíveis de serem feitos. Observe agora os trajetos escolhidos por outros colegas. São os mesmos que você escolheu?

b) Se você fosse medir a distância entre a localidade $A$ e a localidade $B$ que trajeto escolheria para fazê-lo? Explique porque escolheu tal trajeto para fazer a medição da distância entre a localidade A e a localidade B. 
c) Utilizando o papel quadriculado (Folha - 03) faça um modelo do cenário da foto (Folha - 01). Procure determinar a distância entre a localidade A e a localidade B. Observe a trajetórias que seus colegas escolheram para medir a distância. É a mesma trajetória que a sua?

d) Quantos trajetos existem entre a localidade A e a localidade B que tenham essa mesma medida feita por você como sendo a distância entre A e B? 


\section{$\underline{\text { Atividade }-02}$}

Seu professor entregou agora uma foto aérea da região litorânea da cidade. Observando a Folha - 02, responda aos questionamentos feitos abaixo.

a) Queremos navegar da localidade A para a localidade B. Trace pelo menos três trajetos que sejam possíveis de serem feitos. Observe agora os trajetos escolhidos por outros colegas. São os mesmo que você escolheu?

b) Se você fosse medir a distância entre a localidade $A$ e a localidade $B$ que trajeto escolheria para fazê-lo? Explique porque escolheu tal trajeto para fazer a medição da distância entre a localidade A e a localidade $B$. 
c) Utilizando a foto que você recebeu (Folha - 02), procure determinar a distância entre a localidade $\mathrm{A}$ e a localidade B. Observe a trajetória que seu colega escolheu para medir a distância. É a mesma trajetória que a sua?

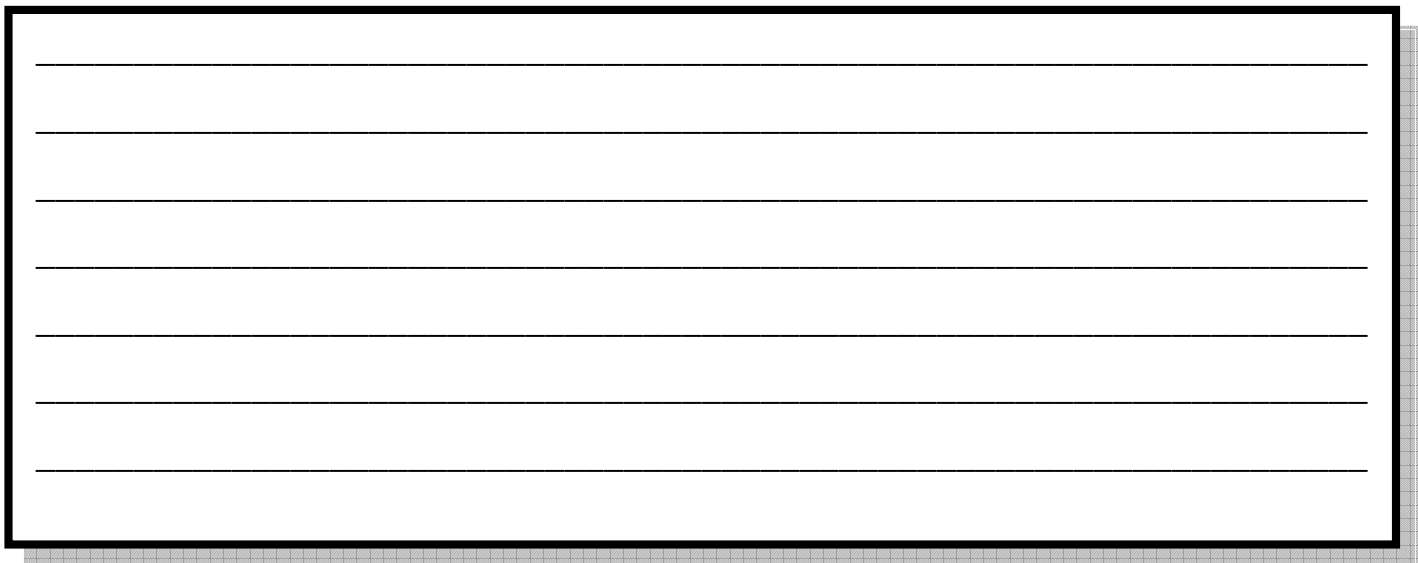

d) Quantos trajetos existem entre a localidade A e a localidade B que tenham essa mesma medida feita por você como sendo a distância entre A e B? Comparando com o mesmo item da Atividade - 01 o que você pode observar?

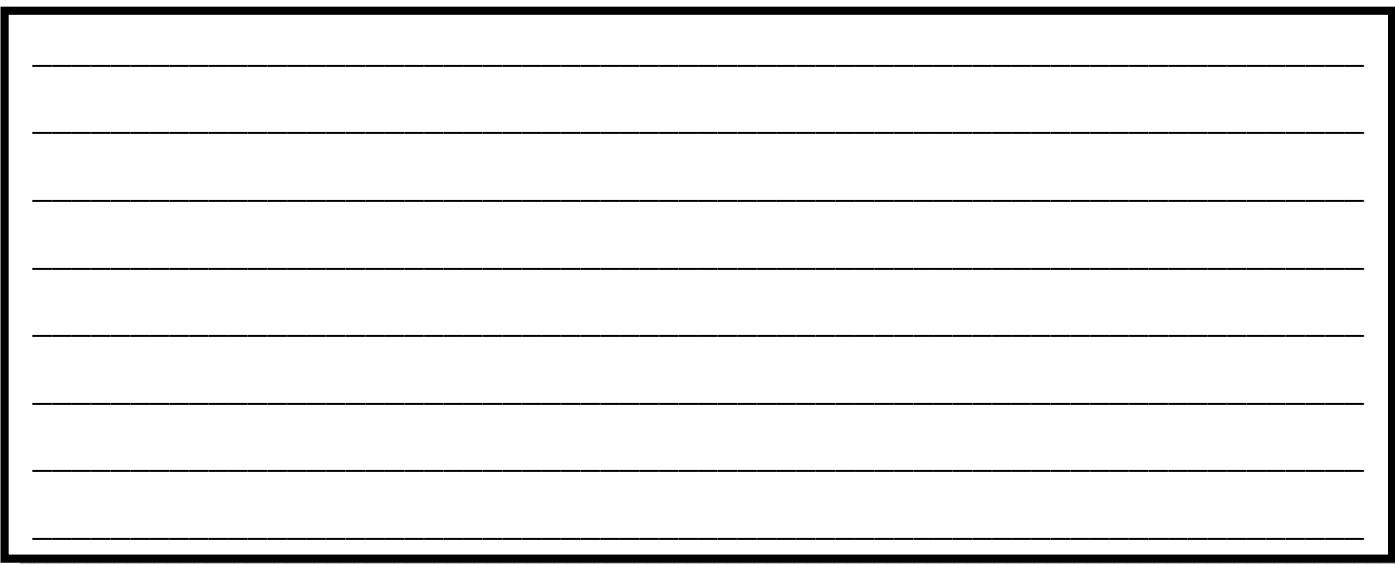


$\underline{\text { Atividade }-03}$

O seu professor irá levá-lo para o laboratório de informática para realizar esta atividade.

\section{$\underline{\text { Atividade }-04}$}

O seu professor irá passar um vídeo que o ajudará nessa tarefa. Após assistir ele irá fornecer uma tabela juntamente com a folha - 05 para você praticar e entender melhor o cálculo da distância do taxi. Então mãos a obra.

\section{$\underline{\text { Atividade }-05}$}

O seu professor irá passar um vídeo que o ajudará nessa tarefa. Após assistir ele irá fornecer uma tabela juntamente com a folha - 04 para você praticar e entender melhor o cálculo da distância euclidiana. Então mãos a obra.

\section{$\underline{\text { Atividade - } 06}$}

O seu professor irá levá-lo para o laboratório de informática para realizar esta atividade. 